\title{
Effects of long-term changes in forest canopy structure on rainfall interception loss
}

César Ramiro Cisneros Vaca 


\section{Graduation Committee}

Chair and Secretary prof. dr. ir. A. Veldkamp Supervisor prof. dr. ing. W. Verhoef

University of Twente

University of Twente

Co-supervisor dr. ir. C. van der Tol

University of Twente

Members

prof. dr. Z. Su prof. dr. F.D. van der Meer

University of Twente

University of Twente prof. dr. ir. R. Uijlenhoet Wageningen University prof. dr. O. Klemm University of Munster prof. dr. H-J. Hendricks-Franssen

Forschungzentrum Julich

ITC dissertation number 338

ITC, P.O. Box 217, 7500 AE Enschede, The Netherlands

ISBN: $\quad 978-90-365-4691-1$

DOI: $\quad$ http://dx.doi.org/10.3990//1.9789036546911

Printed by: ITC Printing Department, Enschede, The Netherlands

(C) César Ramiro Cisneros Vaca, Enschede, The Netherlands All rights reserved. No part of this publication may be reproduced without the prior written permission of the author. 


\section{EFFECTS OF LONG-TERM CHANGES IN FOREST CANOPY STRUCTURE ON RAINFALL INTERCEPTION LOSS}

\section{DISSERTATION}

to obtain

the degree of doctor at the University of Twente, on the authority of the Rector Magnificus, prof. dr. T.T.M. Palstra, on account of the decision of the graduation committee, to be publicly defended on Wednesday, December 5, 2018 at $14.45 \mathrm{hrs}$

by

César Ramiro Cisneros Vaca born on July 16, 1980 in Quito, Ecuador 
This dissertation is approved by:

prof. dr. ing. W. Verhoef (supervisor)

dr. ir. C. van der Tol (co-supervisor) 
for Myri, Victoria and Adrián 



\section{Summary}

In the last decades, forest ecosystems around the world have suffered unprecedented pressure from the society on demand of its resources. This situation can turn even worst in the near future considering the effects of climate variability, climate change and growing population. One of the forest ecosystem services that can be reduced is its the capacity to retain the rain before it becomes run-off or flood-waters. This particular process is known as rainfall interception.

When rain falls over a forested area one portion is temporarily captured by leaves/needles, branches, stems and on other foliage elements. Another part instead goes directly to the forest floor without interaction with the canopy at all. This last portion is better known as free or direct throughfall. The portion captured by the canopy, as far as the rain continues, will saturate the foliage and eventually will drop to the forest floor as secondary throughfall. Rainwater can also found a path through the stems to drain down, in that case, it is known as stemflow. In this way, all the rain that has reached the top of the forest seems that sooner or later will arrive at the forest floor and that has only been delayed on its trajectory. However, this is not fully true, large quantities that could account for up to half of the precipitated water can be evaporated back to the atmosphere without reaching the ground.

The process of rainfall interception loss has been studied from the last century. Several cases in different types of forest have demonstrated variability in the amounts of water that a forest can intercept and the resultant effects. In some cases, the fact that forest can also decrease the water availability for stream-flow or groundwater recharge has been in debate. Other questions have also raised as: where does the energy to sustain the evaporation during rain come from? How can the meteorological conditions affect the process? Or, how can the interception loss accurately be quantified and projected into the future under different scenarios?

Some of these questions have been studied at plot scale and for relatively short periods of time (couple of years). But, in few cases, the effects of long-term (decades) changes in the forest structure have been analysed in detail. In the Speulderbos forest, a study site located close to the small settlement of Garderen in the centre of the Netherlands, there was a unique opportunity to re-evaluate (after 25-years) the interception process and to propose a model that can use remote sensing data to extend the results to larger areas.

Rainfall interception loss was evaluated in Speulderbos about 25 years ago, the Douglas fir stand showed that $\sim 40 \%$ of precipitation was intercepted and later on evaporated; it was one of the largest values of rainfall interception measured. The main reason for such a large amount was due to its large canopy storage capacity. 
The hypothesis at the beginning of the present study was that, due to natural effects as tree growing and management practices reducing the density (thinning), the capacity of interception decrease. However, when new measurements were done in 2015-2016, the value of interception loss has just a very slight decrease.

To support the new study it was necessary to take samples of throughfall to understand the spatial distribution within the plot. Funnel-type collectors distributed randomly inside an array of sub-plots, and every 15 days the collectors were repositioned (roving location), this allowed to collect throughfall in 320 locations; from February to November 2015. The throughfall distribution was more homogeneous as compared to the values reported about 25 years ago in the same site. Slightly different spatial patterns of throughfall in spring and summer were found. Spatial correlation lengths of $12 \mathrm{~m}$ and $8 \mathrm{~m}$ were detected for spring and summer, respectively; which means that maps of throughfall patterns in the forest floor can be obtained. These maps are useful to study how the soil is moistened, the relations with root water uptake, also how nutrients can be distributed in the forest floor.

The water and energy budget during wet-canopy conditions were analysed in the study site for the two growing seasons of 2015 and 2016. Based on the wet-canopy water balance equation, derived interception losses were $37 \%$ and $39 \%$ of gross rainfall, respectively. The interception loss at the forest was similar to that measured at the same site years before ( $\mathrm{I}=38 \%$ ), when the forest was younger (29 years old, vs. 55 years old in 2015). In the past, the forest was denser and had a higher canopy storage capacity ( $2.4 \mathrm{~mm}$ then vs. $1.90 \mathrm{~mm}$ in 2015$)$, but the aerodynamic conductance was lower $\left(0.065 \mathrm{~m} \mathrm{~s}^{-1}\right.$ then vs. $0.105 \mathrm{~m} \mathrm{~s}^{-1}$ in 2015), and therefore past evaporation rates were lower than evaporation rates found in the present study $\left(0.077 \mathrm{~mm} \mathrm{~h}^{-1}\right.$ vs. $0.20 \mathrm{~mm} \mathrm{~h}^{-1}$ in 2015$)$

The sources of energy to sustain wet-canopy evaporation were net radiation (35\%), a negative sensible heat flux (45\%), and a negative energy storage change (15\%). The findings emphasize the importance of quantifying downward sensible heat flux and heat release from canopy biomass in tall forest in order to improve the quantification of evaporative fluxes in wet canopies.

In the last step of this investigation, the integrated radiative transfer and energy balance model SCOPE (Soil Canopy Observation, Photochemistry and Energy fluxes) (van der Tol et al., 2009), originally developed for remote sensing applications, was extended with a module for the interception, storage and dripping of precipitation. The interception of water was modelled in analogy to the interception of light. The model was validated against Eddy-covariance fluxes, throughfall and canopy wetness data of a mature Douglas-fir stand in Speulderbos during summer of 2015. The results showed modelled time series of throughfall were in good agreement with the measurements. This is a first step to develop a remote sensing application able to be fed with remote sensing data and open up a new way to estimate rainfall interception loss at different spatial scales.

This dissertation as a whole aims to contribute to improve the knowledge about the effects of long-term changes in forest structure on the rainfall interception loss process, by collecting new evidence and by proposing a new modelling approach that allowed to use remote sensing inputs. 


\section{Samenvatting}

Op veel plaatsen in de wereld hebben bossen de afgelopen decennia geleden onder de toegenomen vraag naar hulpbronnen. Door groeiende bevolking en klimaatverandering kan deze druk in de nabije toekomst nog toenemen. Eén van de 'ecosysteemdiensten' van bossen is de capaciteit om water vast te houden voordat het tot afvoer komt. Dit specifieke proces is bekend als neerslaginterceptie. Wanneer regen valt in een bebost gebied, dan zal een deel onderschept en tijdelijk geborgen worden door bladeren, naalden, takken, stammen en andere bovengrondse delen van het bos. Een ander deel bereikt direct de bodem zonder in aanraking te komen met het bladerdek. Dit laatste deel staat bekend als vrije, directe of primaire doorval. Het deel dat door het bladerdek wordt onderschept, zal bij aanhoudende regen het bladerdek verzadigen, waarna het op de bodem druppelt als secundaire doorval. Regenwater kan ook zijn weg vinden naar de bodem via de stammen. In dat geval spreken we van stamstroom. Een deel van het regenwater bereikt dus vertraagd de bodem, maar een ander deel, tot wel 50 procent van de regen, verdampt nog voordat het de bodem kan bereiken.

Het proces van neerslaginterceptie is al sinds de vorige eeuw een onderwerp van studie. Uit veldstudies in verschillende bostypes blijkt dat de neerslaginterceptie behoorlijk variabel is, zowel in hoeveelheid interceptie als in het effect op andere processen. Of neerslaginterceptie in alle gevallen leidt tot minder water in de beken en rivieren of in het grondwater, is nog een onopgelost vraagstuk. Andere vragen zijn ook gesteld, zoals: 'Waar komt de energie vandaan om het verdampingsproces gaande te houden?' 'Wat is de invloed van meteorologische omstandigheden?' En: 'Hoe kunnen interceptieverliezen nauwkeurig geschat worden, en voorspeld worden in scenario's voor de toekomst?' Sommige van die vragen zijn beantwoord op plotschaal en voor relatief korte periodes (enkele jaren). In enkele gevallen zijn de veranderingen op de lange termijn (decades) in bosstructuur geanalyseerd. In het Speulderbos, een studiegebied vlakbij het dorp Garderen midden op de Veluwe, bestond de mogelijkheid om terug te keren en na 25 jaar om het interceptieonderzoek van destijds te herhalen, en om een model te construeren voor het gebruik van aardobservatiedata voor het extrapoleren van resultaten naar een groter gebied.

Het interceptieverlies is geëvalueerd voor een plantage van grove den (Douglas fir) in het Speulderbos van 25 jaar geleden; toen bedroeg het verlies maar liefst $40 \%$ van de neerslag: Een van de hoogste schattingen gerapporteerd in de literatuur. De oorzaak van dit grote interceptieverlies van de hoge capaciteit van het bos om water te bergen.

De hypothese bij aanvang van deze studie was dat door natuurlijke effecten 
zoals de groei van bomen, en onderhoud zoals uitdunnen, de interceptiecapaciteit zou zijn afgenomen. Uit metingen in 2015-2016 bleek echter dat de afname in interceptieverlies maar klein was. Voor de nieuwe studie was het nodig om de ruimtelijke verdeling van doorval te meten. Trechtervormige collectoren werden op willekeurig gekozen posities in een regelmatig rooster van kleine gebiedjes in het bos geplaatst. Elke 15 dagen werden de collectoren verplaats zodat in totaal op 320 locaties de doorval is gemeten tussen februari en november 2015. De verdeling van de doorval was homogener dan 25 jaar geleden op dezelfde plek. De ruimtelijke patronen in het voorjaar en in de zomer waren iets verschillend. De ruimtelijke correlatielengte was $12 \mathrm{~m}$ in het voorjaar en $8 \mathrm{~m}$ in de zomer. Plattegronden van de doorvalpatronen laten zien hoe de bodem door de regen bevochtigd wordt, een proces dat van belang is voor de opname van water door de wortels en de verdeling van nutriënten. De balansen van water en energie tijdens natte omstandigheden zijn geanalyseerd voor het studiegebied voor de groeiseizoenen van 2015 en 2016. Uit de waterbalans bleek dat het interceptieverlies 37 en $39 \%$ was voor die twee jaren. Dit was vergelijkbaar met het verlies jaren eerder (38\%), toen het bos jonger was (29 jaar versus 55 jaar in 205). In het verleden was het bos dichter en had een hogere bergingscapaciteit ( $2.4 \mathrm{~mm}$ versus $1.90 \mathrm{~mm}$ in 2015), maar de aerodynamische geleidbaarheid was lager $\left(0.065 \mathrm{~m} \mathrm{~s}^{-1}\right.$ versus $0.105 \mathrm{~m} \mathrm{~s}^{-1}$ in 2015), en daardoor was de snelheid van verdamping vroeger lager dan nu $\left(0.077 \mathrm{~m} \mathrm{~h}^{-1}\right.$ versus 0.20 $\mathrm{mm} \mathrm{h}^{-1}$ in 2015). De energiebronnen die de verdamping gaande houden waren de netto straling (35\%), de neerwaartse stroom van voelbare warmte $(45 \%)$, en de onttrekking van warmte aan het gewas (15\%). Deze cijfers onderstrepen het belang van het kwantificeren van de neerwaartse voelbare warmtestroom en de flux vanuit de biomassa in hoge bossen, om zo de schatting van de verdamping in het natte bladerdek te schatten.

Als laatste stap in het onderzoek is het geïntegreerde model voor stralings- en energietransport SCOPE ('Soil Canopy Observation, Photochemistry and Energy fluxes') (van der Tol et al., 2009), dat oorspronkelijk bedoeld is voor toepassingen met aardobservatiedata, uitgebreid met een module voor de simulatie van interceptie, berging en druppelen van (natte) vegetatie. Het onderscheppen water is gemodelleerd in analogie met de onderschepping van licht. Het model is gevalideerd met Eddy Covariantie flux data, doorval en metingen van de natheid van het gewas de eerder genoemde volwassen plantage van grove den (Douglas-fir) in het Speulderbos voor de zomer van 2015. De resultaten van de simulaties kwamen goed overeen met de metingen. Dit is eerste stap naar de ontwikkeling van een aardobservatie gedreven model voor de ruimtelijke schatting van neerslaginterceptie op diverse ruimtelijke schalen. Dit proefschrift draagt bij aan de kennis over de effecten van lange-termijnveranderingen in bosstructuur op het proces van neerslaginterceptie, door het verzamelen van empirisch bewijs en door het ontwikkelen van een nieuw model dat gebruik maakt van aardobservatie. 


\section{Acknowledgements}

This work of several years could not have been possible without the direct and indirect contribution of many people. I am very grateful to all of them, and I just hope that for the urgency of writing I missed to thank some of them.

First of all, I want to thank prof. Wout Verhoef for his support and guidance along this years of my PhD study. I am also profoundly grateful to my daily supervisor $\mathrm{dr}$. Christiaan van der Tol, who has been very patience and supportive. Christiaan has dedicated a lot of his time to teach me from the basics about equipment installation to writing skills. I have learn a lot from Christiaan, specially how to be patience and to keep optimistic during the difficult moments.

This work would not have been possible without the funding of the Secretariat for Science and Technology of Ecuador (SENESCYT).

I want to express my deep gratitude to dr. Chandra Ghimire who shared a lot of his knowledge and advice me during the harder times of my study. Chandra also became a good friend, and he was very supportive and at the same time very critical in reviewing the manuscripts that configure my thesis.

I am also very grateful to Prof. Bob Su, although he was not involved in my research topic, he was always supportive during my fieldworks campaigns and also motivating to attend conferences and workshops.

My study days in ITC could not be joyful without the support of my officemates, Junping, Peiqi, Nastia and Egorito. With them, we have shared many experiences not only academics but also of daily life. Thanks for the dinners, beers, coffees, teas, jokes and so on while we were surviving the $\mathrm{PhD}$ life. Thanks a lot, guys.

I am also in deep debt with Murat who drive me many times to Speulderbos, spent many days in the cold weather, and collaborate during the data collection period. Similarly, thanks to the people from TU Delft César Jimenez, Bart Schilperoort, and Miriam Conders who were sharing experiences during the fieldwork campaigns in Speulderbos.

I would also like to express my gratitude to Tina But-Castro, Anke de Koning, Gabriel Parodi, Loes Colerbrander and Theresa van der Boogaard, for their support in all kind of issues during this time. I further appreciate all my $\mathrm{PhD}$ colleagues from the Water Resources Department: Sylo Motila Lekula, Harm-Jan, Bagher, Benhaz, Sammy, Sara, Jing, Donghai, Xiaojing Soxapapantriaus, Novi, Jan, Sammy, Ruosha, Binbin, Tian, Peipei, Mengmen, Hong, Xiaolong, Margaret, Yasser, George, Louis, Chenglian.

To all people who I meet during this years, especially with our close friends and neighbors Fernando, Andrea and Leo, with them we share a lot of experiences and 
good moments even the birth of our children. Thanks a lot!

To my parents Omar and Lolita who have always been my inspiration and guide. To my siblings Susy, Omar, Wilmar, Mayrita who support me from a far distance. Also to my parents in law José and Ligia, and to Mireya, Alexandra, Santiago, and Henry for helping us along this time.

This achievement could not be possible without the support and love of my wife, Myri. She walked with me on this journey, we came to the Netherlands, and we start to build our family. We learned a lot from each other far from home, we enjoy a new culture, and we kept strong during the difficult times. These years have been the most enjoyable of my life. She gave me my two other loves Victoria and Adrián; they are my inspiration every day. Thanks a lot for everything, my love. 


\section{Contents}

Contents vii

1 Introduction 1

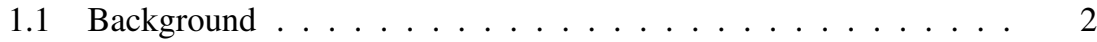

1.2 The process of rainfall interception loss . . . . . . . . . . 3

1.2.1 Climatic factors . . . . . . . . . . . . . . 3

1.2.2 Vegetation characteristics .................. 4

1.3 Modelling rainfall interception . . . . . . . . . . . . . . . . 5

1.3.1 Rutter model .................. . . . . 5

1.3.2 Gash model . . . . . . . . . . . . . . . . 8

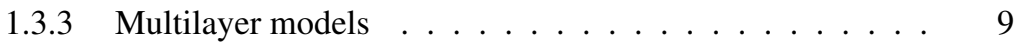

1.4 Problem definition . . . . . . . . . . . . . . . . . . . 9 9

1.5 Research questions ................... 11

1.6 Thesis outline . . . . . . . . . . . . . . . 11

2 Study site and instrumentation $\quad 13$

2.1 Study site . . . . . . . . . . . . . . . . . . . . . . . 14

2.2 Instrumentation . . . . . . . . . . . . . . . . . . . . . . . . . . . . . . .

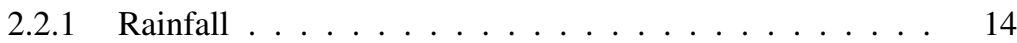

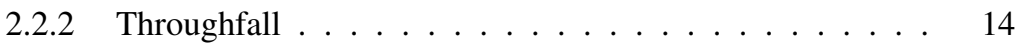

2.2 .3 Stemflow . . . . . . . . . . . . . . . 17

2.2.4 Net radiation and soil heat flux . . . . . . . . . . . . . 17

2.2.5 Turbulent heat fluxes . . . . . . . . . . . . . . . . . 18

2.2.6 Canopy wetness ................... 19

2.2.7 Thermal dissipation probes . . . . . . . . . . . 19

3 Spatial Patterns and Temporal Stability of Throughfall 21

3.1 Introduction . . . . . . . . . . . . . . . . . . 22

3.2 Study Area . . . . . . . . . . . . . . . . . . . 23

3.3 Field Measurements . . . . . . . . . . . . . . . . . . . . 23

3.3.1 Rainfall ................... 23

3.3.2 Throughfall .................. 23

3.4 Data Analysis . . . . . . . . . . . . . . . . . . . . 26

3.4.1 Spatial Variability of Throughfall . . . . . . . . . . 26

3.4.2 Temporal Persistence of Throughfall . . . . . . . . . . 28

3.5 Results . . . . . . . . . . . . . . . . 28 
3.5.1 Throughfall . . . . . . . . . . . . . . . 28

3.5.2 Spatial Patterns of Throughfall . . . . . . . . . . . . 28

3.5.3 Temporal Persistence of Throughfall . . . . . . . . . . . . 31

3.6 Discussion . . . . . . . . . . . . . . . . . . 32

3.6.1 Throughfall Variability . . . . . . . . . . . 32

3.6.2 Spatial Patterns of Throughfall . . . . . . . . . . . . . 33

3.6.3 Temporal Persistence of Throughfall . . . . . . . . . . . 34

3.7 Conclusions . . . . . . . . . . . . . . . . . . . 35

4 The influence of long-term changes in canopy structure on interception loss

4.1 Introduction . . . . . . . . . . . . . . . . . 38

4.2 Materials and methods . . . . . . . . . . . . . . 40

$4.2 .1 \quad$ Rainfall . . . . . . . . . . . . . . . . . . . . 40

4.2 .2 Throughfall . . . . . . . . . . . . . . 40

4.2 .3 Energy storage . . . . . . . . . . . . . . . . . 40

4.2.4 Modelling rainfall interception . . . . . . . . . . . . . . 41

4.3 Results . . . . . . . . . . . . . . . . . . . 46

$4.3 .1 \quad$ Rainfall . . . . . . . . . . . . . . . . . 46

4.3.2 Throughfall, stemflow, and derived interception loss . . . 46

4.3.3 Canopy-related parameters . . . . . . . . . . . . 48

4.3.4 Energy balance closure and performance of the sonic anem-

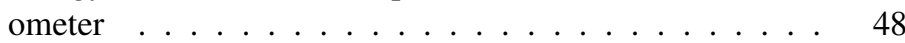

4.3.5 Wet-canopy evaporation rates . . . . . . . . . . . . . 49

4.3.6 Modelling rainfall interception . . . . . . . . . . . . . 53

4.4 Discussion . . . . . . . . . . . . . . . . . . . . . 54

4.4 .1 Canopy storage capacity $\ldots \ldots \ldots \ldots$

4.4.2 Wet-canopy evaporation rate . . . . . . . . . . . 57

4.4 .3 Rainfall interception . . . . . . . . . . . . . . . 60

4.4 .4 Conclusion . . . . . . . . . . . . . . 61

5 Modelling rainfall interception loss with SCOPE 63

5.1 Introduction . . . . . . . . . . . . . . . . . . . . . . . 64

5.2 Materials and Methods . . . . . . . . . . . . . . . . . 66

5.2 .1 The water budget model . . . . . . . . . . . . 66

5.2 .2 Canopy experiment . . . . . . . . . . . . . 70

5.2 .3 Numerical simulations . . . . . . . . . . . . . . . . 73

5.3 Results . . . . . . . . . . . . . . . . . . . . . . . 74

$5.3 .1 \quad$ Energy fluxes . . . . . . . . . . . . . . . . . . . 74

5.3.2 Modelled water balance _. . . . . . . . . . . . . . 77

5.3.3 Canopy drying time and evaporative fluxes . . . . . . . . . 77

5.3 .4 Numerical simulations . . . . . . . . . . . . . . . . . . 81

5.4 Discussion . . . . . . . . . . . . . . . . . . . 84

5.4 .1 Energy fluxes . . . . . . . . . . . . . . . . . . . . . 84

5.4 .2 Water balance . . . . . . . . . . . . . . . . 84

5.4.3 Canopy drying time and evaporative fluxes . . . . . . 85

5.4 .4 Numerical simulations . . . . . . . . . . . . . . . 86

5.4.5 Potential input from remote sensing observations . . . . . 86 
5.5 Conclusions . . . . . . . . . . . . . . . 88

6 Synthesis 89

6.1 Summary of the research results . . . . . . . . . . . . . . 90

6.1.1 Spatial patterns and temporal stability of throughfall . . . 90

6.1.2 Sources of energy driving evaporation of intercepted rainfall 91

6.1.3 Effects of natural growing and thinning in the rainfall interception loss process . . . . . . . . . . . . 92

6.1.4 A new multilayer modelling approach to estimate rainfall interception loss . . . . . . . . . . . . . . . . . . 93

6.2 Perspectives ......................... 94

A List of abbreviations and symbols $\quad 95$

Bibliography $\quad 99$ 



\section{List of Figures}

1.1 The conceptual framework of the running water balance in Rutter model (adapted from Gash and Morton (1978)) . . . . . . . . . . . . . .

2.1 Study area in Speulderbos: (a) study site in the Netherlands; (b) top view of the Douglas-fir canopy; (c) funnel-type collector used to quantify throughfall in the study site in the absence of understory. . . . . . . 15

2.2 Flux tower in the 'Speulderbos' study site . . . . . . . . . . . . 15

2.3 Throughfall measurements in the 'Speulderbos' study site . . . . . . 16

2.4 Stemflow measurements in the 'Speulderbos' study site . . . . . . . . . 18

2.5 Eddy-covariance measurements in the "Speulderbos" study site . . . 19

2.6 Leaf wetness sensor (Model 237) placed in a Douglas fir branch in the "Speulderbos" study site . . . . . . . . . . . . . . 20

2.7 Three thermal dissipation probes (TDP) placed in a Douglas fir stem in the 'Speulderbos' study site . . . . . . . . . . . . . 5 8

3.1 Throughfall sampling scheme. The black crosses (+) represent the marked grid spaced at $8 \mathrm{~m}$, on the $\mathrm{x}$ and $\mathrm{y}$ direction. Black triangles represent trees with symbol size scaled to DBH. The black circles represent the position of the funnel-type collectors in one period (Prd). Each collector was located by randomly selecting an azimuth (Az) between 0 and 360 degrees, and a radius distance (r) between $0 \mathrm{~m}$ and $4 \mathrm{~m}$ (e.g. see the upper right corner) . . . . . . . . . . . . . . .

3.2 Estimated standardized variograms of $T F$ for (a) spring season with fitted exponential model; (b) summer season with fitted exponential model. Each point was labeled with the respective number of pairs per lag distance. . . . . . . . . . . . . . .

3.3 TF-p maps (as \% PG) for (a,b) spring periods: Prd-4 and Prd-6; (c,d) summer periods: Prd-9 and Prd-11. Filled black triangles represent trees (size proportional to DBH), and black circles represent the funnel-type collectors. . . . . . . . . . . . . . . . .

3.4 Time stability plot of normalized $T F$ for 32 stationary funnel-type collectors. Black dots are values of normalized $T F$ for each funnel-type collector of the stationary periods (Periods 11-15). Black asterisks are the averaged values of normalized $T F$. The numbers on the $\mathrm{x}$-axis are field labels for the collectors sorted by lowest averaged normalized $T F$

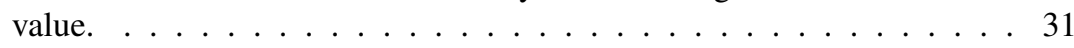


3.5 Normalized $T F$ versus distance to nearest tree. Black dots represent the normalized throughfall value for each funnel-type collector. Each symbol is labeled with the collector number. . . . . . . . . . . . .

4.1 Determination of canopy-related parameters using the mean method and the individual event analysis. (a) Linear regression using data-set 1 ; events selected in Case A. Circles represent rainfall events with total rainfall less than that necessary for saturation; crosses represent data with enough rainfall to saturate the canopy. (b) Linear regression using data-set 1; events selected in Case B (similar legend to a). (c) Individual event analysis (IEA) on 17 September 2015, the plot of data used to estimate canopy direct throughfall and saturation storage capacity. Dots represent values of cumulative rainfall vs. cumulative $T F$. The direct throughfall regression equation was $T F=0.07 P G$, and the saturation regression equation was $T F=0.68 P G-1.38$. Canopy saturation point was calculated as the intersection of the two linear regressions,

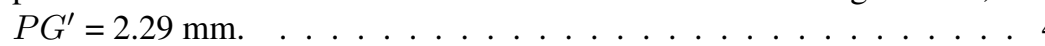

4.2 (a) Half-hour interval of turbulent heat fluxes $(H$ and $\lambda E)$ vs. available energy $\left(R_{\mathrm{n}}-G-Q\right)$ for the study site. The solid line represents the 1:1 line and the dashed line represents linear regression forced through the origin. (b) Half-hour averages of standard deviation of the vertical wind speed $\sigma w\left(\mathrm{~m} \mathrm{~s}^{-1}\right)$ vs. friction velocity $u^{*}\left(\mathrm{~m} \mathrm{~s}^{-1}\right)$, wet-canopy

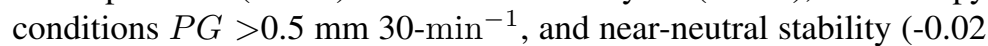
$<(z-d) / L<0.02) \ldots \ldots \ldots \ldots \ldots \ldots \ldots \ldots$. . . . . . . .

4.3 Distributions of wet-canopy evaporation rates during daytime (07:00-19:00 UTC+1), night time (19:00-07:00 UTC+1), and combined day and night. Two different methods applied: (a-c) energy balance residual $\left(E_{\mathrm{EB}-\mathrm{EC}}\right)$ and $(\mathrm{d}-\mathrm{f})$ Penman-Monteith $\left(E_{\mathrm{PM}-\mathrm{EC}}\right) \ldots \ldots \ldots \ldots$. . . . . . . 51

4.4 Linear regression of friction velocity $u^{*}$ against horizontal wind speed $u$ for near-neutral hours $(-0.02<(z-d) / L<0.02)$ and from a southwesterly wind direction. . . . . . . . . . . . . . .

4.5 Sensitivity analysis of the parametrized original Gash model. Run 1, all parameters derived from the mean method. Run 2, canopy parameters $(S, p)$ derived from IEA and the evaporation rate from the energy balance residual method. Contour lines representing the RMSE for different combinations of the parameters' canopy storage capacity $(S)$ and the ratio $\bar{E} / \bar{R}$. (a) Sensitivity analysis using calibration data-set 1 (19 June to 31 October 2015. (b) Sensitivity analysis using validation data-set 2 (19 June to 31 October 2016). The red circles represent the corresponding parameters used in the model Run 1 and Run 2. . . . .

5.1 Modelled fluxes of net radiation $\left(R_{\mathrm{n}}\right)$, latent heat $(\lambda E)$ and sensible heat ( $H$ ) for (a) 2 July 2015, and (b) 27 July 2015. Black plotted points $(\square)$ denoted estimated values of sensible heat by the eddy covariance technique $\left(H_{E C}\right) \ldots \ldots \ldots \ldots \ldots \ldots \ldots \ldots$

5.2 Time series of throughfall observed $\left(T F_{\mathrm{Obs}}\right)$ and predicted $\left(T F_{\mathrm{Tot}}\right)$ during the period 2 July to 30 July $2015 \ldots \ldots \ldots \ldots \ldots$

5.3 Scatter plot of $T F$ observed vs $T F$ modelled per rainfall event. . . . . 77 
5.4 Temporal distribution of: (a) Estimated evaporative fluxes of intercepted precipitation $\left(E_{\mathrm{I}}\right)$, transpiration $\left(E_{\mathrm{T}}\right)$, total Evapotranspiration $\left(E_{\mathrm{Tot}}\right)$, rainwater storage $(S)$ and (b) rainwater stored in the vertical profile (60 layers) for the period 13 July 2018 to 15 July 2015 . . . . . . . . . .

5.5 Vertical profiles of (a) rainwater storage and (b) leaf temperature (average per layer) on 14 July 2015 (DOY 195 , from $12 \mathrm{~h}$ to $24 \mathrm{~h}$ ). . . . . .

5.6 Vertical profiles (average per layers) of (a) latent heat flux $(\lambda E)$, (b) sensible heat flux $(H)$ during the canopy drying phase on 14 July 2015 (from $12 \mathrm{~h}$ to $24 \mathrm{~h}$ ). . . . . . . . . . . . . . . . . . . . . .

5.7 Dew formation (a) detected by 2 leaf wetness sensors (LWS) located at $20 \mathrm{~m}$ and $26 \mathrm{~m}$ height within the canopy during 6th of July 2015 (DOY 187), no rain was observed during that day. (b) Dew formation modelled at the top layers of the canopy. . . . . . . . . . . . . . .

5.8 Daily distribution of transpiration flux $\left(E_{\mathrm{T}}\right)$. After a rainfall event starting at 5:00, the canopy is wet (also detected by the LWS), around 11:00 the canopy is getting dry and transpiration is beginning. The time when transpiration flux has started is compared with three thermal dissipation probes (TDP; installed in three different trees) and it matches with the modelled transpiration flux. The dashed gray line represent a diurnal cycle of SFD during a sunny day $\left(\mathrm{SFD}_{\text {sun }}\right) \ldots \ldots$. . . . . 81

5.9 Inter-comparison of modelled aerodynamic resistance for the proposed scenarios representing past ( $\mathrm{SCN} 1)$, and future $(\mathrm{SCN} 3)$ in relation to the present scenario $(\mathrm{SCN} 2$, line $1: 1), \ldots \ldots \ldots \ldots$

5.10 Ilustration of the drying phase for the three proposed scenarios representing past (SCN1), present (SCN2), and future (SCN3). (a) Comparison of water stored in the canopy normalized to $S_{\max }$ for the three scenarios. (b) Comparison of $E_{\mathrm{I}}$ for the three scenarios along the drying phase on 14 July 2018. 



\section{List of Tables}

1.1 Principal characteristics of physically based models (after Muzylo et al., 2009), $I$ =interception loss, $T F=$ Throughfall $S F=$ Stemflow. . . . . .

2.1 Main micro-meteorological instruments installed on the Speulderbos flux tower. . . . . . . . . . . . . . . . 17

3.1 Characteristics of throughfall measurements. . . . . . . . . . . . . 25

3.2 Parameters of the fitted standardized-variograms and converted periodvariogram models. . . . . . . . . . . . . . . . . . .

4.1 Statistical description of collection periods of throughfall and average amounts for a sample size $n=32 \ldots \ldots \ldots \ldots$. . . . . .

4.2 Comparison of stand parameters and biomass dry weight (DW) for the Douglas fir stand in Speulderbos. Aboveground biomass determined by means of stem survey and allometric relationships from Bartelink (1996). 42

4.3 Main equations of the analytical Gash (1979) interception model. . . . 43

4.4 Average micro-meteorological characteristics for half-hour periods with more than $0.25 \mathrm{~mm}(30 \mathrm{~min})^{-1}$ of $P G$ for day $(07: 00-19: 00 \mathrm{UTC}+1)$ and night conditions $(19: 00-07: 00 \mathrm{UTC}+1) \ldots \ldots$. . . . . . . . 51

4.5 Summary statistics for the wet evaporation rates estimated for the study period by different methods: energy balance $\left(\bar{E}_{\mathrm{EB}-\mathrm{EC}}\right)$ and Penman-Monteith equation $\left(\bar{E}_{\mathrm{PM}-\mathrm{EC}}\right) . \ldots \ldots \ldots \ldots$

4.6 Comparison of the performance of modelled interception loss using different parametrization. Data-set 1 refers to the period from 19 June to 31 October 2015, and data-set 2 to the period from 1 April to 31 October 2016. Run 1, all parameters derived from the mean method. Run 2, canopy parameters $(S, p)$ derived from IEA and $E$ from the energy balance residual method. . . . . . . . . . . . . . .

4.7 Components of interception loss in $\mathrm{mm}$ (and as percentage of total) for data-set 2 (19 June to 31 October 2016) based on the validated Gash analytical original model. . . . . . . . . . . . . . .

4.8 Summary of canopy properties and interception parameters for Douglas fir forests. . . . . . . . . . . . . . . . 59

5.1 Input parameters in SCOPE used to model energy fluxes time series. . . 71

5.2 Description of canopy parameters used in the numerical simulations. . 74 
5.3 Results from numerical simulations for the three proposed scenarios $(\mathrm{SCN})($ mean $\pm \mathrm{SD}) . \ldots \ldots \ldots \ldots$ 
Introduction 


\subsection{Background}

Rainfall is the primary input of the hydrological cycle, and its distribution over the planet is a determining factor for the presence of ecosystems. After rainfall, interception loss is the first in the sequence of hydrological processes that take place on the land surface. Rainfall interception loss (loss of rainwater due to evaporation of intercepted water) represents the fraction of rainfall that does not reach the ground, and by definition, it is unavailable for soil infiltration or run-off (Horton, 1919; Brutsaert, 2005).

Despite that rainfall interception loss is a relatively small component in the hydrological cycle, it plays an important role in the land-atmosphere interactions. Over forested canopies its values range from 10-50\% of season-long or annual rainfall (Carlyle-Moses and Gash, 2011). On a global scale it accounts for 20,100 \pm $9,800 \mathrm{~km}^{3}$ of water per year (Coenders-Gerrits et al., 2014). Rainfall intercepted by vegetation is, apart of hydrological applications, also important for plant-water interactions. Some of the cost of leaf wetting in plant functioning are related to growth of pathogens and the leaching of nutrients, but also leaf wetting can improve plant-water relations and lead to increased photosynthesis (Dawson and Goldsmith, 2018).

The history of rainfall interception measurements is long and started in the early twentieth-century (Horton, 1919, benchmark papers in Gash and Shuttleworth, 2007). Many studies have been carried out since in different forest ecosystems. These studies have covered measurements over a wide range of forest types. Among the most abundant ones are coniferous forest (Gash et al., 1980; Rutter et al., 1971; Johnson, 1990), temperate deciduous forest (Dolman, 1987; Carlyle-Moses and Price, 1999) and tropical forest (Lloyd and Marques, 1988; Tobón M et al., 2000). Even though rainfall interception in forests has received more attention than in any other land cover, rainfall interception by crops is also relevant, in particular for soil erosion (Bui and Box, 1992), crop disease management (Huber and Gillespie, 1992), agro-forestry (Jackson, 2000), and irrigation management (Kozak et al., 2007).

In the literature, different terminology has been used to refer to rainfall interception loss interception. Sometimes it can be interpreted as a stock or interception storage $(C,[\mathrm{~L}])$, or sometimes as a flux as rainfall interception loss $\left(I,\left[\mathrm{~L} \mathrm{~T}^{-1}\right]\right)$ temporary held in the canopy elements to be later returned to the atmosphere by evaporation $\left(E_{I},\left[\mathrm{~L} \mathrm{~T}^{-1}\right]\right)$. The storage, interception and evaporation are related as (Savenije, 2005):

$$
I=\frac{d C}{d t}+E_{I}
$$

If Eq 1.1 is integrated between two periods when the canopy was dry, then the water volume per unit surface area (water depth) lost by the wet canopy evaporation results, often called the 'net interception': $I_{\mathrm{n}}=\int_{0}^{t} E_{I} d t$. This quantity is often presented as a percentage or fraction of the gross rainfall $(P G)$ over the integration period.

A standard way to indirectly estimate rainfall interception loss is to get the residual between $P G$ measured above the canopy (or sometimes on an open space close by), and the so-called net rainfall. Net rainfall is the sum of throughfall (TF) 
and stemflow $(S F)$, both adequately quantified below the canopy. The most direct method to measure rainfall interception loss is the whole tree lysimeter (Dunin et al., 1988). This method is not always feasible. More sophisticated techniques have also been tested in the past as microwave signal attenuation (Bouten et al., 1991) or gamma-ray attenuation (Calder and Wright, 1986), and most recently, methods based on compression sensors (Friesen et al., 2008), and accelerometers (van Emmerik et al., 2017) have emerged. However, many of these methods perform well at small scales, but at a larger scale, they are not (yet) applicable. In this respect, remote sensing in combination with modelling is a suitable additional approach.

\subsection{The process of rainfall interception loss}

In one the first studies of rainfall interception loss, Horton (1919) recognised that the interception loss is a function of the duration of precipitation, the evaporation rate during the precipitation event, and of the water storage capacity of the vegetated surface. The two first can be grouped as climatic factors, while the last one can be named as vegetation characteristics. A detailed description of these groups follows.

\subsubsection{Climatic factors}

Rainfall is the primary climatic factor controlling interception loss. Not only the amount of rain but also the intensity and duration of rainfall influence in the process. Around the world, substantial variations of rainfall characteristics occur between or within seasons, and together with the vegetation characteristics, they control the interception process (Crockford and Richardson, 2000). The fraction of rainfall interception loss decreases asymptotically with rainfall depth (i.e. larger amounts of rainfall results in less interception loss). The exact relationship between rainfall and interception loss is further determined by the frequency and intensity of rainfall events. For instance, in areas where precipitation occurs as a series of small events with dry spells in between $I_{\mathrm{n}}$ is larger than in areas with more continuous and relatively large events (Carlyle-Moses and Gash, 2011).

Regarding rainfall intensity and its relationship with the canopy storage capacity there are different points of view. Several studies found that for high intensity periods the canopy storage capacity can be reduced due to splashing and shaking of foliage (Horton, 1919). Other authors, in contrary, suggests that high rainfall intensities can result in an increase of storage capacity due to the so called 'dynamic storage' (Keim et al., 2006; Reid and Lewis, 2009).

Other climatic factors to consider are air temperature and humidity, which are linked to the evaporative demand. A high evaporative demand results in rapid drying and high $I_{\mathrm{n}}$. For instance, Llorens et al. (1997) found that medium duration events with low rainfall intensities under dry conditions in a pine forest, resulted in a $I_{\mathrm{n}}$ of $49 \%$, which was almost three times larger than the $I_{\mathrm{n}}$ observed for long events with low rainfall intensity and during wet atmospheric conditions.

Other climatic factors to consider are air temperature and humidity, which are linked to the evaporative demand. A high evaporative demand results in rapid drying and high $I_{\mathrm{n}}$. For instance, Llorens et al. (1997) found that medium duration events with low rainfall intensities under dry conditions in a pine forest, resulted in a $I_{\mathrm{n}}$ of 
49\%, which was almost three times larger than the $I_{\mathrm{n}}$ observed for long events with low rainfall intensity and during wet atmospheric conditions.

One of the most intriguing issues is that the energy required to sustain evaporation rates from forest canopies, which usually ranges from 0,07 to $0.45 \mathrm{~mm}$ $\mathrm{h}^{-1}$ (Carlyle-Moses and Price, 1999; Klaasen et al., 1998), frequently exceeds the limited available energy (Stewart, 1977). Advected energy has been proposed as one of the possible sources of energy required for the evaporation (Stewart, 1977; Wallace and McJannet, 2006). A wet canopy would be cooler than the surrounding air canopy, causing the damp canopy to be a sensible heat sink (Stewart, 1977). Potential sources of this additional sensible heat are oceans, nearby dry vegetation, or even the forest itself (Shuttleworth and Calder, 1979; Wallace and McJannet, 2006). In that case, wind direction can also be considered as an essential factor to regulate the amount of sensible heat advected toward the wetted canopy.

\subsubsection{Vegetation characteristics}

Canopy height $\left(h_{\mathrm{c}}\right)$ is another relevant vegetation property. van Dijk et al. (2015), in a exhaustive energy balance residual analysis of 128 FLUXNET sites, quantified latent heat of evaporation $(\lambda E)$. The average $\lambda E$ for sites with tall vegetation $\left(h_{\mathrm{c}}\right.$ $\geq 3 \mathrm{~m}$ ) during wet-canopy conditions was $45 \pm 18 \mathrm{~W} \mathrm{~m}^{-2}$, versus $35 \pm 17 \mathrm{~W}$ $\mathrm{m}^{-2}$ for short vegetation $\left(h_{\mathrm{c}}<3 \mathrm{~m}\right)$. Another characteristic of vegetation crucial for the interception loss process is the canopy storage capacity $(S)$. This feature is related to the vegetation type and the biophysical properties of the canopy elements such as water repellency, leaf thickness, and the density of the foliage components (leaf/needles and wood). Storage capacity also depends on the stand composition, the stand density, leaf area index (LAI), wood area index (WAI), leaf angles, and the cover fraction.

Several authors have established direct relations between leaf area index (LAI) and canopy storage capacity $(S)$. For instance, Pitman (1989) presented the link for maximum storage capacity equal to $0.46 \cdot \mathrm{LAI}$ for a bracken fern in open habitats. Other publications instead have presented generalized expressions, for instance, for broad-leaved trees $(0.15 * \mathrm{LAI})$ and needle-leaved trees $(0.3 * \mathrm{LAI})$ (Watanabe and Mizutani, 1996; Carlyle-Moses and Price, 2007). Other authors (e.g. Moors, 2012), suggest that the relation between $S$ and LAI is better represented by an exponential function. This kind of ties, however, depends on other seasonally varying vegetation characteristics and in rainfall intensity as well. Pypker et al. (2005) described how short-term (seasonal) and long-term (decadal) changes of forest canopy structure could influence the storage capacity. They found that the storage capacity was higher in an old-growth Douglas fir forest compared to a young stand although both had nearly equal LAI values. Pypker et al. (2005) attributes this effect to the increased surface area of branches and boles in the old growth forests, but most importantly, to the occurrence of epiphytes plants in the canopy.

The cover fraction is in turn related to canopy sparseness, and this influences the roughness and aerodynamic conductance of the canopy and in consequence evaporation. Teklehaimanot et al. (1991) evaluated the effect of tree spacing in rainfall interception loss, and concluded that the boundary layer conductance per tree increased with increasing spacing, while the boundary layer conductance per unit surface area decreased as the density of trees decrease. 
The differences in vegetation characteristics between the growing and the dormant season appear to have a relatively small effect on $I_{\mathrm{n}}$, which is somewhat counterintuitive. For instance, Herbst et al. (2008) found that a leafless canopy maintained a relatively high interception loss throughout the year of about $20 \% P G$ during the leafless period, in comparison with the $29 \% P G$ in the leafed period.

Furthermore, it has to be considered the health condition of the vegetation and contamination levels to which it is exposed. In a recent study, Klamerus-Iwan et al. (2018) found that along with age and increasing degree of fungal infection, a common oak exhibited a higher water storage capacity.

\subsection{Modelling rainfall interception}

Several models have been developed to study interception. These models range from simple regression models (Horton, 1919; Helvey and Patric, 1965), to physically based numerical (Rutter et al., 1971), analytical (Gash, 1979) and stochastic models (Calder, 1986).

In a review of rainfall interception models, Muzylo et al. (2009) identified fifteen physically based models representing distinct concepts of the interception process. Those fifteen models (Table 1.1) can be grouped into two subcategories. The first group uses a probability distribution to describe the interception of raindrops. This group is restricted to two models: Calder one-layer (Calder, 1986) and two-layer model (Calder, 1996). The second group uses a volume or mass balance for the redistribution of rainfall. This group can be subdivided into two: i) those that employ a continuous running water balance approach and, ii) those that use an analytical solution approach based on rainfall events. These approaches are named Rutter-type models (for running water balance models) and Gash-type models (for event-based models) after their respective original developers (Muzylo et al., 2009).

In general, the literature of rainfall interception modelling is dominated by four models (Carlyle-Moses and Gash, 2011): the original Rutter model (Rutter et al., 1971, 1975), the original Gash model (Gash, 1979), and their reformulations (Valente et al., 1997; Gash et al., 1995). The limited deviations from the original Rutter and Gash models are due to either their parameter requirements (i.e. Calder two-layer model), usually not so easy to get or by the unusual techniques to obtain some specific parameters. Some other models are relatively new and very little used (i.e. Murakami, 2006; Zeng et al., 2000), and some have been developed for a specific vegetation type. Concerning the two main approaches (Gash and Rutter) and their reformulations, there has been a steady of abandonment of the running water balance approach. One of the reason has been the success of the original and sparse Gash models, but also because Rutter's model is more data demanding (Muzylo et al., 2009). Despite the good results in the approach modelling, there are still some drawbacks in model applications. An inadequate validation of the models, few comparative studies, uncertainties of measurements and parameter variability are the main problems (Muzylo et al., 2009; Carlyle-Moses and Gash, 2011).

\subsubsection{Rutter model}

Rutter et al. (1971) were the first to present a physically based model that predicts 
Table 1.1 Principal characteristics of physically based models (after Muzylo et al., 2009), $I=$ =interception loss, $T F=$ Throughfall $S F=$ Stemflow.

\begin{tabular}{|c|c|c|c|c|c|c|c|c|c|}
\hline \multirow{2}{*}{ Model } & \multicolumn{2}{|c|}{ Input temporal scale ${ }^{a}$} & \multicolumn{3}{|c|}{ Output variable } & \multirow{2}{*}{$\begin{array}{l}\text { Number of } \\
\text { parameters }\end{array}$} & \multirow{2}{*}{ Layers } & \multirow{2}{*}{$\begin{array}{l}\text { Spatial } \\
\text { Scale }\end{array}$} & \multirow{2}{*}{ Reference } \\
\hline & Rainfall & Meteo & $I$ & $T F$ & $\overline{S F}$ & & & & \\
\hline \multicolumn{10}{|l|}{ Rutter-type } \\
\hline Rutter & Hourly $^{b}$ & Hourly $^{b}$ & $\mathrm{X}$ & $\mathrm{X}$ & $\mathrm{X}$ & 7 & 1 & Stand & Rutter et al. (1971) \\
\hline $\begin{array}{l}\text { Sellers and } \\
\text { Lockwood }\end{array}$ & Hourly & Hourly & $X$ & $\mathrm{X}$ & & $2+4 \times \mathrm{n} \mathrm{n}^{c}$ & Multiple & Stand & Sellers et al. (1981) \\
\hline Massman & $10 \mathrm{~min}$ & $10 \mathrm{~min}$ & $\mathrm{X}$ & $\mathrm{X}$ & & 4 & 1 & Stand & Massman (1983) \\
\hline Liu J. & Daily & Not clear & $\mathrm{X}$ & & & $4+2 \mathrm{x} \mathrm{n}^{c}$ & Multiple & Stand & J. Liu (1988) \\
\hline Liu S. & Hourly $^{d}$ & Hourly $^{d}$ & $\mathrm{X}$ & & & 3 & 1 & Stand & S. Liu (1997) \\
\hline Xiao & Hourly ${ }^{d}$ & Hourly $^{d}$ & $\mathrm{X}$ & $\mathrm{X}$ & $\mathrm{X}$ & 14 & Multiple & Tree & Xiao et al. (2000) \\
\hline Rutter sparse & Hourly $^{b}$ & Hourly $^{b}$ & $\mathrm{X}$ & $\mathrm{X}$ & $\mathrm{X}$ & 5 & 1 & Stand & Valente et al. (1997) \\
\hline \multicolumn{10}{|l|}{ Gash-type } \\
\hline Gash & Hourly $^{d}$ & Hourly & $\mathrm{X}$ & $\mathrm{X}$ & $\mathrm{X}$ & 4 & 1 & Stand & Gash (1979) \\
\hline Mulder & Daily & Daily & $\mathrm{X}$ & & & 2 & 1 & Stand & Mulder (1985) \\
\hline Gash sparse & Hourly $^{d}$ & Hourly & $\mathrm{X}$ & $\mathrm{X}$ & $\mathrm{X}$ & 4 & 1 & Stand & Gash et al. (1995) \\
\hline Zeng & Hourly & Hourly $^{e}$ & $\mathrm{X}$ & & & 3 & 1 & Stand & Zeng et al. (2000) \\
\hline $\begin{array}{l}\text { van Dijk and } \\
\text { Bruijnzeel }\end{array}$ & Daily & Hourly & $\mathrm{X}$ & $\mathrm{X}$ & $\mathrm{X}$ & 7 & 1 & Stand & $\begin{array}{l}\text { van Dijk and } \\
\text { Bruijnzeel (2001) }\end{array}$ \\
\hline Murakami & Hourly ${ }^{f}$ & Hourly ${ }^{g}$ & $\mathrm{X}$ & & & 4 & 1 & Stand & Murakami (2006) \\
\hline Calder stochastic & Hourly & Hourly & $\mathrm{X}$ & & & 6 & 1 & Stand & Calder (1986) \\
\hline Calder two-layer & Hourly & Hourly & $\mathrm{X}$ & & & 16 & 2 & Stand & Calder (1996) \\
\hline
\end{tabular}

${ }^{a}$ Minumum requirement

${ }^{b}$ High resolution of calculations

${ }^{c} \mathrm{n}=$ Number of layers

${ }^{d}$ Or daily or event

${ }^{e}$ From hourly to yearly

$f_{\text {And daily }}$

${ }^{g}$ Not necessary if $E$ rate obtained from regression

rainfall interception loss. The model is described as a running water balance where the core is the storage of rainwater in the canopy. Gains in canopy storage are driven by intercepted water and losses by evaporation and drainage. Because the rates of evaporation and drainage depend on storage, the model was developed as a running water balance in time of rainfall, throughfall, evaporation, and changes in storage. Later on, Rutter et al. (1975) complemented the model by including a stemflow module which mainly consists of rain that is diverted to a compartment in the trunks.

The conceptual basis of Rutter's model is shown in Fig. 1.1. The main inputs to the model are rainfall and meteorological data. There are four important parameters used to represent the canopy structure: the free throughfall coefficient $(p)$, the stemflow partitioning coefficient $\left(p_{\mathrm{t}}\right)$, the canopy storage capacity $(S)$, and the trunk storage capacity $\left(S_{t}\right)$. The model considers that one portion of the rainfall that reaches the top of the forest can freely pass through the canopy, and the remaining part is temporally stored and can either drain to the ground as throughfall or be evaporated back to the atmosphere, or reach the ground as stemflow via the trunks. The outputs of the model are throughfall, stemflow and interception loss. The model uses the following equations:

$$
\left(1-p-p_{\mathrm{t}}\right) \int R d t=\int D d t+\int E d t+\Delta C
$$




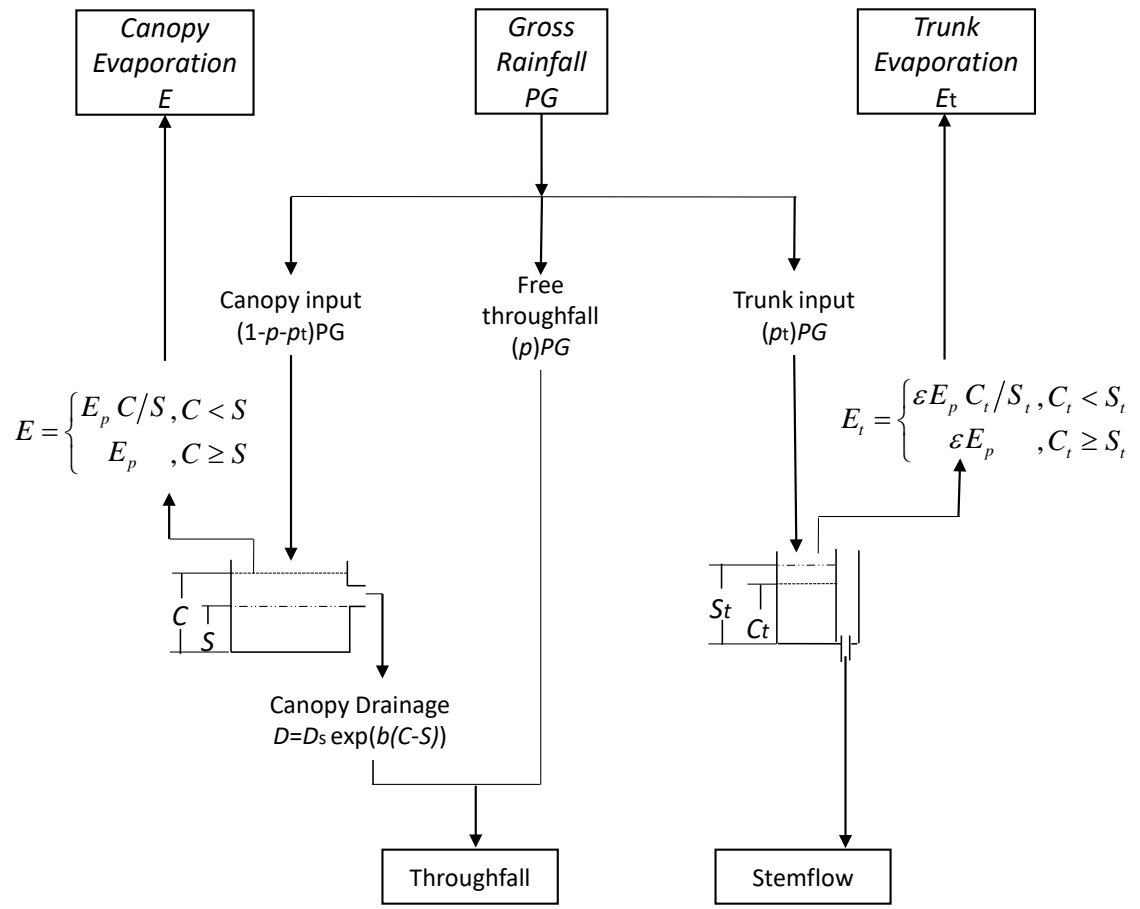

Figure 1.1 The conceptual framework of the running water balance in Rutter model (adapted from Gash and Morton (1978))

where $R$ is the intensity of $P G, D$ is the rate of drainage from the canopy, $E$ is the evaporation rate of water intercepted by the canopy, $\Delta \mathrm{C}$ is the change in canopy storage.

The mass balance of water stored on the trunks is described by:

$$
p_{\mathrm{t}} \int R d t=S F+\int E_{\mathrm{t}} d t+\Delta C_{\mathrm{t}}
$$

where $S F$ is the stemflow, $E_{\mathrm{t}}$ is the evaporation rate of the water stored on the trunks, and $\Delta C_{\mathrm{t}}$ is the change in the trunk storage.

Rutter's model assumed that evaporation from the saturated canopy $(C>S)$ equals the potential evaporation rate $\left(E_{\mathrm{P}}\right)$. However, when the canopy is partially wet $(C \leq S)$ evaporation is calculated as: $E=E_{\mathrm{P}}(C / S)$. $E_{\mathrm{P}}$ is calculated using the Penman-Monteith equation with the canopy resistance set to zero.

In Rutter's model it is assumed that drainage is not generated before canopy is saturated $(C<S)$. When the canopy reach saturation $(C \leq S)$, the rate of drainage $D$ is calculated as:

$$
D=D_{\mathrm{s}} \exp [b(C-S)]
$$

where $D_{\mathrm{s}}$ is the rate of drainage when $C=S$ and $b$ is an empirical coefficient. 
Similarly, for the canopy, stemflow and trunk evaporation are calculated from the following equations:

$$
\begin{aligned}
& E_{\mathrm{t}}=\left\{\begin{array}{lll}
\epsilon E_{\mathrm{P}} & \text { if } & C_{\mathrm{t}} \leq S_{\mathrm{t}} \\
\epsilon E_{\mathrm{P}}\left(C_{\mathrm{t}} / S_{\mathrm{t}}\right) & \text { if } & C_{\mathrm{t}}<S_{\mathrm{t}}
\end{array}\right. \\
& S F=\left\{\begin{array}{lll}
C_{\mathrm{t}}-S_{\mathrm{t}} & \text { if } & C_{\mathrm{t}} \leq S_{\mathrm{t}} \\
0 & \text { if } \quad C_{\mathrm{t}}<S_{\mathrm{t}}
\end{array}\right.
\end{aligned}
$$

the constant $\epsilon$ describe a proportional relation between the rate of evaporation from saturated trunks and the evaporation of the saturated canopy.

A revised version of the Rutter model was presented by Valente et al. (1997); the reformulated model was adapted to work in sparse forests stands where the openness between tree canopies was significant. In the original version, it was assumed that evaporation occurs for the whole canopy, whereas for the reformulated version it is divided into two: an open area with no cover, and an area covered by tree canopies and tree boles. Evaporation is then assumed that only occur from the covered area. Similarly to the original model, the sparse version of Rutter's model uses the Penman-Monteith equation to calculate the potential evaporation (Valente et al., 1997).

\subsubsection{Gash model}

Gash (1979) proposed the first analytical interception model by providing a simplified solution to Rutter's model. The central assumption in the Gash model is that the rainfall pattern is represented by a series of discrete rainfall events which are separated by intervals sufficiently long for the canopy and stems to get completely dry. Under this assumption, an analytical integration of the total rainfall interception loss is carried out, by replacing the actual rates of evaporation and rainfall of each storm by the average rates deduced for all storms. Each rainfall event in Gash model is divided into three phases: i) canopy wetting-up, ii) saturation and iii) drying phase. Additionally, Gash (1979) explained that two simplifying assumptions were needed to carry out the analytical integration. Those were: i) meteorological conditions prevailing during any wetting-up phase are sufficiently similar to those prevailing for the rest of the storms, ii) there is virtually no drip from the canopy during the wetting-up period, and the amount of water retained in the canopy at the end of the storm is quickly reduced to $S$. The Gash model differentiates rainfall events according to the capacity of $P G$ to saturate the canopy. Rainfall is either insufficient ( $P G<P G^{\prime}, m$ storms) or sufficient to saturate the canopy ( $P G \geq P G^{\prime}, n$ storms). The amount of rainfall necessary to saturate the canopy $P G^{\prime}$ can be iteratively estimated as suggested by Klaasen et al. (1998). More details about the application of the Gash model are presented in Chapter 4.

The original Gash-model has been reformulated for sparse forests (Gash et al., 1995). Later on, considering that for many types of vegetation covers the canopy density presents seasonal variations, van Dijk and Bruijnzeel (2001) improved the revised model of Gash et al. (1995) by using time-variant model parameters. 


\subsubsection{Multilayer models}

Several multilayer approaches have been proposed to improve the knowledge of how rainfall is vertically distributed within the canopy and to quantify the influence of canopy structural composition on the temporal dynamics of drainage and storage. Three approaches follow the Rutter-type framework, for a vertically distributed canopy: Sellers and Lockwood (1981), Liu (1988), and Xiao et al. (2000). Additionally, Watanabe and Mizutani (1996) presented another multilayer model differing from the Rutter type models in the way evaporation is calculated. They estimated evaporation on a leaf basis by using the energy budget equation within a 40-layer canopy.

The model proposed by Sellers and Lockwood (1981) can be considered as an improved Rutter model, and the authors concluded that it adds physical realism to its predecessor. According to Sellers and Lockwood (1981), Rutter model underestimates about $20 \%$ of the interception loss from low-intensity rainstorms when they compared the models over a pine forest using one year of hourly data. Due to the larger number of parameters, the model has not been used much (Muzylo et al., 2009). The multilayer model proposed by (Liu, 1988), is a theoretical model that solves the water-balance by dividing the canopy into infinitesimal layers. A significant innovation in the Liu (1988) model is that shading between layers is considered. Although the model has improved in the way that canopy structural parameters are closely connected with the interception process, one of the pitfalls is that the evaporation rates are assumed as constants. A new version of Liu (1988) was developed by (Liu and Liu, 2008), this model was designed to work for inhomogeneous canopies, but no further applications of this model are found in the literature. The model proposed by Xiao et al. (2000) is different from the previous models because it works at tree-scale. The improvement of this model is that it considers the three-dimensional architecture of the tree. A disadvantage is the increased number of parameters needed to characterise the tree architecture. The model proposed by Watanabe and Mizutani (1996) had the intention to explore the micro-meteorological aspects of the rainfall interception process. Its main innovation is to solve the water and energy balance at leaf level under different micro-climatic conditions within the canopy. The model was tested with experiments at leaf level and at canopy level demonstrating the abilities to reproduce vertical profiles of radiation, air temperature, and air humidity within the canopy.

\subsection{Problem definition}

Interception loss from tall canopies is an essential component of the water balance of forests, for that reason, it has received considerable attention (Carlyle-Moses and Gash, 2011; Muzylo et al., 2009). Since several decades ago, a wide range of species has been investigated under a wide variety of climatic conditions (see reviews of Llorens et al., 1997; Muzylo et al., 2009). However, most of the time these studies focused on small temporal and spatial scales. One of the reasons is that studying interception loss through a water balance approach is demanding regarding sampling efforts to measure throughfall and stemflow components. Therefore, many interception studies are spatially limited to relatively small areas and the length 
of the studied periods is no more than few years. Long-term comparative multitemporal studies are not so common in the literature, but they are important because changes in forest structure resultant from factors as tree phenology, management practices, changes in species composition, or stand development directly affects to the interception process. In some cases comparisons have been limited to monitoring the water balance components of two (or more) stands of different ages concurrently (i.e. Pypker et al., 2005; Keim et al., 2005). Shortly, forests will face unprecedented pressure from changes in climate, invasive species, and increasing societal demand for ecosystem services (Vose et al., 2012). These antecedents make it mandatory to develop new tools that allow us to model and simulate the effects of short-term and long-term changes in canopy properties on the components of the water cycle.

Many studies evaluate rainfall interception loss employing the water balance approach, it means by using direct measurements of rainfall, throughfall and stemflow. Besides that this approach provides reasonable estimations, it is necessary to design an adequate sampling strategy to capture representative measurements. Analysis of throughfall samples in several studies have found evidence of spatial correlation among the measurements (Keim et al., 2005; Staelens et al., 2006; Raat et al., 2002), however, other reviews did not find any spatial correlation (Loustau et al., 1992; Zimmermann et al., 2009). Even though the differences in the detected/absent spatial patterns among forest ecosystems can be attributed to different factors as the type of forest ecosystem, or abiotic factors such as rainfall amount, rainfall intensity, or wind speed, little is known about how forest management practices and forest growing could affect the spatial variability of throughfall. A systematic study of the effect of such factors on the spatial variability and temporal stability of throughfall merits attention.

Furthermore, there has always been an intriguing issue in the rainfall interception studies about what are the sources that supply energy to sustain evaporation during wet canopy conditions. Carlyle-Moses and Gash (2011) highlight the opportunities that exist to derive new insight into the rainfall interception process by using the vast amount of data that exist today, especially from eddy covariance systems. Most recently van Dijk et al. (2015) evaluated data from the 128 FLUXNET sites and provide some clues about why the conventional application of Penman-Monteith equation underestimates evaporation during wet-canopy conditions in comparison with water balance derived values. Following those clues, in detail, it is possible to improve the knowledge of the rainfall interception process.

Regarding the modelling approaches, those multi-layer models that improve the physical realism of the rainfall interception process have never made it to full operational use (Muzylo et al., 2009). One of the reasons is that they are data demanding, however, considering the current availability of remote sensing products, flux-sites networks datasets and robust meteorological datasets, that should not be an obstacle any more to derive new insights into the interception evaporation process. New models that include more detailed processes such as the vertical and spatial variability of interception loss are needed. 


\subsection{Research questions}

This study aims to improve the knowledge of the rainfall interception loss by measuring and modelling the main components of the water and energy budget. Several issues of the canopy interception loss regarding the spatial variability and temporal persistence of throughfall, the quantification of the sources of energy involved in the evaporation of intercepted rainfall, and equifinality in the parametrisation of models are addressed. The main objective of the study is to understand and predict the effects of long-term changes in forest canopy structure on the rainfall interception loss process, using a physically based model that explicitly considers the link between canopy structure and the water and energy budgets. This objective was reached by solving the following research questions:

- How long-term (decades) changes in canopy structure affect the spatial variability and persistence of throughfall at fine-scale?

- How much are the contributions from different sources of energy that drive latent heat flux involved in the evaporation of intercepted rainfall?

- How long-term (decades) canopy structural changes related to natural growth and thinning affects the rainfall interception loss process?

- Is it possible to link a radiative transfer model with a water budget model as a first step to extend it in applications that assimilate remote sensing information to estimate rainfall interception loss?

\subsection{Thesis outline}

A large dataset of measurements was collected in the experimental site 'Speulderbos', the plot is located near to the settlement of Garderen, in the centre of the Netherlands. Speulderbos is a 2.5 ha stand of evergreen Doulgas fir in a temperate humid climate. Chapter 2 describes in detail the study site; the instrumentation deployed, the measurements techniques and other technical aspects of the study. Measurements of vegetation properties, micrometeorology and energy fluxes were carried out on the site.

On Chapter 3, the temporal stability and spatial variability of throughfall measurements are investigated. By using a roving sample technique, from February to November of 2015, throughfall measurements were collected on 320 different locations on the forest floor. Geo-statistical techniques were used to analyse the spatial correlation lengths presented for spring and summer seasons. Temporal stability of the measurements was also evaluated within the plot. Because similar studies were performed about 25 year ago, we were able to evaluate the effects of forest growth and thinning on the spatial variability of throughfall, and on its temporal stability as well.

In Chapter 4, for two growing seasons (2015-2016) measurements form eddycovariance flux tower were combined with precipitation, throughfall and stemflow to study the rainfall interception loss process in a mature Douglas fir stand (ca. 55 years old). Two indirect methods used to estimate canopy storage capacity were evaluated with the support of leaf wetness sensors deployed on the canopy. Using the energy budget approach the sources of energy that drive latent heat flux involved in the evaporation of intercepted rainfall were quantified. Additionally, we parametrise 
Gash (1979) model and evaluate the sensitivity of the most critical parameters. Due to the advantage of historical studies in the plot, it was possible to evaluate the effect of the long-term changes in the canopy structure on the rainfall interception loss process by comparing the collected measurements with previous studies performed when the stand was younger (29 years old).

In Chapter 5, a new framework to model rainfall interception loss is presented, it describes the physically based link between canopy structure and rainfall interception loss. This purpose was achieved by adapting the 'Soil-Canopy-Observation of Photosynthesis and Energy Fluxes' (SCOPE) model (van der Tol et al., 2009) to solve the water budget and estimate rainfall interception loss. The equations that describe the interception, water storage, dripping and evaporation from the 60 layers of the model are presented in detail. The model was then evaluated with the measurements obtained from the Speulderbos site. Numerical simulations were also done for past, present and future scenarios considering changes in the canopy structure. Recommendations about how the model can be adapted to include remote sensing data are also presented at the end of this chapter.

This dissertation ends with Chapter 6 presenting a Synthesis of the obtained results, the main conclusions, and recommendations for future developments and applications. 


\section{Study site and instrumentation}




\subsection{Study site}

The study was conducted within a 2.5 ha evergreen Douglas fir (Pseudotsuga menziesii) stand located in the forested area of "Speulderbos" $\left(52^{\circ} 15^{\prime} 04\right.$ " N, $05^{\circ} 41^{\prime}$ 25 "E) at an elevation of 50 m.a.s.l., near the settlement of Garderen, the Netherlands (Fig. 2.1). The site is equipped with a $47 \mathrm{~m}$ scaffolding tower (Fig. 2.2), which supports measurement of a range of micrometeorological data. The plot is surrounded by several stands of other species such as beech, oak, and hemlock. The climate is classified as temperate-humid. Based on "de Bilt" weather station data, located at $38 \mathrm{~km}$ southwest of the plot, the average $( \pm$ SD) annual precipitation for the period 2000-2015 was $864( \pm 92) \mathrm{mm}$. In general, July is the wettest month, with about $12 \%$ of the annual rainfall, and April the driest month, with $4 \%$ of the annual rainfall. The mean annual value of temperature is $10.6^{\circ} \mathrm{C}( \pm 0.6)$ with January being the coldest month $\left(3.7 \pm 2{ }^{\circ} \mathrm{C}\right)$ and July the warmest month $\left(18.2 \pm 1.6^{\circ} \mathrm{C}\right)$ (Royal Dutch Meteorological Institute, KNMI (2015)). The soil in the study area is a Typic Dystochrept on a thick heterogeneous sandy loam and loamy sand textured ice-pushed river sediments (Tiktak and Bouten, 1994).

Active reforestation in the area, previously sand dunes, started at the end of the nineteenth century. The current stand was planted with 2-year old seedlings in 1962. For the study period canopy height was about $34 \mathrm{~m}$, whereas stem density and mean diameter at breast height $(\mathrm{DBH})$ were 571 trees $^{-1}$ and $34.8( \pm 8.9) \mathrm{cm}$, respectively. The leaf area index of the plot (LAI, using a LI-COR LAI 2000 Plant Canopy Analyser) was 4.5 ( \pm 0.38) (Fig. 2.1b). No other tree species were recorded in the plot and understory was largely absent (Fig. 2.1c).

\subsection{Instrumentation}

\subsubsection{Rainfall}

Gross rainfall $(P G, \mathrm{~mm})$ was measured in a nearby, well-exposed clearing (ca. 250 $\mathrm{m}$ from the centre of the 'Speulderbos' plot) using two tipping bucket rain gauge (Rain Collector II, Davis Instruments, Hayward, CA, USA) with a resolution of 0.2 $\mathrm{mm}$ per tip. The orifice of the rain gauge was positioned at $1.5 \mathrm{~m}$ above the ground to avoid ground-splash effects. The automatically recorded data were stored by a HOBO event logger at 1-min interval (Onset Computer Corporation, Bourne, MA, USA). Gross rainfall was also collected at the top of the $47 \mathrm{~m}$ scaffolding tower operated by University of Twente (ITC-UT) (at ca. $200 \mathrm{~m}$ distance from the clearing) using two tipping bucket rain gauges (Onset HOBO-RG3, resolution $0.2 \mathrm{~mm}$ ). The data at the top of the tower were only used to fill a few gaps (from 23 July 2015 to 12 August 2015; 24 May 2016 to 9 June 2016) in the data at the clearing using a linear regression equation that linked 10-min rainfall totals at the two locations $\left(R^{2}\right.$ $=0.93, n=1000)$.

\subsubsection{Throughfall}

Throughfall $(T F, \mathrm{~mm})$ was measured by an automated gutter system and validated by an arrangement of manual (roving sampling) funnel-type collectors. The auto- 
(a)

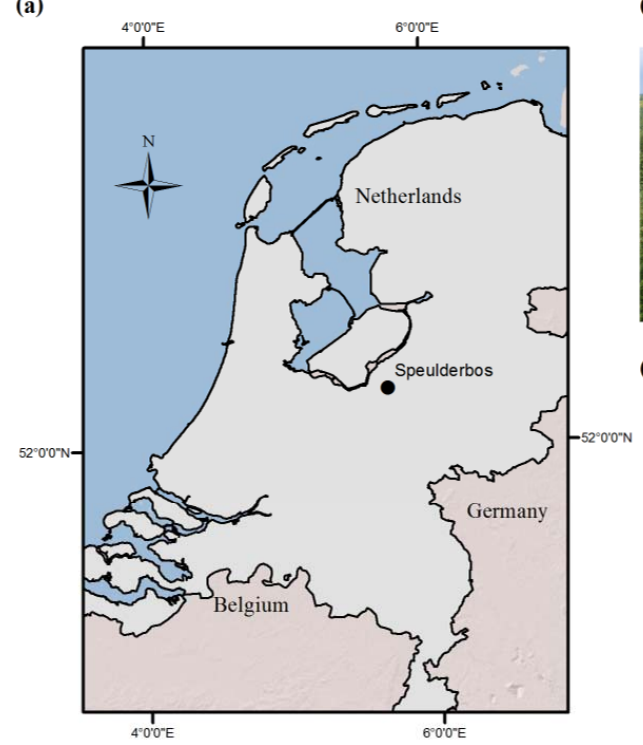

(b)

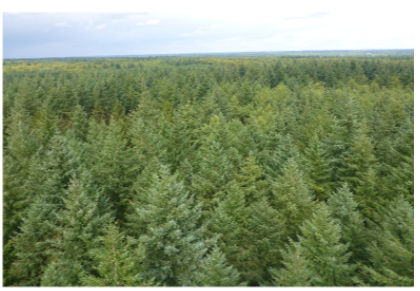

(c)

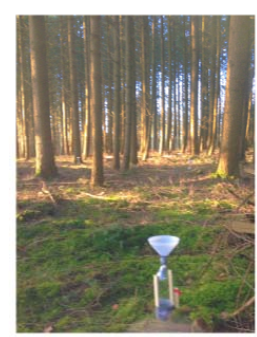

Figure 2.1 Study area in Speulderbos: (a) study site in the Netherlands; (b) top view of the Douglas-fir canopy; (c) funnel-type collector used to quantify throughfall in the study site in the absence of understory.

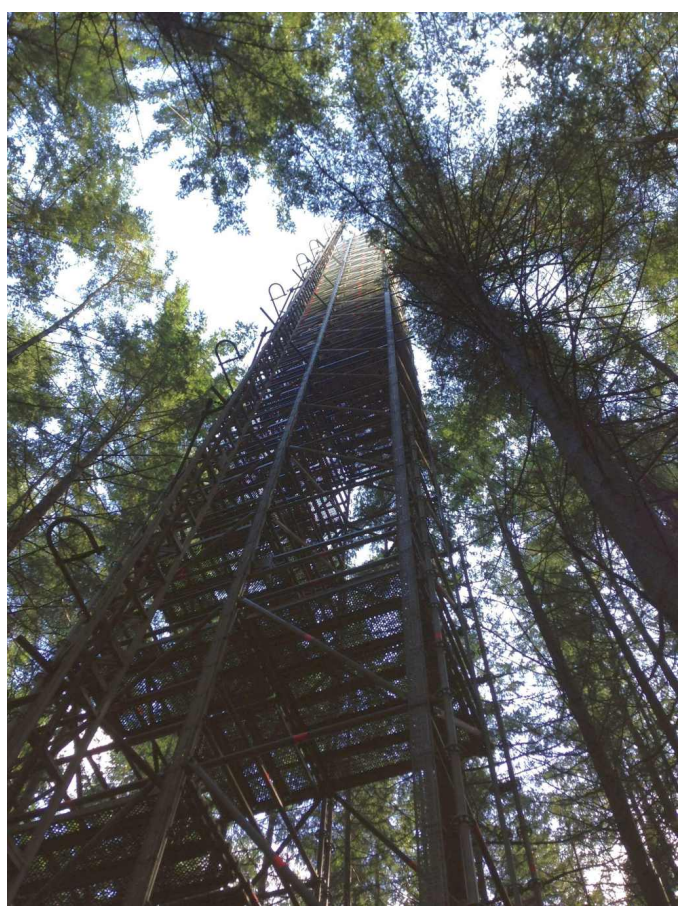

Figure 2.2 Flux tower in the 'Speulderbos' study site 
mated gutter system consisted of four stainless steel gutters $(200 \mathrm{~cm}$ x $30 \mathrm{~cm}$ each), randomly located in the plot and connected by pairs to two tipping buckets (V2A UP Umweltanalytische Produkte $\mathrm{GmbH}$ ) (Fig. 2.3). As no apparent alignment of the trees was observed in the planted stand, no specific orientation of the gutters was considered. The gutters were mounted on a wooden frame, about $60 \mathrm{~cm}$ from the forest floor and at an inclination of $10 \%$ to facilitate drainage to the tipping buckets. Combining two gutters and correcting for the inclination provided a total catch area of $1.2 \mathrm{~m}^{2}$ yielding $0.084 \mathrm{~mm}$ per tip. The tipping buckets were connected to a data logger (CR23X, Campbell Scientific Ltd.) and tip pulses were recorded at a $1 \mathrm{~min}$ resolution. The gutters and the tubes were cleaned every 7 to 15 days to avoid clogging due to falling litter. In addition, $T F$ was measured using funnel-type collectors. The manual array of collectors was operated from 17 February to 2 November 2015. A stratified random sampling approach was used to ensure an even spread of sampling locations. We defined a plot size of $32 \mathrm{~m}$ x $64 \mathrm{~m}$, which was divided into 32 square sub-plots of $8 \mathrm{~m} \times 8 \mathrm{~m}$ each; each sub-plot was marked in its centre. Collectors (32 in total) were placed at some distance from each marked point, by generating random values for an azimuth angle and distance from the grid point. The azimuth angles ranged from 0 to $360^{\circ}$ and the distances from 0 to $4 \mathrm{~m}$. In case the randomly selected position coincided with the position of a stem, the azimuth angle was maintained while the distance was adjusted until the collector was located next to the tree base and the adjusted distance was recorded. The funnel-type collectors consisted of a $2 \mathrm{~L}$ collector and a funnel $\left(165 \mathrm{~cm}^{2}\right.$ orifice area). The orifices of the gauges were positioned $50 \mathrm{~cm}$ above the forest floor to avoid splash-in from the ground. The funnel-type collectors were read (and relocated) bi-weekly (i.e. roving sampling; Ritter and Regalado, 2014). Measured TF volumes were converted to equivalent depth (in $\mathrm{mm}$ ) by dividing the volume of water in each gauge by the orifice area.

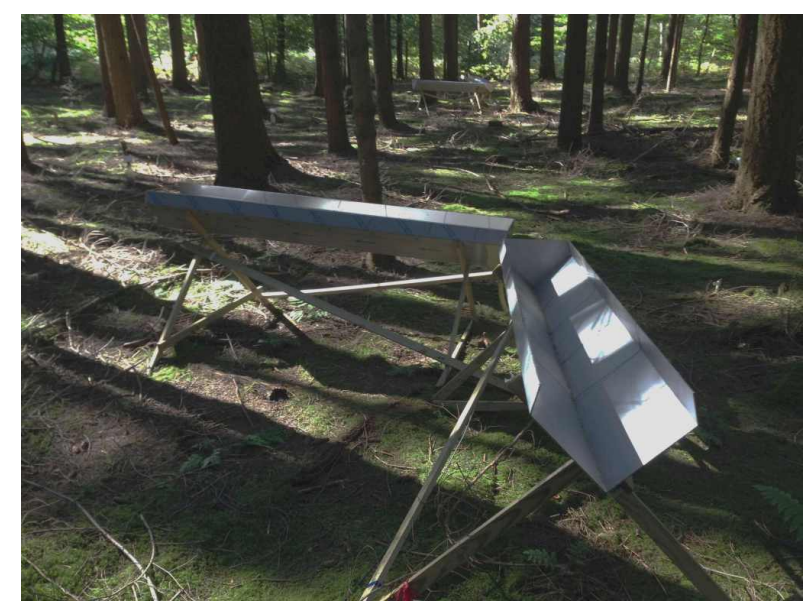

Figure 2.3 Throughfall measurements in the 'Speulderbos' study site 
Table 2.1 Main micro-meteorological instruments installed on the Speulderbos flux tower.

\begin{tabular}{|c|c|c|c|}
\hline Data-logger & Instruments & Parameters & Height $(\mathrm{m})$ \\
\hline \multirow[t]{2}{*}{ CR-5000 } & $\begin{array}{l}\text { Sonic anemometer CSAT3 } \\
\text { (Campbell Sci. Inc.) }\end{array}$ & $\begin{array}{l}\text { Wind speed 3D components, } \\
\text { and sonic temperature }\end{array}$ & 47 \\
\hline & $\begin{array}{l}\text { Gas analyser LI7500 } \\
\text { (Li-Cor Biosciences) }\end{array}$ & $\begin{array}{l}\text { Water vapour, } \\
\text { and } \mathrm{CO}_{2} \text { concentrations }\end{array}$ & 47 \\
\hline \multirow[t]{2}{*}{ CR23X_1 } & $\begin{array}{l}\text { Net radiometer CNR1 } \\
\text { (Kipp and Zonen) }\end{array}$ & $\begin{array}{l}\text { Four components } \\
\text { of net radiation }\end{array}$ & 35 \\
\hline & $\begin{array}{l}2 \text { Leaf wetness sensors } \\
\text { Model } 237 \text { (Campbell Sci. Inc.) }\end{array}$ & Canopy wetness status & 26,20 \\
\hline \multirow[t]{6}{*}{ CR-1000 } & $\begin{array}{l}\text { Temperature and humidity } \\
\text { CS215 (Campbell Sci. Inc.) }\end{array}$ & $\begin{array}{l}\text { Air temperature, } \\
\text { and relative humidity }\end{array}$ & 46 \\
\hline & $\begin{array}{l}\text { Temperature and humidity } \\
\text { CS215 (Campbell Sci. Inc.) }\end{array}$ & $\begin{array}{l}\text { Air temperature, } \\
\text { and relative humidity }\end{array}$ & 38 \\
\hline & $\begin{array}{l}\text { Temperature and humidity } \\
\mathrm{HC} 2-\mathrm{S} 3 \mathrm{C} 03 \text { (Rotronic) }\end{array}$ & $\begin{array}{l}\text { Air temperature, } \\
\text { and relative humidity }\end{array}$ & 32 \\
\hline & $\begin{array}{l}\text { Temperature and humidity } \\
\text { HC2-S3C03 (Rotronic) }\end{array}$ & $\begin{array}{l}\text { Air temperature, } \\
\text { and relative humidity }\end{array}$ & 24 \\
\hline & $\begin{array}{l}\text { Temperature and humidity } \\
\text { HC2-S3C03 (Rotronic) }\end{array}$ & $\begin{array}{l}\text { Air temperature, } \\
\text { and relative humidity }\end{array}$ & 16 \\
\hline & $\begin{array}{l}\text { Temperature and humidity } \\
\text { HC2-S3C03 (Rotronic) }\end{array}$ & $\begin{array}{l}\text { Air temperature, } \\
\text { and relative humidity }\end{array}$ & 4 \\
\hline \multirow{2}{*}{ CR23X_2 } & Barometer (Campbell Sci. Inc.) & Air pressure & 1 \\
\hline & 2 soil heat flux plates HFP01 & Soilheat flux & -0.08 \\
\hline
\end{tabular}

\subsubsection{Stemflow}

Following a stratified sampling approach, stemflow $(S F, \mathrm{~mm})$ was measured on four trees with differing DBHs, representative of the whole stand. The four diameter size classes were $<30,31-40,41-50$, and $>50 \mathrm{~cm}$. Each set-up consisted of a halved plastic tube wrapped around the tree stem in a spiral fashion, starting at a height of ca. $80 \mathrm{~cm}$; the lower end of the tube was connected to a closed tipping bucket (Onset HOBO ${ }^{\circledR}$ S-RGA Rain Gauge, resolution $0.254 \mathrm{~mm}$ ). Silicon sealant was applied between the stem and the plastic tube to seal the gaps (and hence avoid stemflow loss). Stemflow proved to be only a minor component of the wet-canopy water balance. As the sampled trees covered the whole range of diameter classes within the plot, total stemflow in the plot was calculated by multiplying the stemflow volumes by the number of trees for each diameter class (cf. Levia and Germer, 2015, Eq. 2). Stemflow measurements were carried out over 113 days from 27 July to 11 November 2016. During this period, a total of $240 \mathrm{~mm}$ of rain was received at the plot.

\subsubsection{Net radiation and soil heat flux}

Net radiation $\left(R_{\mathrm{n}}\right)$ was measured by a four-component net radiometer (model CNR1, Kipp and Zonen) mounted at $35 \mathrm{~m}$ above ground (Table 2.1), and averages were stored at $10 \mathrm{~min}$ intervals, except during three periods, totalling 120 days, 


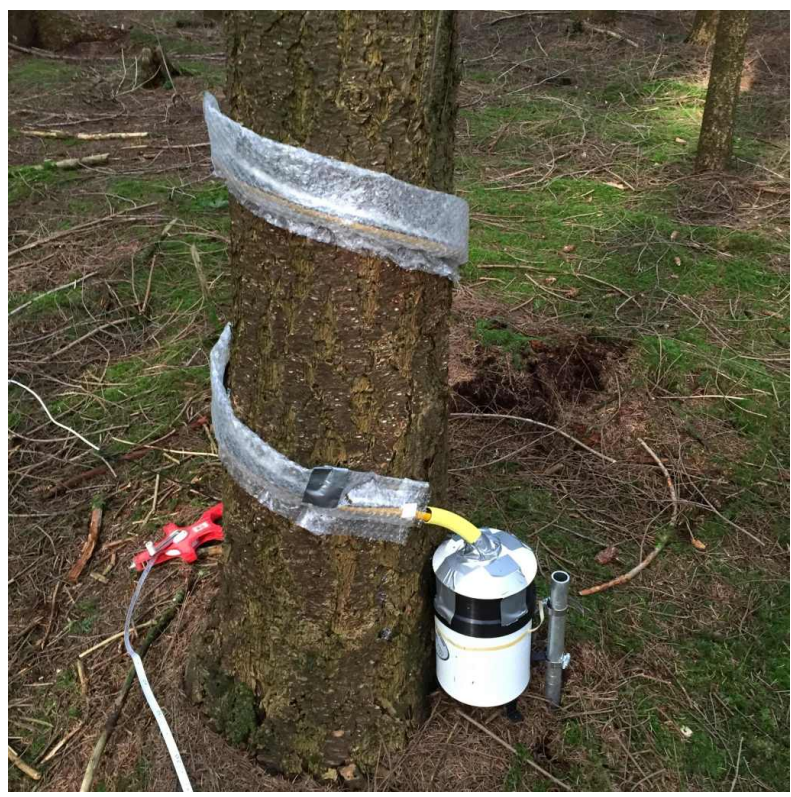

Figure 2.4 Stemflow measurements in the 'Speulderbos' study site

encountering instrument failure (from 24 April to 23 June 2016, from 17 July to 4 August 2016, and from 15 September to 14 October 2016). Soil heat flux $(G)$ was estimated by combining measurements from two heat flux plates (HFP01, Hukseflux) both installed at $8 \mathrm{~cm}$ depth, and temperature profile measurements at five different depths $(1,3,8,20$, and $50 \mathrm{~cm})$. Estimations of $G$ at ground level were carried out following the harmonics method (Verhoef et al., 1996) with the derivatives of the Fourier series calculated analytically according to van der Tol (2012).

\subsubsection{Turbulent heat fluxes}

Sensible $(H)$ and latent $(\lambda E)$ heat fluxes were estimated by the eddy-covariance technique with a sonic anemometer (CSAT3, Campbell Sci. Inc.) and an open path gas analyser (LI7500, LI-COR Biosciences) mounted at $47 \mathrm{~m}$ (Table 2.1, Fig. 2.4).

Thirty minute turbulent fluxes were processed with the EddyUH ver. 1.7 software (University of Helsinki, https://www.atm.helsinki.fi/Eddy_Covariance/EddyUH software.php, last access: February 2017). As initial estimates for EddyUH, a displacement height $(d)$ of 0.7 of canopy height $\left(h_{\mathrm{c}}\right)$ (Stull, 2012) and a roughness length $\left(z_{0}\right)$ of $0.06 h_{\mathrm{c}}$ (Weligepolage et al., 2012) were used. Furthermore, the following corrections were performed: de-spiking, 2-D coordinate rotation, crosswind correction to sonic temperature according to Liu et al. (2001), high-frequency spectral corrections according to Moncrieff et al. (1997) and Aubinet et al. (2000), low-frequency spectral corrections according to Rannik and Vesala (1999), correction for humidity effect on sonic heat flux according to Schotanus et al. (1983), and WPL correction according to Webb et al. (1980). We disregarded turbulence data with an overall quality flag above 2 in accordance with the Foken et al. (2005) 
quality flag system.

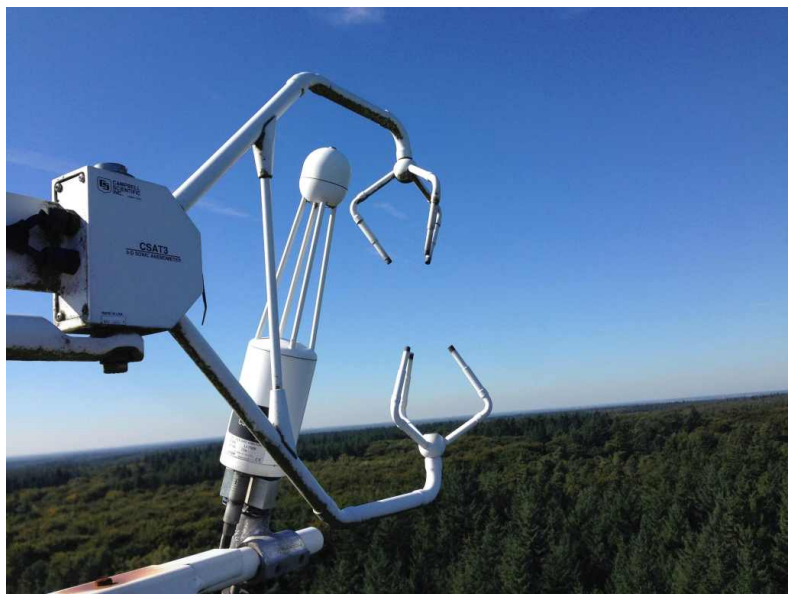

Figure 2.5 Eddy-covariance measurements in the "Speulderbos" study site

\subsubsection{Canopy wetness}

Three leaf wetness sensors (LWSs) (Model 237, Campbell Sci. Inc.) were installed at 20,24, and $26 \mathrm{~m}$ above ground, in the middle of the living crown. Ringgaard et al. (2014) used 4 LWSs located within the canopy and demonstrated that the parametrization of the analytical model for interception loss by Gash et al. (1995) was improved. An LWS consists of a circuit board that emulates the leaf surface, with interlacing gold-plated fingers on it. The LWS estimates foliage wetness by determining the electrical resistance on the surface of the sensor. Sensors were placed over the needles in the middle of the branches and tilted about $60^{\circ}$ to avoid rainwater puddling on the electrodes (Fig. 2.6).

\subsubsection{Thermal dissipation probes}

Three thermal dissipation probes (TDP) (UP GmbH, Munich, Germany) were installed in different trees. One of the TDP sensors was installed in a tree next to the scaffolding tower (Fig. 2.7), in the same tree where the LWSs were placed, while the others TDPs were placed in trees around the tower at a distance not longer than 25 $\mathrm{m}$. Sensors were always put on the northern side of the trunks to avoid sun-exposure and were insulated using a radiation shield to prevent any externally induced heat influence. TDP sensors are widely used to evaluate tree transpiration by measuring xylem sap flux density $\left(J_{p}\right)$ and multiplying by sapwood area $\left(A_{x}\right)$ (Granier, 1985). It has been demonstrated that sap flux density (SFD) can be used to monitor the canopy drying time, as sap flux is interrupted when the canopy is wet and resumes as the canopy dries up and transpiration starts (Kume et al., 2006, 2008a). 


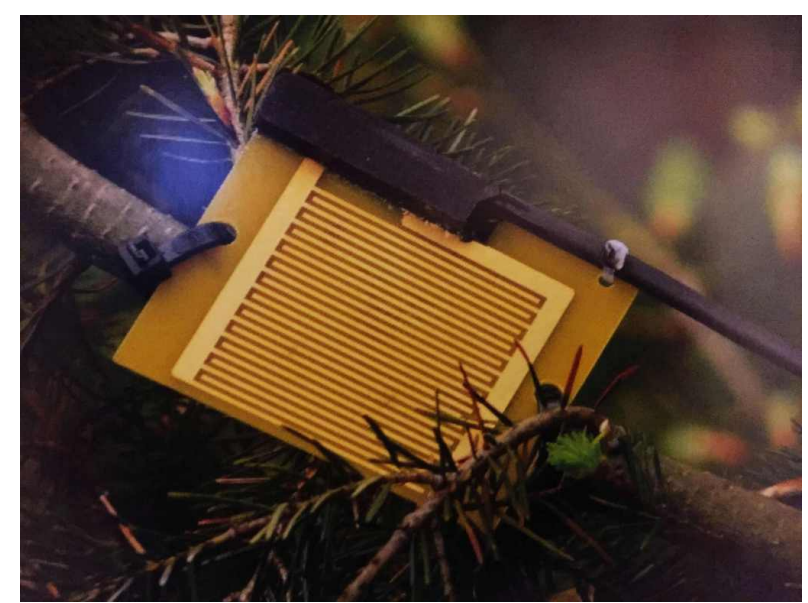

Figure 2.6 Leaf wetness sensor (Model 237) placed in a Douglas fir branch in the "Speulderbos" study site

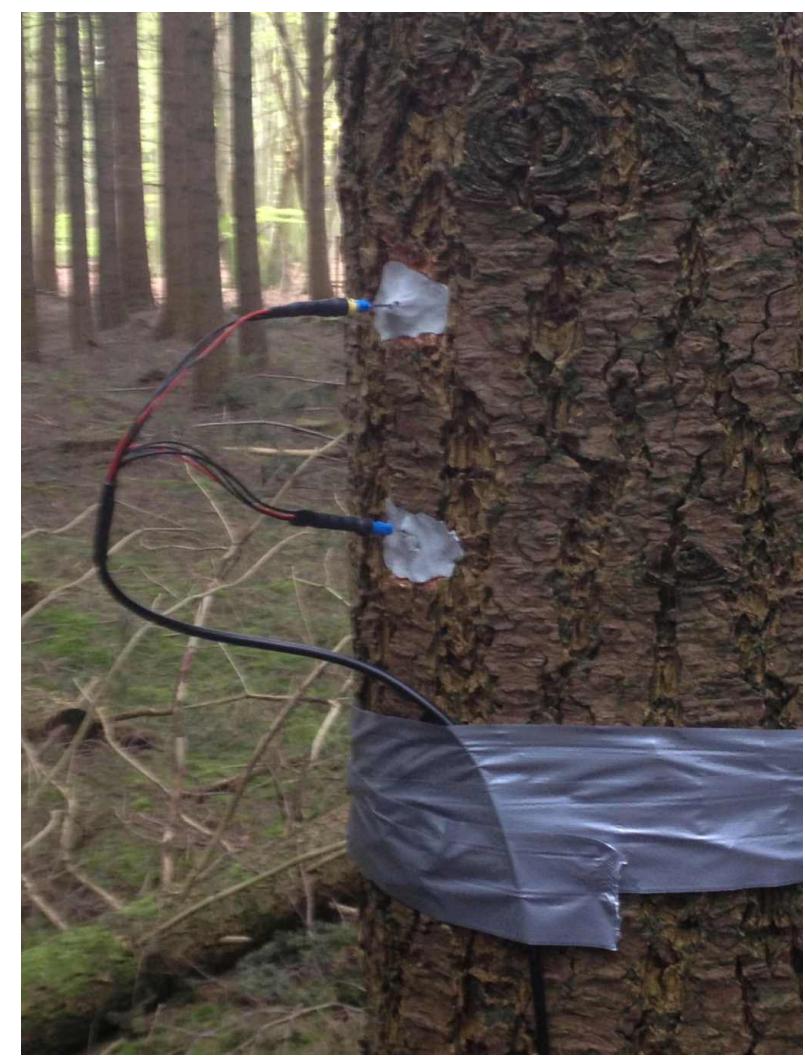

Figure 2.7 Three thermal dissipation probes (TDP) placed in a Douglas fir stem in the 'Speulderbos' study site 


\section{Spatial Patterns and Temporal Stability of Throughfall}

This chapter is based on: Cisneros Vaca, C., Ghimire, C., van der Tol, C., 2018. Spatial Patterns and Temporal Stability of Throughfall in a Mature Douglas-fir Forest. Water 10, 317. https://doi.org/10.3390/w10030317. 


\begin{abstract}
Forest plays a key role in spatial distribution of rainfall and nutrients at fine spatial scales. Areas of localized rainfall and nutrient input at the soil surface may have a large effect on several hydrological and bio-geochemical processes. In this chapter, a Douglas-fir stand was revisited to evaluate the changes in throughfall spatial distribution and its temporal stability due to forest growth and thinning. We used 32 funnel-type collectors distributed in a random stratified array (320 locations) within a 0.2 ha plot to measure throughfall amounts from February to November 2015 . The throughfall variability was much lower as compared to the values reported $\sim 25$ years ago in the same site. We further assessed the spatial patterns of throughfall in spring and summer. We detected a spatial correlation length of $12 \mathrm{~m}$ and $8 \mathrm{~m}$ for spring and summer, respectively, which are higher than the values reported for other mature Douglas-fir forests in similar climatic conditions. Temporal stability plots confirmed that detected spatial patterns were stable in time.
\end{abstract}

\title{
3.1 Introduction
}

Forest ecosystems play a significant role in the redistribution of water and nutrients that reaches the terrestrial surface by means of throughfall $(T F)$ and stemflow $(S F)$ (Raat et al., 2002; Levia and Frost, 2006; Zimmermann et al., 2008; CarlyleMoses and Gash, 2011). Throughfall and stemflow patterns below forest canopies have been shown to be highly variable in time and space (Levia and Frost, 2006; Lloyd and Marques, 1988; Zimmermann and Zimmermann, 2014). The spatial variability of $T F$ is a critical issue at different temporal and spatial scales, because it has a direct impact on several hydrological and biogeochemical processes such as soil water dynamics (Bouten et al., 1992), water chemistry (Raat et al., 2002; Bouten et al., 1992; Hsueh et al., 2016), nutrient cycling (Zimmermann et al., 2008; Kimmins, 1973), root water uptake (Bouten et al., 1992), and root growth (Ford and Deans, 1978). Moreover, the spatial variability of throughfall is known to affect the accuracy of estimates on stand-scale interception losses (Shinohara et al., 2009; Holwerda et al., 2006). Thus, evaluations of spatial variability of $T F$ are of practical importance for effective measurements in the estimation of stand-scale $T F$.

Spatial variability of throughfall has been traditionally expressed using coefficient of variation (CV) (e.g., Raat et al., 2002; Holwerda et al., 2006; Staelens et al., 2006; Sun et al., 2015). Several studies demonstrated that CV decreases asymptotically with the increase in size of the rainfall events, (e.g., Holwerda et al., 2006; Sun et al., 2015; Loustau et al., 1992; Bellot and Escarre, 1998; Carlyle-Moses et al., 2014). Similarly, CV decreases with the increase of the total rainfall depth in studies that aggregate $T F$ from several events at larger temporal resolution (i.e., weekly, monthly) (Zimmermann and Zimmermann, 2014). Less common in the literature is the description of spatial patterns of throughfall using geostatistical methods, which can be used to produce $T F$ distribution maps as long as structured variograms are found. However, in cases in which the spatial variability has been studied in terms of correlation length, the results have been highly variable. For instance, Keim et al. (2005) quantified patterns of $T F$ using variograms and identified the spatial correlation lengths of throughfall of $\sim 5$ to $10 \mathrm{~m}$ in coniferous stands. Also Staelens et al. (2006) found spatial correlation lengths of 3 to $4 \mathrm{~m}$ in the leafed period of a 
beech stand. In contrast, some researchers did not find any spatial autocorrelation in $T F$ data (Loustau et al., 1992; Zimmermann et al., 2009). Such large differences in spatial patterns among forest ecosystems can partly be attributed to the type of forest ecosystem and management practices (Lloyd and Marques, 1988; Keim et al., 2005; Zimmermann et al., 2009; Levia et al., 2011), while spatial variability is also influenced by abiotic factors such as rainfall amount, rainfall intensity, and wind speed (Zimmermann et al., 2009; Levia et al., 2011). Nevertheless, little is known about how forest management practices affect the spatial variability of throughfall. As such, a systematic study of the effect of forest management practices on the spatial variability of throughfall merits attention.

This study assessed the $T F$ spatial variability at a fine-spatial scale in a mature Douglas-fir (Pseudotsuga menziesii) stand located in Speulderbos, in the center of the Netherlands. The site has been monitored for several decades (Su et al., 2009). Raat et al. (2002) evaluated the coefficient of variation (CV) of throughfall and its temporal persistence in the Speulderbos site around 25 years ago. In the present study, the site of Raat et al. (2002) was revisited to evaluate the changes in the TF spatial distribution and its temporal stability due to forest growth and thinning. The aims of this study were to (i) evaluate the effects of forest growth and thinning on the spatial variability and patterns of $T F$; and (ii) examine the temporal stability of spatial $T F$ patterns after canopy structure changes due to forest growth and thinning.

\subsection{Study Area}

\subsection{Field Measurements}

\subsubsection{Rainfall}

Because the instrumentation for $P G$ described in Chapter 2 was installed on 01 June 2015, and throughfall was started earlier than that (see below), cumulative rainfall data for the first six periods of measurement from 17 February 2015 to 12 June 2015 were obtained by inverse distance weighted (IDW) interpolation using hourly cumulative rainfall from the three nearest KNMI weather stations in de Bilt, Lelystad, and Deelen located at 39, 25, and $25 \mathrm{~km}$, respectively, from the study area

\subsubsection{Throughfall}

A stratified random sampling approach was used for the throughfall measurement ( $T F, \mathrm{~mm}$ ) to ensure an even spread of sampling locations. Plot size was decided based on (i) previous studies carried out in the same plot (cf. Raat et al., 2002; Bouten et al., 1992) to allow a direct comparison and (ii) previous studies with similar approaches in similar forest type elsewhere (cf. Carlyle-Moses et al., 2014; Keim et al., 2005). Based on the above mentioned criteria and logistic limitations, we defined a plot size of $32 \mathrm{~m} \mathrm{x} 64 \mathrm{~m}$ that was divided into 32 square sub-plots of $8 \mathrm{~m} \times 8 \mathrm{~m}$ each. Considering the study of Keim et al. (2005), in which the plot size was selected to be at least three times of the crown size, the width and length of our plot were sufficient ( 3 to 6 times larger than the crown size, respectively) to perform spatial analysis. Collectors (32 in total) were placed at some distance from 
each marked point by generating random values for an azimuth angle and distance from grid point. The azimuth angles ranged from 0 to 360 degrees and the distances from 0 to $4 \mathrm{~m}$ (Figure 3.1 ). In case the randomly selected position coincided with the position of a stem, the azimuth angle was maintained while the distance was adjusted until the collector was located next to the tree base and the adjusted distance was recorded. The funnel-type collectors consisted of a $2 \mathrm{~L}$ collector and a funnel $\left(165 \mathrm{~cm}^{2}\right.$ orifice area). The orifices of the gauges were positioned $50 \mathrm{~cm}$ above the forest floor to avoid splash-in from the ground. The funnel-type collectors were read bi-weekly. Measured Tf volumes were converted to equivalent depth (in $\mathrm{mm}$ ) by dividing the volume of water in each gauge by the orifice area. From 17 February 2015 to 2 November 2015, TF was measured 15 times (herein after referred to as Periods (Prd); Table 3.1). For the Prd-1 to Prd10, we applied the roving method by randomly generating new positions and placing the funnel-type collectors after each $T F$ measurement. For the Prd-11 to Prd-15, we used the non-roving technique (i.e., the gauges were not relocated after measurement). The purpose for applying the non-roving technique during the last stage of the study was to examine the temporal stability of the $T F$ in the plot. The 15 periods of measurements were grouped by season as winter (Prd-1 and Prd-2), spring (Prd-3 to Prd-6), summer (Prd-7 to Prd-11), and fall (Prd-12 to Prd-15). The CV of each period was calculated in order to compare with previous estimations in the same site by Raat et al. (2002). Periods of $T F$ measurements were also characterized by the number of rainfall events that occur within the period. An event was defined as the period of time with at least 0.4 $\mathrm{mm}$ of rain, separated by a dry period of at least $3 \mathrm{~h}$ (cf. Klaasen et al., 1998).

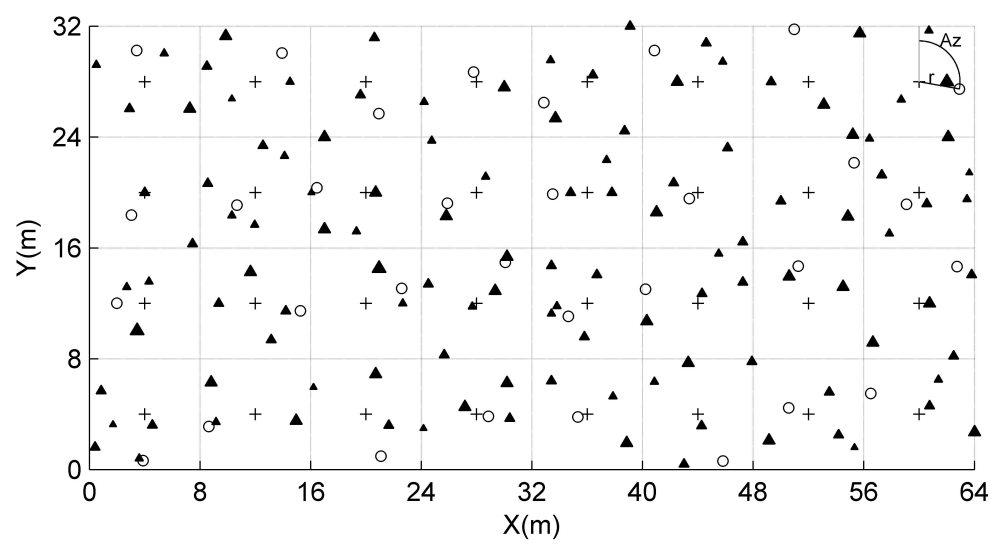

Figure 3.1 Throughfall sampling scheme. The black crosses (+) represent the marked grid spaced at $8 \mathrm{~m}$, on the $\mathrm{x}$ and y direction. Black triangles represent trees with symbol size scaled to $\mathrm{DBH}$. The black circles represent the position of the funnel-type collectors in one period (Prd). Each collector was located by randomly selecting an azimuth (Az) between 0 and 360 degrees, and a radius distance $(r)$ between $0 \mathrm{~m}$ and $4 \mathrm{~m}$ (e.g. see the upper right corner) 
Table 3.1 Characteristics of throughfall measurements.

\begin{tabular}{|c|c|c|c|c|c|c|c|c|c|c|c|}
\hline $\operatorname{Prd}^{a}$ & $\begin{array}{c}\text { Date } \\
(\mathrm{dd} / \mathrm{mm} / 2015)\end{array}$ & $\begin{array}{l}P G^{b} \\
(\mathrm{~mm})\end{array}$ & $\begin{array}{c}\overline{T F}( \pm \mathrm{SD}) \\
(\mathrm{mm})\end{array}$ & $\begin{array}{l}T F_{\text {median }} \\
(\mathrm{mm})\end{array}$ & Skew & $\begin{array}{l}\text { Coeff. of } \\
\text { Variation }\end{array}$ & $\begin{array}{c}\overline{T F} \\
(\% P G)\end{array}$ & $\begin{array}{c}\text { No. of } \\
\text { Events }{ }^{c}\end{array}$ & $\begin{array}{c}R^{d} \\
\left(\mathrm{~mm} \mathrm{~h}^{-1}\right)\end{array}$ & $\begin{array}{c}\text { Wind } \\
\text { speed }^{e} \\
\left(\mathrm{~m} \mathrm{~s}^{-1}\right)\end{array}$ & $\begin{array}{c}\text { Longest } \\
\text { duration } f \\
\text { (h) }\end{array}$ \\
\hline 1 & $17 / 02-17 / 03$ & 61.8 & $36.6(6.1)$ & 36.5 & -0.89 & 16.7 & 59.2 & 13 & 1.4 & 5.8 & 23.4 \\
\hline 2 & $17 / 03-03 / 04$ & 64.3 & $43.7(5.2)$ & 42.9 & 0.45 & 12.0 & 68.0 & 15 & 1.5 & 6.1 & 10.8 \\
\hline 3 & $03 / 04-01 / 05$ & 14.4 & $7.3(1.8)$ & 7.3 & 0.12 & 24.6 & 50.6 & 7 & 1.9 & 4.4 & 3.2 \\
\hline 4 & $01 / 05-16 / 05$ & 26.9 & $8.7(1.4)$ & 8.5 & 0.55 & 15.8 & 32.4 & 7 & 2.1 & 5.9 & 4.5 \\
\hline 5 & $16 / 05-30 / 05$ & 21.0 & $6.7(1.9)$ & 6.3 & 0.18 & 28.6 & 31.9 & 11 & 1.5 & 4.4 & 4.0 \\
\hline 6 & $30 / 05-12 / 06$ & 18.9 & $11.2(1.6)$ & 11.3 & -0.82 & 14.3 & 59.2 & 4 & 1.2 & 6.1 & 9.2 \\
\hline 7 & $12 / 06-29 / 06$ & 49.4 & $37.3(6.0)$ & 37.1 & 0.11 & 16.0 & 75.5 & 8 & 0.9 & 2.9 & 4.8 \\
\hline 8 & $29 / 06-15 / 07$ & 39.7 & $20.0(3.4)$ & 20.5 & -1.11 & 17.0 & 50.3 & 6 & 1.0 & 4.3 & 9.4 \\
\hline 9 & $15 / 07-01 / 08$ & 109.8 & $74.1(7.5)$ & 75.2 & 0.36 & 10.1 & 67.5 & 10 & 1.3 & 4.4 & 6.7 \\
\hline 10 & $01 / 08-15 / 08$ & 13.7 & $7.4(1.7)$ & 7.3 & -0.31 & 22.8 & 53.9 & 4 & 0.9 & 3.2 & 6.2 \\
\hline 11 & $15 / 08-28 / 08$ & 101.5 & $71.4(8.2)$ & 69.9 & 0.44 & 11.4 & 70.4 & 6 & 1.0 & 4.2 & 54 \\
\hline 12 & $28 / 08-15 / 09$ & 98.1 & $62.4(6.6)$ & 63.1 & -0.61 & 10.5 & 63.6 & 12 & 1.2 & 3.4 & 5.9 \\
\hline 13 & $15 / 09-29 / 09$ & 35.2 & $16.2(2.0)$ & 15.8 & 0.17 & 12.6 & 46.0 & 9 & 0.7 & 3.4 & 5.9 \\
\hline 14 & $29 / 09-19 / 10$ & 36.6 & $25.1(2.6)$ & 25.0 & 0.23 & 10.4 & 68.6 & 9 & 0.6 & 2.6 & 11.5 \\
\hline 15 & $19 / 10-02 / 11$ & 6.2 & $2.6(0.8)$ & 2.6 & 1.66 & 29.3 & 41.7 & 2 & 0.3 & 3.8 & 13.7 \\
\hline
\end{tabular}

${ }^{a}$ Prd-11 to Prd-15 had stationary arrangement.

${ }^{b}$ Rainfall amounts for Prd-1 to Prd-6 were interpolated (IWD) from the three nearest KNMI weather stations (de Bilt, Deelen, and Lelystaad)

${ }^{c}$ An event was defined as the period of time with at least $0.4 \mathrm{~mm}$ of rain, separated by a dry period of at least $3 \mathrm{~h}$.

${ }^{d}$ Mean of rainfall intensity (event based)

${ }^{e}$ Mean of wind speed (event based).

${ }^{f}$ Longest duration of an event is the maximum duration in hours of a rainfall event during the period of $T F$ collection. 


\subsection{Data Analysis}

\subsubsection{Spatial Variability of Throughfall}

The regionalized variable theory (Journel and Huijbregts, 1978) was applied to model spatial correlation structures by means of variograms. The variogram model was estimated using the method-of-moments (MoM) that consists of two steps: calculating the experimental variogram and fitting a variogram model. The experimental variograms are usually calculated according to Matheron (1962) equation which was applied as follows:

$$
\gamma(h)=\frac{1}{2 N(h)} \sum_{i=1}^{N(h)}\left[T F_{i}-T F_{i+h}\right]^{2},
$$

in which $\gamma(h)$ is the semi variance, $T F_{i}$ and $T F_{i+h}$ are the throughfall observations located at $i$ and $i+h$, respectively, and $N(h)$ is the number of pairs separated by the lag distance $h$. The variogram is characterized by three parameters: sill, range, and the nugget. The sill is the limit of the variogram with $h$ tending to infinite The range is the lag distance at which the variogram reaches the sill. The range describes the length scale over which the observations are correlated; for this reason it is also known as spatial correlation length. The nugget is the discontinuity of the variogram at the origin.

Spatial analysis requires a minimum number of observations to obtain a proper variogram (at least 100) (Webster and Oliver, 1992). To overcome the lack of enough observations, Sterk and Stein (1997) proposed a method to extend the analysis into the space-time domain and join data from multiple storms to map wind blow mass transport. The same methodology has been successfully applied to study spatial variability of $T F$ at fine-scale in Spain and Iran (Fathizadeh et al., 2014; Gómez et al., 2002). Following Sterk and Stein (1997), the first step of pooling the spatial variation of $T F$ is to standardize the observations to the overall mean with the following equation:

$$
T F_{i, j}^{\prime}=\frac{T F_{i, j}}{\overline{T F}_{j}} \hat{\mu}
$$

in which $T F_{i, j}^{\prime}$ is the standardized $T F$ observation at the location $i$ and for the period $j$, and $\overline{T F}_{j}$ and $\hat{\mu}$ are the period's mean $T F$ and the overall mean of the pooled observations, respectively.

The variograms were then calculated using the standardized data of several periods:

$$
\hat{\gamma}(h)=\frac{1}{2 n(h)} \sum_{j=1}^{m} \sum_{i=1}^{n_{j}(h)}\left(T F_{i, j}^{\prime}-T F_{i+h, j}^{\prime}\right)^{2},
$$

in which $T F_{i, j}^{\prime}$ and $T F_{i+h, j}^{\prime}$ denote the pair of standardized observations, separated by the distance $h$, for the period $j$. Using this formulation, each pair of observations 
within the same period contributes to the estimation of the standardized variogram, irrespective of the time that the measurements were made.

We pooled $T F$ observations from 4 periods (Prd-3, Prd-4, Prd-5, and Prd-6) in spring, and from 3 periods (Prd-7, Prd-9, and Prd-11) in the summer season. Prd- 8 and Prd-10 were not included in summer pool, because the first one presented a strongly skewed distribution (out of the [-1 1] range suggested by Webster and Oliver (2007) and the second presented a relatively low $P G$ that was not comparable with the other pooled periods.

Equation (3.3) was applied to generate two experimental standardized variograms, one for the spring and another for the summer season. We used a maximum lag distance of $36 \mathrm{~m}$, that is, one half of the largest distance within the plot ( $\mathrm{Zi}$ mmermann et al., 2009). Experimental standardized variograms were fitted using 4 standard variograms models widely used to represent the spatial distribution of throughfall (namely exponential, Gaussian, spherical, and pure nugget), (i.e., Zimmermann et al., 2009; Voss et al., 2016; Zimmermann et al., 2010). Models were evaluated at different lag sizes ranging from 1 to $4 \mathrm{~m}$ at intervals of $0.1 \mathrm{~m}$. To select the best fitted model, the criteria of the smallest sum of square errors was used (Webster and Oliver, 2007). The model with the minimum sum of square errors and its respective lag size were considered for further calculations. For the data analysis we used R software, version 3.2.3 (R Development Core Team, 2015). Additionally, gstat package (Pebesma, 2004) was used for geostatistical analysis.

Each of the two fitted models was converted to 4 and 3 period-variogram models for spring and summer, respectively. To achieve this, we considered that the range of spatial dependence of $T F$ was independent of the $P G$, which means that same range was inferred for all the periods of the same season. The sill parameter $(C)$ and the nugget effect $\left(C_{0}\right)$ were estimated using the overall mean $\hat{\mu}$ and the $T F$ mean per period, $\overline{T F}_{j}$, with the following equations:

$$
\begin{aligned}
& C_{j}=C_{\mathrm{s}}\left(\frac{\overline{T F}_{j}}{\hat{\mu}}\right)^{2} \\
& C_{0}^{j}=C_{0}^{s}\left(\frac{\overline{T F}_{j}}{\hat{\mu}}\right)^{2}
\end{aligned}
$$

in which $C_{s}$ and $C_{0}^{j}$ are the sill and nugget effect parameters of the standardized variograms, respectively.

Maps of $T F$ were created using ordinary kriging with the corresponding periodvariogram. We assessed the period models using a leave-one-out cross-validation. The cross-validation consists of predicting values of throughfall at each location $i$ by means of ordinary kriging but leaving out the observed value on the location $i$. From the cross validation we estimated the mean absolute errors (MAE) and the relative MAE $\left(\mathrm{RMAE}=\mathrm{MAE} / \overline{T F}_{j}\right)$. To depict the spatial variation of $T F$ in the plot, we created maps of $T F$ as percentage of rainfall ( $T F$-p) by dividing the kriged $T F$ map to the respective $P G$ of the period. 


\subsubsection{Temporal Persistence of Throughfall}

Time stability plots (TSP) were used to investigate the temporal persistence of throughfall (cf. Raat et al., 2002; Keim et al., 2005). To make a comparison among different periods, we calculated a "normalized" throughfall (cf. Keim et al., 2005) as:

$$
\overline{\overline{T F}}_{i, j}=\frac{T F_{i, j}-\overline{T F}_{j}}{S_{j}}
$$

in which $T F_{i, j}$ is $T F$ collected at location $i$ during period $j$, and $\overline{T F}_{j}$ and $S_{j}$ are the respective mean and the standard deviation calculated for every period. We computed these values for $i=32$ locations, and $j=5$ stationary periods of the data collection (Prd-11 to Prd-15). We created TSP by ranking the values of normalized throughfall from the smallest to the largest, showing the relative deviation of $T F$ from the mean. TSPs describe two types of temporal persistence: extreme persistence and general persistence. Extreme persistence is identified in steep tails in the plot, and its presence indicates either sites persistently very wet or very dry (Raat et al., 2002; Keim et al., 2005). General persistence is described by the slope of the line in the middle quantiles and indicates whether the collectors are persistently wetter or drier than the mean.

\subsection{Results}

\subsubsection{Throughfall}

Between 17 February 2015 and 2 November 2015, $T F$ was measured for 15 periods; we excluded Prd-1 and Prd-2 from the analysis, because some records of snowfall were detected in the nearest weather station in Deelen. During these periods (Prd-3 to Prd-15), a total of $572 \mathrm{~mm}$ of rain was recorded. Similarly, measured $T F$ totals for the same period was $350 \mathrm{~mm}$, representing $61.2 \%$ of gross rainfall. Tf totals for the spring, summer, and autumn seasons were $33.9 \mathrm{~mm}(42 \%$ of $P G), 210.2 \mathrm{~mm}$ (67\% of $P G$ ), and $106.3 \mathrm{~mm}(60 \%$ of $P G)$, respectively.

\subsubsection{Spatial Patterns of Throughfall}

The similarity between the mean and a median values of $T F$ (Table 3.1) and estimated skewness coefficients within the limits $[-1,1]$ indicates that $T F$ observations exhibited a distribution close to normal. Only Prd-8 presented a skewness coefficient larger than 1; then, it was excluded from subsequent analysis. Distance to the nearest tree was not a good predictor for any period of measurements $\left(R^{2}<0.2\right)$.

One hundred twenty five (spring) and 94 (summer) $T F$ (standardized) observations were used to estimate combined variograms. The best-fitting models (based on the sum of square errors) for the combined variograms were exponential for both seasons. The lag sizes that minimize the sum of square error in the fitting were $3 \mathrm{~m}$ and $2.7 \mathrm{~m}$ for spring and summer, respectively. The effective range parameter was about $12 \mathrm{~m}$ and $8 \mathrm{~m}$ for spring and summer variograms, respectively. Partial sill 
effect was detected only for spring season (1.5), and the sill parameter was $3.8 \mathrm{~m}^{2}$ and $59.6 \mathrm{~m}^{2}$ for spring and summer, respectively (Table 3.2, Figure 3.2).

Table 3.2 Parameters of the fitted standardized-variograms and converted periodvariogram models.

\begin{tabular}{|c|c|c|c|c|c|c|c|c|c|c|c|c|}
\hline \multirow[t]{2}{*}{ Season } & \multirow{2}{*}{$\begin{array}{l}\hat{\mu} \\
(\mathrm{mm})\end{array}$} & \multirow[t]{2}{*}{ Prd } & \multirow{2}{*}{$\begin{array}{l}T F \\
(\mathrm{~mm})\end{array}$} & \multicolumn{4}{|c|}{$\begin{array}{l}\text { Standardized } \\
\text { Variogram }\end{array}$} & \multicolumn{5}{|c|}{ Period Variograms } \\
\hline & & & & Model $^{a}$ & $a^{b}$ & $C_{0}^{S}$ & $C_{S}$ & $a^{\prime}$ & $C_{0}$ & $C$ & $\begin{array}{l}\text { MAE } \\
(\mathrm{mm})\end{array}$ & $\begin{array}{l}\text { RMAE } \\
(\%)\end{array}$ \\
\hline \multirow[t]{4}{*}{ Spring } & 8.5 & 3 & 7.3 & Exp & 12.3 & 1.5 & 2.3 & 12.3 & 1.1 & 1.7 & 1.4 & 19.5 \\
\hline & & 4 & 8.7 & & & & & 12.3 & 1.6 & 2.5 & 1.2 & 13.9 \\
\hline & & 5 & 6.7 & & & & & 12.3 & 0.9 & 1.4 & 1.5 & 22.5 \\
\hline & & 6 & 11.2 & & & & & 12.3 & 2.6 & 4.1 & 1.3 & 11.5 \\
\hline \multirow[t]{3}{*}{ Summer } & 60.4 & 7 & 37.3 & Exp & 7.8 & 0 & 59.6 & 8.1 & 0 & 22.7 & 5.1 & 13.6 \\
\hline & & 9 & 73.4 & & & & & 8.1 & 0 & 80.0 & 5.5 & 7.5 \\
\hline & & 11 & 71.4 & & & & & 8.1 & 0 & 83.3 & 6.7 & 9.4 \\
\hline
\end{tabular}

${ }^{a}$ Model applied to fit the variogram: Exponential (Exp)

${ }^{b}$ Effective ranges $(a)$ were calculated for exponential model $($ Effective range $=$ range $\times 3$ )

a)

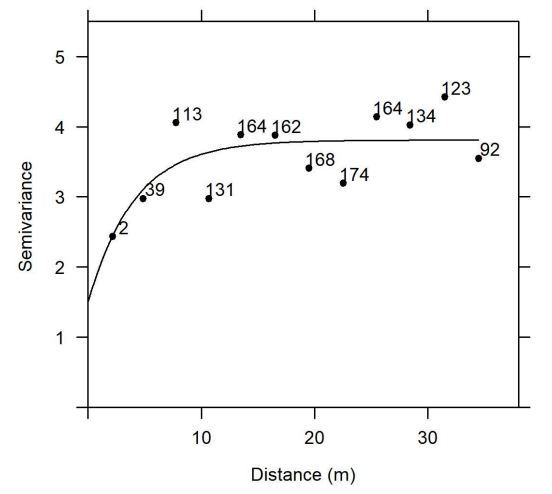

b)

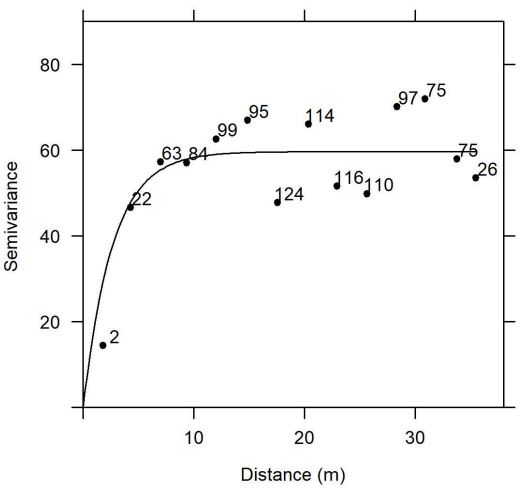

Figure 3.2 Estimated standardized variograms of $T F$ for (a) spring season with fitted exponential model; (b) summer season with fitted exponential model. Each point was labeled with the respective number of pairs per lag distance.

Frequent occurrence of rainfall events is expected to enhance interception loss (and reduce $T F$ ) due to frequent canopy wetting and drying. This effect can be observed in Figure 3.3, although total $P G$ was larger in Prd-4; TF-p was larger for Prd-6. This could be explained largely by the number of rainfall events during those periods (4 in Prd-6 vs. 7 in Prd-4; Table 3.1). However, this effect is not consistent in other periods, and considerable scatter was evident (Table 3.1). This could be attributed to the differences in other factors (e.g., rainfall intensity, wind speed) among the periods. 
Figure 3.3 TF-p maps (as \% $P G$ ) for (a,b) spring periods: Prd-4 and Prd-6; (c,d) summer periods: Prd-9 and Prd-11. Filled black triangles represent trees (size proportional to DBH), and black circles represent the funnel-type collectors. 


\subsubsection{Temporal Persistence of Throughfall}

Temporal persistence of $T F$ was analyzed for Prd-11 to Prd-15 (stationary position). The time stability plot (Figure 3.4 ) showed a tail, indicating persistence of extremely dry collectors. Funnel collectors \#19 and \#22 were positioned at extremely very dry sites, while none of the collectors was positioned at any extremely wet site.

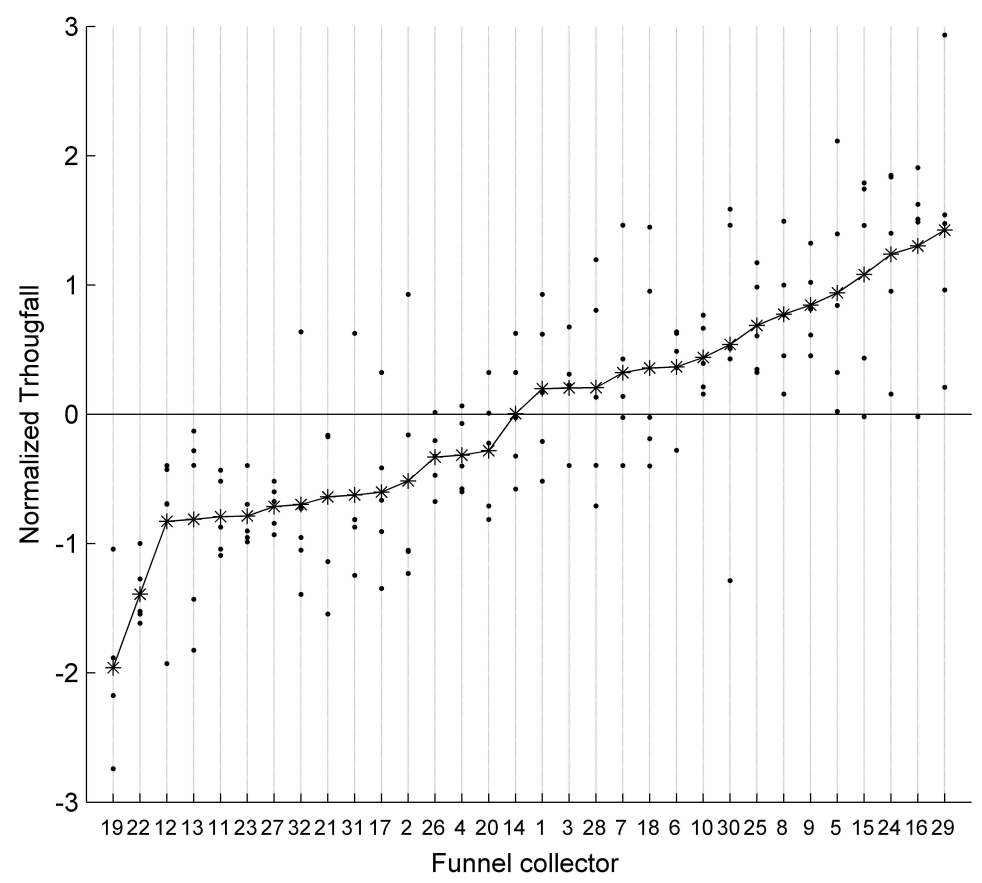

Figure 3.4 Time stability plot of normalized $T F$ for 32 stationary funnel-type collectors. Black dots are values of normalized $T F$ for each funnel-type collector of the stationary periods (Periods 11-15). Black asterisks are the averaged values of normalized $T F$. The numbers on the $\mathrm{x}$-axis are field labels for the collectors sorted by lowest averaged normalized $T F$ value.

The general persistence is related to the slope of the line in the middle quartiles. A gentle slope indicates that $T F$ observations are not different from the mean. The general persistence was moderate considering that 15 collectors were not significantly different from the mean (t-test, $\alpha=0.05$ ), 3 observations were excluded from the analysis due to disturbances, and 9 collectors were significantly wetter and 5 significantly drier than the mean (t-test, $\alpha=0.05$ ).

From field observations, we found that some of the collectors located close to the tree stem have low $T F$. However, the linear correlation between the distance to the nearest tree (DNT) and the averaged normalized $T F$ was weak (Figure 3.5). The observations indicated that over a distance of $0-1 \mathrm{~m}$ to the nearest tree, two of the three extremely dry collectors were found, while in the same range of distance 
one wet collector was found. The driest collector was located at a distance of $1.3 \mathrm{~m}$ from the nearest tree.

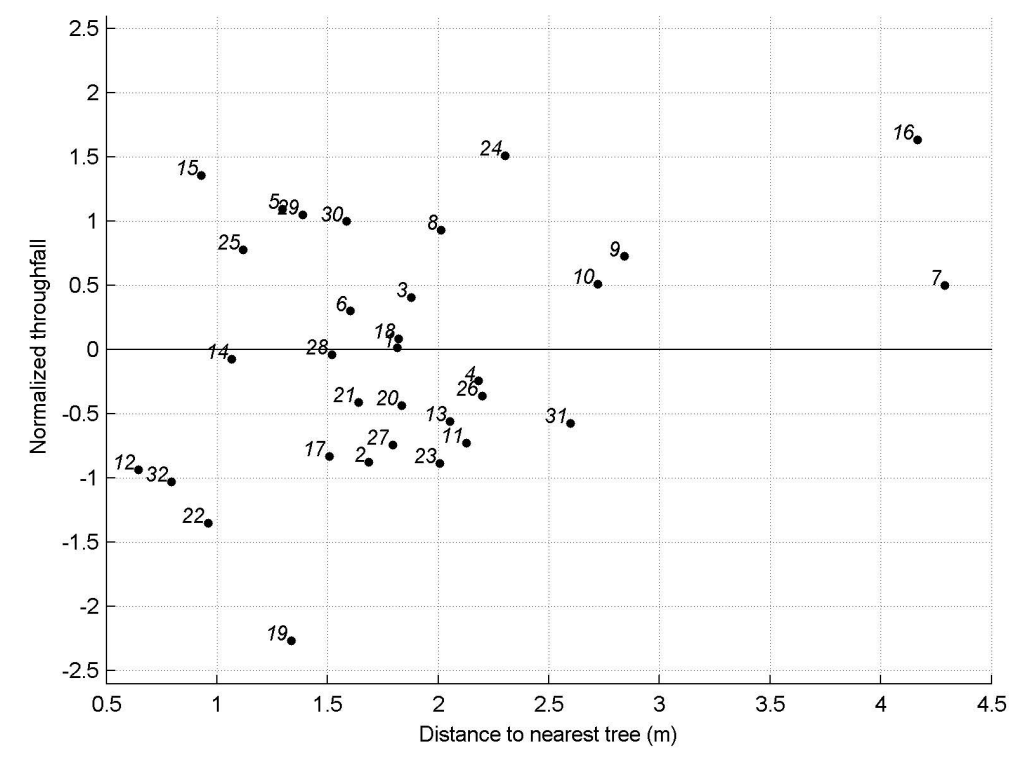

Figure 3.5 Normalized $T F$ versus distance to nearest tree. Black dots represent the normalized throughfall value for each funnel-type collector. Each symbol is labeled with the collector number.

\subsection{Discussion}

\subsubsection{Throughfall Variability}

The average variability in $T F(\sim 16 \%)$ for the fifteen periods was about $15 \%$ less than the values reported by Bouten et al. (1992) for the same plot when the forest was denser (885 trees $\mathrm{ha}^{-1}$ ) and shorter (mean height $\sim 20 \mathrm{~m}$ ) than at the time of the present study. Likewise, the average $\mathrm{CV}$ found in the present study was $\sim 5 \%$ lower than the values reported by Raat et al. (2002) for the same plot. Effects of forest thinning or seasonal changes in stand structures on spatial variability of throughfall (CV) are documented by few other studies (Staelens et al., 2006; Sun et al., 2015). For example, Sun et al. (2015) reported a significant decrease in $\mathrm{CV}$ of $T F$ in Japanese cypress plantation because of strip thinning. Similarly, Staelens et al. (2006) found a significantly higher mean CV of $T F$ in a leafy period than that observed in a leafless period. One possible explanation for the reduction in throughfall $\mathrm{CV}$ in the studied plot is that thinning practice occurred in winter 1995-1996. After forest thinning or canopy pruning, openness increases, which, in turn, leads to decrease in canopy storage capacity (i.e., lower rainfall is needed to stabilize the $T F$ rate) and increase in throughfall rate (cf. Sun et al., 2015). 
Another possible explanation for the lower $\mathrm{CV}$ of $T F$ found in the present study as compared to the other two studies can be related to the amount of throughfall collected across the periods. In many studies it was found that aggregation of small events can cause higher variation in $T F$ than an aggregation of large events (Raat et al., 2002; Zimmermann and Zimmermann, 2014; Bouten et al., 1992; Kimmins, 1973). The latter is closely related to the temporal resolution of the measurements. Staelens et al. (2006) reported that the CV decreased with increasing length of the sampling interval (i.e., increase in the amount of throughfall received). A similar effect was observed in the present study: in periods with a higher amount of rainfall, $\mathrm{CV}$ ranged from $10 \%$ to $17 \%$, whereas in periods with a lower amount of rainfall, $\mathrm{CV}$ values ranged from $28.8 \%$ to $29.3 \%$ (Table 3.1 ). The weekly period of $T F$ observation used by Bouten et al. (1992) (as opposed to $\sim 15$ day intervals in the present study) with lower accumulated values of $T F$ may thus result in higher CV. The sampling interval in the present study was similar to that used by Raat et al. (2002), but their study was concentrated in the months with low rain intensities. The CV found by Raat et al. (2002) was indeed lower than the one estimated by Bouten et al. (1992), and higher than the CV in the present study.

\subsubsection{Spatial Patterns of Throughfall}

Based on the skewness coefficient, we found that most of our periods of measurements presented Gaussian distribution (Table 3.1). Many of the cases found in the literature are event-based studies; they showed skewed frequency distributions of throughfall. However, there are also some studies, mainly in temperate forest, that show a Gaussian behavior, (e.g., Loustau et al., 1992). In a maritime pine stand Loustau et al. (1992) reported normal distribution of throughfall (52 collectors) for most of 32 individual storms. Likewise, in two (young and old) Douglas-fir stands Keim et al. (2005) found non skewed distributions of $T F$ (94 collectors) 8 storms $(P G>19 \mathrm{~mm})$.

Similarly, skewness evaluated in our study was within the normality limits for all but in one period (Prd-8) (Table 3.1). Such normality in the observations distribution seems to be an effect of the aggregation period used for the measurement of $T F$. A similar finding was reported by Zimmermann and Zimmermann (2014) in their study in a 12-year old teak plantation in Panamá (i.e., octile skew range [-0.2, 0.2] for weekly measurements).

Previous descriptions of throughfall patterns through variograms have shown contrasting results (see comparisons in Zimmermann et al., 2009; Voss et al., 2016). The study of Bouten et al. (1992) at Speulderbos forest with 36 collectors and weekly measurements reported that spatial patterns of throughfall around trees can be determined effectively through variograms, but they did not report the obtained parameter values. This is an indicator that, at least in a younger state of the forest and before thinning, the spatial correlation of throughfall can be determined. In a storm based study over two Douglas-fir stands in the Pacific Northwest, Keim et al (2005) found no strong but evident spatial correlations of throughfall equal to $5 \mathrm{~m}$ for both, a mid-age (60 year, crown size of $5 \mathrm{~m}$ ), and an old (600 years, crown size of $10 \mathrm{~m}$ ) stand, respectively. However, they did not fit a variogram model, and the reported range was inferred from the experimental variogram plots. 
Voss et al. (2016) reported that for tropical forest in Panamá, the accuracy of the variogram parameters is largely influenced by the number gauges used. In addition, the very low spatial variability of $T F$ (Table 3.1) found at our study site indicates that the forest type (e.g., mono species or species-rich) and presence or absence of understory shrubs play an important role in the redistribution rainfall in the forest floor. Therefore, the number of throughfall gauges to capture the $T F$ spatial variability properly as recommended by Voss et al. (2016) may not necessarily be applicable in all the forest types. Moreover, Voss et al. (2016) further recommended that the extent of the plot should exceed several times the range, and our study fulfilled that requirement.

Two other studies at fine scale have effectively used the methodology proposed by Sterk and Stein (1997) to study spatial distribution of $T F$. Gómez et al. (2002) detected spatial correlation structure in $T F$ distribution in mature olive trees. Also, Fathizadeh et al. (2014) reported a spatial correlation length of $T F$ measurements of approximately 5-6 m beneath Persian oak trees. However, Fathizadeh et al. (2014) found high values RMAE ( 40\% to 100\%) and attributed these to the lack of observational points at short distance. They recommended that random relocation of the gauges between collection periods would reduce the uncertainty.

The application of Sterk and Stein (1997) methodology allowed us to generate information about spatial distribution of $T F$. For instance, spring periods showed a homogeneous distribution of $T F$ for the Prd-4 (Figure 3.3a) while it was more variable during the Prd-6 (Figure 3.3b). Similar analysis can be done for summer periods in case similar spatial distribution of $T F-\mathrm{p}$ for both periods (Prd-9 and Prd-11) can be observed (Figure 3.3c,d). During summer, it seems that the rainfall duration is large enough to saturate the canopy and produce large $T F$-p of $\sim 70 \%$. Also, in the map of Prd-11, there are several blue spots indicating larger $T F-\mathrm{p}$ $(\sim 80 \%)$. Those can also be largely due to the dynamic interplay between event frequency, duration, and intensity vis á vis canopy storage capacity within the period of measurement.

Our study supports the findings of Keim et al. (2005), who detected spatial correlation structure of $T F$ beneath Douglas-fir canopy in a temperate climate. The lack of large number of points can be overcome by pooling $T F$ observations from periods of similar characteristics. Our study had the advantage of random relocation of gauges between collection periods that facilitated the observational points at short distance. The relatively low RMAE (ranging from $8 \%$ to $22 \%$ ) found in our study could also be due to the longer temporal scale of sampling ( biweekly).

\subsubsection{Temporal Persistence of Throughfall}

The majority of studies on persistence of throughfall have reported a systematic temporal trend (i.e., persistently very wet or dry) over time (Raat et al., 2002; Staelens et al., 2006; Sun et al., 2015). The persistence of wet and dry area may well affect the spatial patterns of soil moisture in the forest floor, thereby affecting, for example, root water uptake (Bouten et al., 1992), nitrification-denitrification rates (Raat et al., 2002) and soil micro-flora and fauna distributions (Kaspari and Weiser, 2000). The results of the temporal stability showed throughfall in the present study was (slightly) more stable than it was $\sim 25$ years ago (Raat et al., 2002). Although the differences can partly be related to the sampling designs, the presence of extremely 
dry collectors in this study can largely be attributed to the change in canopy structure due to the enlargement of the living crown. Moreover, we investigated whether there is any relationship between distance to the nearest tree and the amount of $T F$. We did not find a clear correlation between the distance and the normalized $T F$ (Figure 3.5), although extreme dry collectors (\#9 and \#12) were located at less than $1.5 \mathrm{~m}$ to the nearest tree. The literature is not conclusive about this relationship. Some authors found evidence of this relationship (Robson et al., 1994; Kato et al., 2013) and some others reported from weak to no evidence (Loustau et al., 1992; Bellot and Escarre, 1998; Keim et al., 2005; Sun et al., 2015). In their analysis of throughfall before and after forest thinning, Sun et al. (2015) hypothesized that lower throughfall recorded by some of the gauges close to the tree after thinning was due to enhanced interception loss through the enhanced ventilation after thinning. However, evidence supporting this hypothesis is quite scattered and contradictory. For example, Keim et al. (2005) reported few persistently wet gauges close to tree stems in a 60-year old conifer, whereas the result was opposite in an uneven age old conifer stand. Likewise, Sato et al. (2011) reported large spatial variability of throughfall close to trees in the eucalyptus plantation. Such results suggest that not only the distance to the stems but also the foliage aggregation above the positioned gauges could play a larger role in the $T F$ spatial variability.

\subsection{Conclusions}

The study examined spatial variability of throughfall in Douglas-fir stand near the settlement Garderen, the Netherlands. Over the 10 months of the study period, measured throughfall was $431 \mathrm{~mm}(61 \%$ of $P G)$. The spatial variability of $T F$ was lower than that reported by similar studies. This can largely be attributed to the homogeneity of the stand, the absence of understory, and, to some extent, the time scale of aggregation used in the study. The spatial correlation lengths detected in spring and summer season were about $12 \mathrm{~m}$ and $8 \mathrm{~m}$, respectively. By using ordinary kriging, relative $T F$ (throughfall normalized by incoming rainfall) maps were created for 4 periods. Such maps depicted the homogeneous distribution of $T F$ within the studied plot, indicating comparatively low spatial variability of $T F$ in the study area. Throughfall measurements were further analyzed using time stability plots that showed, in general, a persistent pattern with few noticeable very dry spots The latter was probably due to relatively high canopy density above the collectors. 



\section{The influence of long-term changes in canopy structure on interception loss: a case study in Speulderbos, the Netherlands}




\section{Abstract}

The evaporation of intercepted water by forests is a significant contributor to both the water and energy budget of the Earth. In many studies, a discrepancy in the water and energy budget is found: the energy that is needed for evaporation is larger than the available energy supplied by net radiation. In this study, we analyse the water and energy budget of a mature Douglas fir stand in the Netherlands, for the two growing seasons of 2015 and 2016. Based on the wet-canopy water balance equation for these two growing seasons, derived interception losses were estimated to be $37 \%$ and $39 \%$ of gross rainfall, respectively.

We further scrutinized eddy-covariance energy balance data from these two consecutive growing seasons and found the average evaporation rate during wetcanopy conditions was $0.20 \mathrm{~mm} \mathrm{~h}^{-1}$. The source of energy for this wet-canopy evaporation was net radiation (35\%), a negative sensible heat flux (45\%), and a negative energy storage change $(15 \%)$. This confirms that the energy for wet-canopy evaporation is extracted from the atmosphere as well as the biomass.

Moreover, the measured interception loss at the forest was similar to that measured at the same site years before ( $I=38 \%$ ), when the forest was younger (29 years old, vs. 55 years old in 2015). At that time, the forest was denser and had a higher canopy storage capacity ( $2.4 \mathrm{~mm}$ then vs. $1.90 \mathrm{~mm}$ in 2015), but the aerodynamic conductance was lower $\left(0.065 \mathrm{~m} \mathrm{~s}^{-1}\right.$ then vs. $0.105 \mathrm{~m} \mathrm{~s}^{-1}$ in 2015), and therefore past evaporation rates were lower than evaporation rates found in the present study $\left(0.077 \mathrm{~mm} \mathrm{~h}^{-1}\right.$ vs. $0.20 \mathrm{~mm} \mathrm{~h}^{-1}$ in 2015). Our findings emphasize the importance of quantifying downward sensible heat flux and heat release from canopy biomass in tall forest in order to improve the quantification of evaporative fluxes in wet canopies.

\subsection{Introduction}

Rainfall interception is the portion of precipitation temporarily captured by vegetation before evaporating back into the atmosphere. It is by definition unavailable for soil infiltration or runoff. Evaporation from intercepted rainfall is an important component of the water balance, and in coniferous forests it can represent around 25-45\% of gross rainfall $(P G)$ (Rutter et al., 1975; Gash et al., 1980; CarlyleMoses and Gash, 2011). Starting from the early twentieth century (Horton, 1919, benchmark papers in Gash and Shuttleworth, 2007) much research has been done to quantify the magnitude of rainfall interception over different forest ecosystems (cf. Carlyle-Moses and Gash, 2011; Muzylo et al., 2009; Miralles et al., 2010; Llorens and Domingo, 2007). Despite decades of research, the physical processes and atmospheric conditions that allow a large fraction of rainfall to return to the atmosphere are still poorly understood (van Dijk et al., 2015). A key issue is that the water budget often suggests a higher evaporation rate than the available energy permits. In addition, little research has focused on the long-term evolution of rainfall interception loss with forest growth and development, and on the implications for the forest water balance. Improving knowledge of the evolution of rainfall interception with forest growth, in particular the canopy storage and wet-canopy evaporation rate, will provide insight into the role of forests regarding moisture recycling, and will assist when developing both forest management strategies against threats to forest 
water resources and remote sensing techniques to monitor rainfall interception based on forest structure (i.e. Miralles et al., 2010; Cui et al., 2015; Hassan et al., 2017).

In this study, we revisited a site with a Douglas fir plantation in the centre of the Netherlands, the "Speulderbos", for which historical measurements of rainfall interception are available. During the 1990s research focused on the impact of air pollution on forest growth ("Aciforn project") at this site (Evers et al., 1991). Several hydrological studies at that time found high interception losses ( 40\%) from the forest (Tiktak and Bouten, 1994; Klaasen et al., 1998; Bouten et al., 1996), contributing to the debate about forest plantations in the centre of the Netherlands affecting the ground water recharge (Moors, 2012). Detailed measurements and modelling studies at the site included canopy growth and architecture (Evers et al., 1991), soil water dynamics (Tiktak and Bouten, 1994), modelling evaporation and transpiration (Bosveld and Bouten, 2001), spatial patterns of throughfall (Bouten et al., 1992), and measuring and modelling canopy water storage (Bouten et al., 1991, 1996). It was found that the high interception losses in Speulderbos at that time were due to a high leaf area index, resulting in high canopy storage capacity $(2.5 \mathrm{~mm})$ as measured by microwave transmission (Bouten et al., 1991). Evaporation during rainfall contributed minimally to the overall interception loss (Klaasen et al., 1998).

The historical data collected in Speulderbos offer a good opportunity to evaluate the effects of long-term changes in canopy structure on the rainfall interception process and their implications for other phases of the water balance (i.e. soil infiltration, plant water uptake, ground water recharge, and stream discharge). Changes in forest structure can be resultant from different factors such as tree phenology, management practices (Bormann et al., 2015), changes in species composition (Thom et al., 2017), and stand development (Franklin et al., 2002; Freund et al., 2015). Although several studies have analysed the effects of short-term changes (i.e. seasonal) in forest canopy structure on rainfall interception (Dolman, 1987; Price and Carlyle-Moses, 2003; Deguchi et al., 2006; Herbst et al., 2008; Muzylo et al., 2012), far fewer studies have considered the effects of forest growth over longer timescales (i.e. decades, centuries) in forest canopy structure on rainfall interception. In some cases comparisons have been limited to monitoring the water balance components of two (or more) stands of different ages concurrently (i.e. Pypker et al., 2005; Keim et al., 2005).

Due to the long-term maintenance of the research infrastructure at the site, a unique opportunity arose to evaluate the changes in eco-hydrological processes over several decades. We were particularly interested in the water and energy budget of the forest. For this, two variables are of key importance: the water storage capacity of the forest, and the evaporation rate of the wet canopy, which is energy limited. The evaporation rate, in turn, depends on the radiation budget, the aerodynamic roughness, and the heat storage capacity. We expected that thinning of the forest stand in combination with a substantial increase in forest height must have affected the water and energy storage capacity, as well as the forest roughness.

For this study, we combined data collected using an eddy-covariance flux tower with precipitation, stemflow, and throughfall data to obtain an estimate of the interception loss from a mature Douglas fir plantation (ca. 55 years old). The objectives of the present study were to 
i. assess two indirect methods for estimating canopy storage capacity,

ii. quantify the sources of energy that drive the latent heat flux involved in the evaporation of intercepted rainfall,

iii. examine the effect of long-term changes in canopy structure on the rainfall interception losses, and

iv. explore the relative importance of climatic and forest structural factors to overall rainfall interception loss using a physically based interception model.

\subsection{Materials and methods}

\subsubsection{Rainfall}

Gross rainfall $(P G, \mathrm{~mm})$ was measured in a nearby well exposed clearing (ca. 250 $\mathrm{m}$ from the centre of the plot) using two tipping bucket rain gauges (Rain Collector II, Davis Instruments, USA) with a resolution of $0.2 \mathrm{~mm}$ per tip. The orifice of the rain gauge was positioned at $1.5 \mathrm{~m}$ above the ground to avoid ground-splash effects. The automatically recorded data were stored by a HOBO event logger at 1 min intervals (Onset Computer Corporation, USA).

Gross rainfall was also collected at the top of the $47 \mathrm{~m}$ scaffolding tower operated by the University of Twente (ITC-UT) (at ca. $200 \mathrm{~m}$ distance from the clearing), using a tipping bucket rain gauge (Onset HOBO-RG3, resolution $0.2 \mathrm{~mm}$ ). The data collected at the top of the tower were only used to fill gaps in the data from the clearing (from 23 July to 12 August 2015, as well as 24 May to 9 June 2016) using a linear regression equation linking $10 \mathrm{~min}$ rainfall totals of the two locations $\left(R^{2}=\right.$ $0.93, n=500)$.

\subsubsection{Throughfall}

Throughfall $(T f, \mathrm{~mm})$ was measured by an automated gutter system and validated by an arrangement of manual (roving sampling) funnel-type collectors. The automated gutter system consisted of four stainless steel gutters $(200 \mathrm{~cm}$ x $30 \mathrm{~cm}$ each), randomly located in the plot and connected by pairs to two tipping buckets (V2A UP Umweltanalytische Produkte $\mathrm{GmbH}$ ). Using the manual array described in the Chapter 2, TF was measured 15 times. For the first 10 measurement periods, we applied a roving sampling method by randomly relocating the position of the funneltype collectors after each $T F$ measurement (resulting in 320 different positions of the funnel-type collectors). However, the coefficient of variation (CV) in the 10 initial measurement periods was low $(\sim 15 \%)$ and therefore we did not use the roving technique for the remaining 5 measurement periods (i.e. the gauges were not relocated after measurements were taken). A comparison of the manual and automatic measurements is shown in Table 4.1.

\subsubsection{Energy storage}

Energy storage $(Q)$, composed of energy storage in the canopy air $\left(Q_{\text {air }}\right)$ and in the biomass $\left(Q_{\text {bio }}\right)$, was estimated based on measurements of a vertical profile of air temperature and humidity. Further details on the sensors and their location are 
shown in Table 2.1. Energy storage changes in the air $Q_{\text {air }}$ result from the change in the temperature in the air $Q_{\mathrm{T}}$ plus the component resulting from the specific humidity $Q_{\mathrm{q}}$ (cf. Michiles and Gielow, 2008).

$Q_{\text {bio }}$ was estimated as the sum of energy stored in the trunks $\left(Q_{\mathrm{tr}}\right)$, in the branches $\left(Q_{\mathrm{br}}\right)$, and in the needles $\left(Q_{\mathrm{nd}}\right)$. For Douglas fir in the centre of the Netherlands, allometric equations on biomass and its vertical distribution derived from Bartelink (1996) were used (Table 4.2). Specific heat of biomass $\left(c_{\mathrm{v}}\right)$ was assumed to be equal for all components at $2400 \mathrm{~J} \mathrm{~kg}^{-1} \mathrm{C}^{-1}$ (Michiles and Gielow, 2008). A moisture content of $44 \%$ for Douglas fir (Nord-Larsen and Nielsen, 2015), was used to estimate the dry matter content.

$Q_{\text {air }}$ was estimated by dividing the air column into four sections: Section $1(0$ to $10 \mathrm{~m}$ ), Section 2 (10 to $20 \mathrm{~m}$ ), Section 3 ( 20 to $28 \mathrm{~m}$ ), and Section 4 ( 28 to 34 $\mathrm{m})$. Each section was centred on the respective level of temperature and humidity (Table 2.1) considered representative of the entire section. The following equations suggested by McCaughey (1985) were used to estimate $Q_{\text {air }}$ :

$$
\begin{aligned}
& Q_{\text {air }}=Q_{\mathrm{T}}+Q_{\mathrm{q}}, \\
& Q_{\text {air }}=\rho\left(c_{\mathrm{p}} \Delta \bar{T}+\lambda \Delta \bar{q}\right) \Delta z / \Delta t,
\end{aligned}
$$

where $\rho\left(\mathrm{kg} \mathrm{m}^{-3}\right)$ is density of air, $c_{\mathrm{p}}\left(\mathrm{J} \mathrm{kg}^{-1} \mathrm{~K}^{-1}\right)$ is the specific heat of air, $\lambda$ $\left(\mathrm{J} \mathrm{kg}^{-1}\right)$ is the latent heat of vaporization, $\Delta \bar{T}(\mathrm{~K})$ and $\Delta \bar{q}\left(\mathrm{~kg} \mathrm{~kg}^{-1}\right)$ are the change in mean air temperature and specific humidity over time, respectively, $\Delta z(\mathrm{~m})$ is the height thickness of the considered layer, and $\Delta t(\mathrm{~s})$ is the time interval.

$Q_{\text {bio }}$ was estimated by means of the following equation (Oliphant et al., 2004; McCaughey, 1985):

$$
Q_{\text {bio }}=m_{\text {bio }} c_{\mathrm{v}} \Delta T_{\text {bio }} / \Delta t,
$$

where $m_{\text {bio }}\left(\mathrm{kg} \mathrm{m}^{-2}\right)$ is the mass of biomass per unit of horizontal area, $c_{\mathrm{v}}$ $\left(\mathrm{J} \mathrm{kg}^{-1} \mathrm{~K}^{-1}\right)$ is a representative specific heat of the vegetation, and $T_{\text {bio }}(\mathrm{K})$ is a representative biomass temperature. Some studies have used ambient air temperature as a surrogate for $T_{\text {bio }}$ (Oliphant et al., 2004; Thom et al., 1975; Michiles and Gielow, 2008). We used Eq.(4.3) with $T_{\text {bio }}$ equalling air temperature for intervals without rainfall, and wet bulb temperature (Stull, 2011) for intervals with rainfall $(P G>0.5$ mm) (cf. van Dijk et al., 2015).

\subsubsection{Modelling rainfall interception}

\subsubsection{The Gash rainfall interception model}

The Gash analytical model (Gash, 1979) was used to simulate rainfall interception loss $(I, \mathrm{~mm})$. The Gash model assumes that rainfall occurs as a series of discrete events. The Gash model differentiates three phases in a rainfall event: (i) the canopy wetting phase, (ii) the canopy saturation phase, (iii) the canopy drying phase. Table 4.3 summarizes the equations associated with the respective phases. The Gash model 
Table 4.1 Statistical description of collection periods of throughfall and average amounts for a sample size $n=32$.

\begin{tabular}{llllll}
\hline Per. & $\begin{array}{l}\text { Date } \\
(\mathrm{dd} / \mathrm{mm} / 2015)\end{array}$ & Sampling & No. Days & $\begin{array}{l}\text { Cumulative average } \\
T F \text { funnels } \\
(\mathrm{mm})( \pm \mathrm{SD})\end{array}$ & $\begin{array}{l}\text { Cumulative average } \\
T F \text { gutters } \\
(\mathrm{mm})\end{array}$ \\
\hline 1 & $17 / 02-17 / 03$ & Roving & 28 & $36.6(6.1)$ & 33.6 \\
2 & $17 / 03-03 / 04$ & Roving & 17 & $43.7(5.2)$ & 42.9 \\
3 & $03 / 04-01 / 05$ & Roving & 28 & $7.3(1.8)$ & 8.7 \\
4 & $01 / 05-16 / 05$ & Roving & 15 & $8.7(1.4)$ & 8.2 \\
5 & $16 / 05-30 / 05$ & Roving & 14 & $6.7(1.9)$ & 6.6 \\
6 & $30 / 05-12 / 06$ & Roving & 13 & $11.2(1.6)$ & 11.0 \\
7 & $12 / 06-29 / 06$ & Roving & 17 & $37.3(6.0)$ & 38.3 \\
8 & $29 / 06-15 / 07$ & Roving & 16 & $20.0(3.4)$ & 20.1 \\
9 & $15 / 07-01 / 08$ & Roving & 17 & $74.1(7.5)$ & 70.2 \\
10 & $01 / 08-15 / 08$ & Non-roving & 14 & $7.4(1.7)$ & 7.3 \\
11 & $15 / 08-28 / 08$ & Non-roving & 13 & $71.4(8.2)$ & 69.6 \\
12 & $28 / 08-15 / 09$ & Non-roving & 18 & $62.4(6.6)$ & 60.4 \\
13 & $15 / 09-29 / 09$ & Non-roving & 14 & $16.2(2.0)$ & 15.3 \\
14 & $29 / 09-19 / 10$ & Non-roving & 20 & $25.1(2.6)$ & 24.4 \\
15 & $19 / 10-02 / 11$ & Non-roving & 14 & $2.6(0.8)$ & 2.0 \\
\hline
\end{tabular}

Table 4.2 Comparison of stand parameters and biomass dry weight (DW) for the Douglas fir stand in Speulderbos. Aboveground biomass determined by means of stem survey and allometric relationships from Bartelink (1996).

\begin{tabular}{lll}
\hline Parameter & 2015 & $1988^{a}$. \\
\hline Tree density $($ number ha \\
Mean DBH $(\mathrm{cm})$ & 571 & 992 \\
$\mathrm{LAI}^{b}\left(\mathrm{~m}^{2} \mathrm{~m}^{-2}\right)$ & 34.8 & 20.7 \\
Stem wood DW $\left(\mathrm{kg} \mathrm{m}^{-2}\right)$ & 4.5 & $8^{c}$ \\
Branches DW $\left(\mathrm{kg} \mathrm{m}^{-2}\right)$ & 29.9 & 14.6 \\
Needles DW $\left(\mathrm{kg} \mathrm{m}^{-2}\right)$ & 1.2 & 0.9 \\
Total biomass DW $\left(\mathrm{kg} \mathrm{m}^{-2}\right)$ & 33.18 & 16.3 \\
\hline
\end{tabular}

${ }^{a}$ Biomass dry weight values were estimated using density and DBH from Tiktak and Bouten (1994)

${ }^{b}$ LAI measured by using the LI-COR-2000 instrument.

${ }^{c}$ Previous studies in Speulderbos report a LAI of 11: that value was estimated by the destructive method (cf. Heij and Schneider, 1991). For comparative reasons, we use the reported value using the LI-COR photometer.

uses four canopy parameters: (i) canopy storage capacity $S$, which is defined as the amount of water left in a saturated canopy in the absence of evaporation, after rainfall and drainage has ceased, (ii) the free throughfall coefficient $p$, which is the fraction of incident rainfall that reaches the forest floor without touching the forest canopy, (iii) the coefficient $p_{\mathrm{t}}$, which is the fraction of rain diverted to the trunks as $S F$, (iv) stem storage capacity $S_{\mathrm{t}}$, which is the amount of water that can be 
Table 4.3 Main equations of the analytical Gash (1979) interception model.

\begin{tabular}{ll}
\hline Component of the model & Formulation \\
\hline $\begin{array}{l}\text { For } m \text { storms with } P G \text { insufficient } \\
\text { to saturate the canopy }(P G<P G)\end{array}$ & $\left(1-p-p_{\mathrm{t}}\right) \sum_{j=1}^{m} P G_{j}$ \\
$\begin{array}{l}\text { Wetting up the canopy with n storms } \\
\text { large enough to saturate the canopy }(P G \geq P G)\end{array}$ & $n\left(1-p-p_{\mathrm{t}}\right) P G^{\prime}-n S$ \\
$\begin{array}{l}\text { Evaporation from the saturated canopy } \\
\text { during rainfall }\end{array}$ & $\bar{E} / \bar{R} \sum_{j=1}^{n}\left(P G_{j}-P G_{j}^{\prime}\right)$ \\
Evaporation after rainfall event & $n S$ \\
$\begin{array}{l}\text { Evaporation from trunks for q storms } \\
\text { large enough to saturate trunk storage }\end{array}$ & $q S_{\mathrm{t}}$ \\
$\begin{array}{l}\text { Evaporation from trunks for small storms } \\
\text { unable to saturate the trunk storage }\end{array}$ & $p_{\mathrm{t}}^{m+n-q} \sum_{j=1}^{m} P G_{j}$ \\
\hline
\end{tabular}

stored on the stems. In addition to the canopy parameters, the Gash analytical model requires two climatic parameters: the mean evaporation rate $\bar{E}$ and the mean rainfall intensity $\bar{R}$.

For modelling purposes, we divided our data set into two parts: data-set 1 included measurements from 19 June to 31 October 2015, and data-set 2 included measurements from 19 June to 31 October 2016. Data-set 1 was used for parameter estimation (model calibration), and data-set 2 was used for validation.

We used two different parametrizations of the Gash model. In the first parametrization (Run 1) the parameters $S, p$, and $\bar{E} / \bar{R}$ were derived from the water balance (rainfall, throughfall, and stemflow data) by using the mean method (Klaasen et al., 1998). In the mean method, $S, p$, and $\bar{E} / \bar{R}$ were derived from linear regressions of measured $I$ vs. measured $P G$ from multiple events. In the second parametrization (Run 2), the parameters $S$ and $p$ were derived using individual event analysis (IEA) (Link et al., 2004), while the parameter $\bar{E} / \bar{R}$ was calculated with the evaporation rate derived from the energy balance residual and $R$ derived from the tipping bucket measurements. For both parametrizations, values of $S_{\mathrm{t}}$ and $p_{\mathrm{t}}$ as derived with the Gash and Morton (1978) method were used. The methods are discussed in detail in the following sections.

Moreover, the sensitivity of the modelled $I$ to the relevant parameters, namely $S$ and $\bar{E}$ (Gash, 1979; Loustau et al., 1992; Moors, 2012), was evaluated. We used the RMSE as the criterion to test the sensitivity for dataset 1 and dataset 2 separately. By comparing these different runs and the model sensitivity, we were able to evaluate the consistency of the water and energy balance estimates of evaporation as well as the storage capacity of the canopy. 


\subsubsection{Derivation of canopy parameters}

Two methods were used to derive the canopy parameters: the multiple event analysis or mean method (Klaasen et al., 1998) and the individual event analysis (IEA) (Link et al., 2004). As the Gash (1979) model is event based, it is important to discriminate events first. Because the criteria used to discriminate events can have a major effect on the interception modelling, we evaluated two cases of event selection: Case A, considering an event as a period of rain exceeding $0.5 \mathrm{~mm}$ preceded by a dry period of at least $3 \mathrm{~h}$ (cf. Klaasen et al., 1998), and Case B, considering an event as a period of rain exceeding $0.5 \mathrm{~mm}$, with the preceding dryness validated by three LWSs (all indicating fully dry) within the living crown. In addition, for Case B saturated events were considered only those events with $P G \geq 5 \mathrm{~mm}$.

The mean method is a multi-event analysis where $S$ and $p$ are estimated by linear regression of interception loss $(I=P G-T F-S F)$ vs. $P G$. To estimate $p$, the regression is in the form of $I=a P G$ with $a=1-p-p_{\mathrm{t}}$ and only events with a total amount of rainfall unable to saturate the canopy $\left(P G<P G^{\prime}\right)$ are used. The parameters $S$ and $\bar{E} / \bar{R}$ are derived from events large enough to saturate the canopy $\left(P G \geq P G^{\prime}\right)$ with the linear regression in the form of $I=b_{1} P G+b_{2}$, where $b_{1}=\bar{E} / \bar{R}$ and $b_{2}=\left(1-p-p_{\mathrm{t}}\right) / P G^{\prime}$. An iterative procedure is employed where the initial value of $P G^{\prime}$ is visually defined from an $I$ vs. $P G$ graph. After fitting both equations, $P G^{\prime}$ is re-calculated as $P G^{\prime}=b_{2} /\left(a+b_{1}\right)$ and the process is repeated until $P G^{\prime}$ converges (cf. Klaasen et al., 1998; Holwerda et al., 2012).

In contrast, the IEA consists of an analysis of the behaviour of water fluxes during individual events. It is based on the equations proposed in the Gash (1979) analytical model. When rainfall starts $\left(P G<P G^{\prime}\right)$ throughfall increases approximately linearly with $P G(T F=p P G)$ until saturation is reached: $P G \geq P G^{\prime}$. When rainfall saturates the canopy storage capacity $\left(P G=P G^{\prime}\right)$ an inflection point in the $T F$ vs. $P G$ plot occurs and water starts to drain from the canopy. Canopy parameters $p, P G^{\prime}$, and $S$ can be derived using an iterative regression procedure over the plot of cumulative $T F$ vs. cumulative $P G$. The procedure was applied to events selected in Case B (i.e. using LWS and saturation threshold $P G \geq 5 \mathrm{~mm}$ ) and with data records at a 15 min time resolution. Events that did not have sufficient $15 \mathrm{~min}$ records before saturation was reached were discarded. The inflection point $\left(P G^{\prime}\right)$ was calculated as the intersection of two linear regressions, for the wetting-up stage and after canopy saturation.

\subsubsection{Wet-canopy evaporation}

Three methods were used to estimate wet-canopy evaporation rate, based on (i) a water balance approach, (ii) the energy balance residual, and (iii) the Penman-Monteith equation.

Firstly, the wet-canopy evaporation rate $(\bar{E})$ was derived from the value of $\bar{E} / \bar{R}$ (obtained from the mean method). Because the distribution of rainfall intensity was skewed, we used the median rainfall intensity instead of the mean following the recommendations of Schellekens et al. (1999). The thus derived value of $E$ will henceforth be referred to as the "water balance based" evaporation rate.

Secondly, wet-canopy evaporation rates were estimated from the energy balance residual. The quality of the energy balance data (eddy-covariance flux of sensible 
heat, net radiation, ground heat, and storage terms) was verified by calculating the energy balance closure and the energy balance ratio (EBR) for the dry and wet periods for which high-quality data (quality flag $\leq 2$ ) of $\lambda \mathrm{E}$ were available. In addition, the performance of the sonic anemometer (CSAT3) during wet conditions was evaluated by plotting the standard deviation of the vertical wind speed $(\sigma w)$ against friction velocity $\left(u^{*}\right)$ (Gash et al., 1999; van der Tol et al., 2003; Holwerda et al., 2012). According to Monin-Obukhov similarity theory $\sigma w / u^{*}$ in neutral conditions is a universal constant; therefore, the ability of the anemometer to measure $\sigma w / u^{*}$ during wet and dry conditions was tested (Gash et al., 1999).

Wet-canopy evaporation rate was derived using the energy balance residual approach where $\lambda E\left(\mathrm{~W} \mathrm{~m}^{-2}\right)$ is estimated as the residual of the energy balance equation as:

$$
\lambda E=R_{\mathrm{n}}-H-G-Q-G_{\mathrm{P}},
$$

with $H$ derived from the eddy-covariance technique and $G_{\mathrm{P}}$, the photosynthetic energy flux, estimated at $-2 \mathrm{~W} \mathrm{~m}^{-2}$ during the night and at $6 \mathrm{~W} \mathrm{~m}^{-2}$ during the day (Thom, 1975). Equation 4.4 provides a more complete data set than $\lambda E$ based on the eddy-covariance data only, due to the fact that the open path gas analyser is prone to providing low quality data (causing rejections during filtering) during wet periods. The evaporation estimated with Eq. 4.4 is hereinafter referred to as $E_{\mathrm{EB}-\mathrm{EC}}$ :

Finally, the last and most common method to estimate wetcanopy evaporation, the Penman-Monteith (P-M) equation, was used. P-M estimates latent heat flux $\left(\lambda E, \mathrm{~W} \mathrm{~m}^{-2}\right)$ as

$$
\lambda E=\frac{\Delta A+\rho c_{\mathrm{p}}\left(e_{s}-e\right) g_{\mathrm{a}}}{\Delta+\gamma^{\prime}},
$$

with

$$
\gamma^{\prime}=\gamma\left(1+\frac{g_{\mathrm{a}}}{g_{\mathrm{s}}}\right),
$$

where $\Delta\left(\mathrm{hPa} \mathrm{K}^{-1}\right)$ is the slope of the saturated water vapour pressure curve, $\mathrm{A}\left(\mathrm{W} \mathrm{m}^{-2}\right)$ is the available energy, $\gamma^{\prime}$ and $\gamma\left(\mathrm{hPa} \mathrm{K}^{-1}\right)$ are the adjusted and original psychrometric constant, respectively, $\rho\left(\mathrm{kg} \mathrm{m}^{-3}\right)$ is the density of air, $c_{\mathrm{p}}$ $\left(\mathrm{J} \mathrm{kg}^{-1} \mathrm{~K}^{-1}\right)$ is the specific heat of air at constant pressure, $e_{s}(\mathrm{hPa})$ is the saturation vapour pressure at ambient temperature, $e(\mathrm{hPa})$ is the actual vapour pressure, $g_{\mathrm{a}}$ $\left(\mathrm{m} \mathrm{s}^{-1}\right)$ is the aerodynamic conductance, and $g_{\mathrm{s}}\left(\mathrm{m} \mathrm{s}^{-1}\right)$ is the surface conductance

During wet conditions, surface conductance is assumed to be infinitely large (i.e. surface resistance set to zero). Aerodynamic conductance for momentum $g_{\mathrm{a}, \mathrm{M}}\left(\mathrm{m} \mathrm{s}^{-1}\right)$, following Thom (1975), for neutral conditions was derived from the regression of observed friction velocity $\left(u^{*}, \mathrm{~ms}^{-1}\right)$ vs. wind speed $\left(u, \mathrm{~ms}^{-1}\right)$ measured by a sonic anemometer (Gash et al., 1999; van der Tol et al., 2003):

$$
g_{\mathrm{a}, \mathrm{M}}=\left(\frac{u^{*}}{u}\right) u
$$


It is necessary to differentiate between conductance for heat and momentum (Lankreijer et al., 1993). Following the empirical relation proposed by Garratt and Francey (1978), we used $\ln \left(z_{0 \mathrm{M}} / z_{0 \mathrm{H}}\right)=2$ for $g_{\mathrm{a}, \mathrm{H}}$ (cf. Gash et al., 1999; Moors, 2012; Lankreijer et al., 1993). In addition stability corrections for non-neutral hours were implemented according to Paulson (1970). The evaporation estimated with the $\mathrm{P}-\mathrm{M}$ equation is hereinafter referred to as $E_{\mathrm{PM}-\mathrm{EC}}$.

\subsection{Results}

\subsubsection{Rainfall}

Total rainfall $(P G)$ measured during 11 months between 19 June 2015 and 31 October 2016 (excluding the winter season from November 2015 to March 2016) was $955 \mathrm{~mm}$. Mean monthly precipitation was $82 \mathrm{~mm}( \pm 41 \mathrm{SD})$, with a minimum of $43 \mathrm{~mm}$ in May 2016 and a maximum of $156 \mathrm{~mm}$ in August 2015.

A total of 157 events (64 in 2015 vs. 93 in 2016) were identified from half hour rainfall time series during the study period. The frequency distributions of event size, duration and rainfall intensity showed a positively skewed distribution. The mean (and median) event-based amount, duration and intensity were $6.0(3.1) \mathrm{mm}$, $6.5(5.0) \mathrm{h}$, and $1.1(0.74) \mathrm{mm} \mathrm{h}^{-1}$, respectively. The maximal event size, duration and intensity were $66.3 \mathrm{~mm}, 62 \mathrm{~h}$ and $8.5 \mathrm{~mm} \mathrm{~h}^{-1}$, respectively.

\subsubsection{Throughfall, stemflow, and derived interception loss}

Throughfall $(T F)$, measured for the same period as the rainfall, was $577 \mathrm{~mm}$ in total, corresponding to about $60 \%$ of $P G$. The overall standard error (SE) of $T F$ was $48 \mathrm{~mm}$ (i.e. $5 \%$ of $P G$ ). No significant differences (t-test $\alpha<0.05$ ) were found between the mean cumulative $T F$ estimated using either the manual array or the automated gutters, confirming that the automated system was representative for the plot. The homogeneity in the plot was illustrated by a relatively low coefficient of variation (CV) of $\sim 15 \%$ (cf. Table 4.1 ).

The total $S F$ at plot scale was $2.6 \mathrm{~mm}$ (1.1\% of gross rainfall). The contribution to the total $S F$ from the four stem diametric classes, $<30,30-40,40-50$, and $>50$ $\mathrm{cm}$, was $0.8,0.2,0.1$, and $<0.1 \%$, respectively. The SE value of the overall $S F$ was $2 \%$ based on the four stemflow collectors.

The total interception loss estimated for the whole study period based on the wet-canopy water balance was $372 \mathrm{~mm}(39 \% P G)$. The SE for the interception loss estimated as the quadratic mean of the SEs of $T F$ and $S F$ was $52 \mathrm{~mm}$ (i.e. $5.4 \%$ of $P G)$. 
(a)

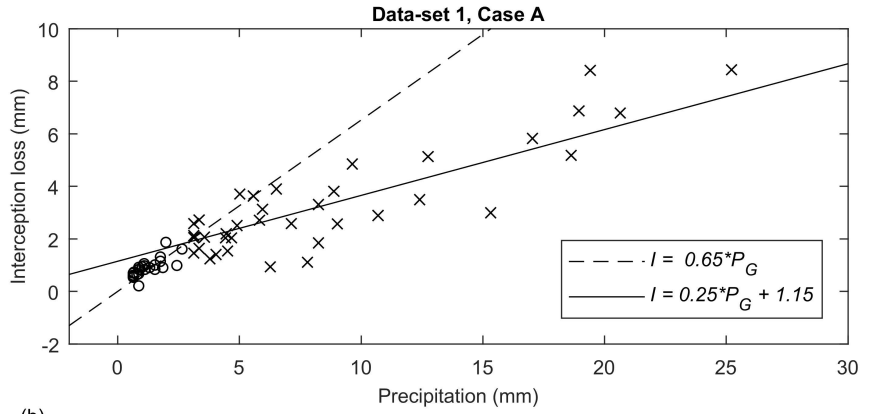

(b)
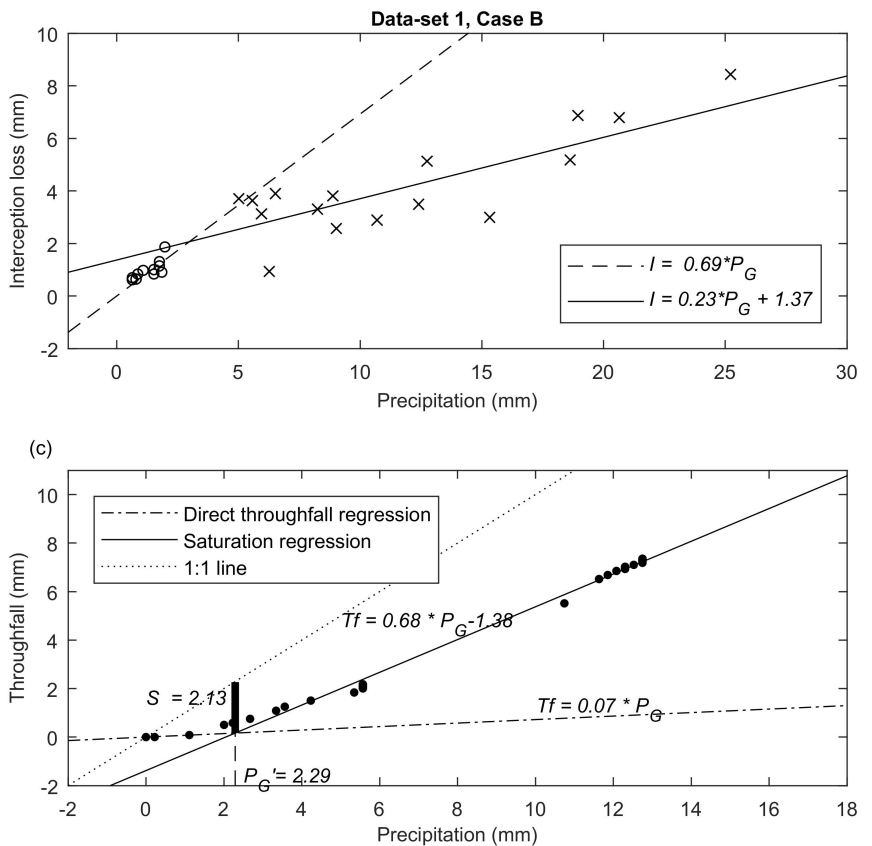

Figure 4.1 Determination of canopy-related parameters using the mean method and the individual event analysis. (a) Linear regression using data-set 1 ; events selected in Case A. Circles represent rainfall events with total rainfall less than that necessary for saturation; crosses represent data with enough rainfall to saturate the canopy. (b) Linear regression using data-set 1 ; events selected in Case B (similar legend to a). (c) Individual event analysis (IEA) on 17 September 2015, the plot of data used to estimate canopy direct throughfall and saturation storage capacity. Dots represent values of cumulative rainfall vs. cumulative $T F$. The direct throughfall regression equation was $T F=0.07 P G$, and the saturation regression equation was $T F=0.68 P G-1.38$. Canopy saturation point was calculated as the intersection of the two linear regressions, $P G^{\prime}=2.29 \mathrm{~mm}$. 


\subsubsection{Canopy-related parameters}

Using the mean method, we analysed data-set 1 (the calibration data set) and found only minor differences in estimated parameter values with respect to the criteria used to select the events (Cases A and B). For Case A, values of $p$ and $S$ were found of $0.32( \pm 0.04)$ and $1.15( \pm 0.25) \mathrm{mm}$, respectively, while for Case $\mathrm{B}$, values of $p$ and $S$ were found of $0.28( \pm 0.05)$ and $1.37( \pm 0.51) \mathrm{mm}$, respectively.

When we selected events based on Case A (PG $\geq 0.5 \mathrm{~mm}$ and dryness separation time of $3 \mathrm{~h}$ ), then the linear regression expression that relates $I$ to $P G$ was $I=$ $0.65 P G\left(R^{2}=0.68 ; n=24\right)$ for non-saturated conditions and $I=0.25 P G+1.15$ $\left(R^{2}=0.67 ; n=40\right)$ for saturated conditions in data-set 1 (Fig. 4.1a). Case B (i.e. excluding events that did not reach the condition of preceding dryness validated with three fully dry LWSs) resulted in linear regressions of $I=0.69 P G\left(R^{2}=0.68 ; n=\right.$ $11)$ for unsaturated conditions $\left(P G<P G^{\prime}\right)$ and $I=0.23 P G+1.37\left(R^{2}=0.75 ; n\right.$ =17) for saturated conditions $(P G \geq 5 \mathrm{~mm})$ (Fig. 4.1b).

The values of the stemflow-related parameters $\left(S_{\mathrm{t}}, p_{\mathrm{t}}\right)$ were obtained using the method of Gash and Morton (1978). The trunk storage capacity $\left(S_{\mathrm{t}}\right)$ was estimated at $0.14 \mathrm{~mm}( \pm 0.05)$ and the proportion of rain diverted to stemflow $p_{\mathrm{t}}$ at 0.029 $( \pm 0.005)\left(R^{2}=0.77 ; n=12\right)$.

Using the IEA method, average values of $p$ and $S$ of $0.17( \pm 0.06)$ and $1.90 \mathrm{~mm}$ $( \pm 0.5)$, respectively, were found for data-set 1 . This result was obtained using the stricter event selection (Case B) to warrant canopy pre-dryness. Seven out of the 17 events in data-set 1 had sufficient data points in the wetting phase to perform the respective regression analysis. One example is shown in Fig. 4.1c.

\subsubsection{Energy balance closure and performance of the sonic anemometer}

The slope of the linear regression of $H+\lambda E$ (from eddy covariance) vs. $R_{\mathrm{n}}-G_{0}-Q$ for wet and dry half-hour periods was 0.96 , while the energy balance ratio (EBR) defined as the sum of $H+\lambda E$ divided by $R_{\mathrm{n}}-G_{0}-Q$ was 0.98 . The RMSE of the regression was $66.3 \mathrm{~W} \mathrm{~m}^{-2}$ for the 30 min interval values of $R_{\mathrm{n}}, H, \lambda E, G$, and $Q$ (Fig. 4.2a).

We studied 124 half-hour periods for wet-canopy conditions $P G>0.5 \mathrm{~mm}$ for the full study period from 19 June 2015 to 31 October 2016. In addition to the eddycovariance data quality flag filtering (see Sect. 2.2.5), we tested the performance of the sonic anemometer by plotting the standard deviation of the vertical wind speed against the friction velocity. According to the Monin-Obukhov similarity theory, the ratio $\sigma w / u^{*}$ should be constant in neutral conditions. We found that the plot presents a strong linear relation (Fig. 4.2b). The slope was consistent with previous estimations (van der Tol et al., 2003), and the offset was very close to zero. 

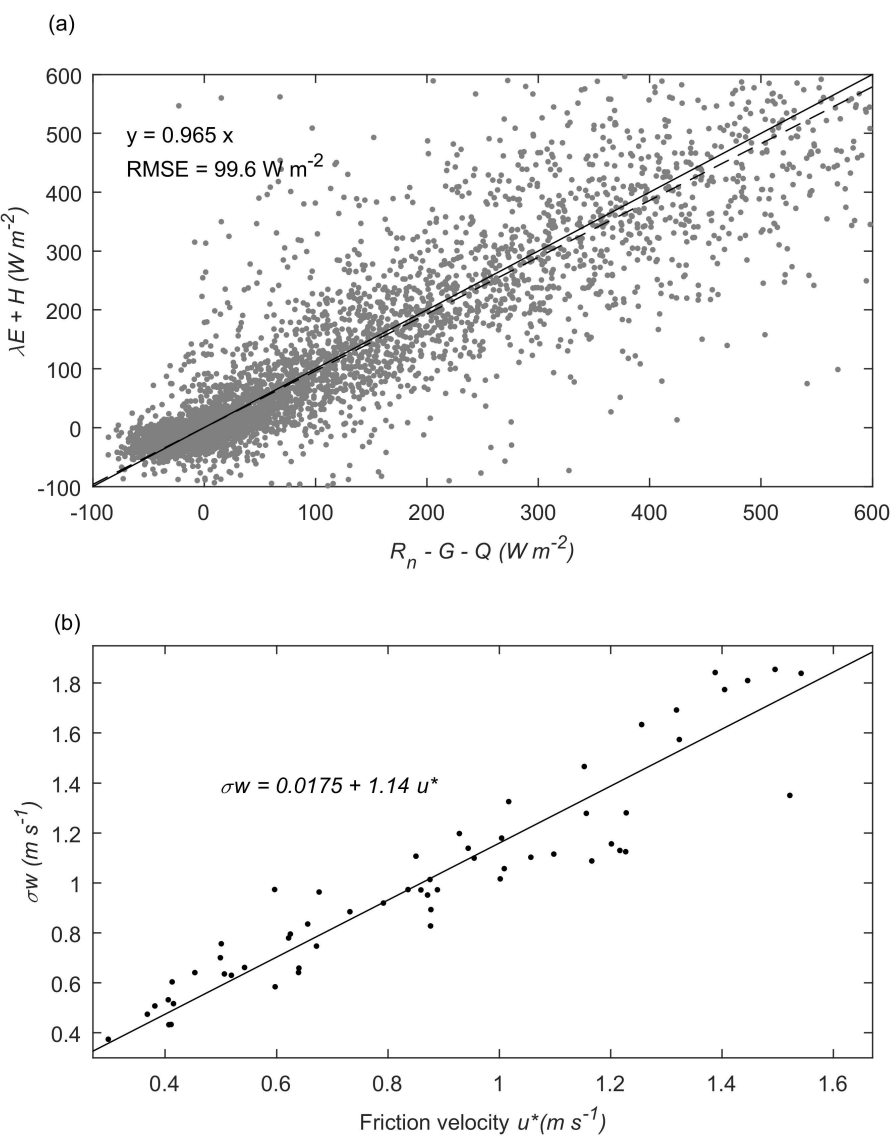

Figure 4.2 (a) Half-hour interval of turbulent heat fluxes ( $H$ and $\lambda E)$ vs. available energy $\left(R_{\mathrm{n}}-G-Q\right)$ for the study site. The solid line represents the 1:1 line and the dashed line represents linear regression forced through the origin. (b) Half-hour averages of standard deviation of the vertical wind speed $\sigma w\left(\mathrm{~m} \mathrm{~s}^{-1}\right)$ vs. friction velocity $u^{*}\left(\mathrm{~m} \mathrm{~s}^{-1}\right)$, wet-canopy conditions $P G>0.5 \mathrm{~mm} \mathrm{30}-\mathrm{min}^{-1}$, and near-neutral stability $(-0.02<(z-d) / L<0.02)$.

\subsubsection{Wet-canopy evaporation rates}

The wet-canopy evaporation rates derived from the water balance approach were estimated from the parameter $\bar{E} / \bar{R}$ obtained after fitting the linear regressions. $\bar{E} / \bar{R}$ values of $0.25( \pm 0.02)$ and $0.23( \pm 0.03)$ were found for Case A and Case $\mathrm{B}$, respectively. Because they were similar, we decided to use Case B (stricter event selection) to derive $\bar{E}$. The parameter $\bar{E} / \bar{R}$ multiplied by the median $R$ of $0.82 \mathrm{~mm} \mathrm{~h}^{-1}$, results in a water-balance based estimated evaporation rate of 0.19 $\mathrm{mm} \mathrm{h}^{-1}$.

Average micrometeorological characteristics of the wet periods are shown in Table 4.4. It is noteworthy that both sensible heat flux $(H)$ and energy storage $(Q)$ 


\section{The influence of long-term changes in canopy structure on interception loss}

were strongly negative during wet periods. This implies a strong cooling of the surface $(Q)$, accompanied by a negative (downward) sensible heat flux. This is the case for wet periods both during the day (07:00 to 19:00 UTC+1) and the night $(19: 00$ to $07: 00 \mathrm{UTC}+1)$. The energy balance residual, which we assume is the latent heat flux (see Eq. 4.4), greatly exceeds the net radiation. Other observations were a very low vapour pressure deficit at the top of the tower and similar average wind speed throughout the day and night (Table 4.4).

Between 19 June 2015 and 31 October 2016 (excluding the winter season from November 2015 to March 2016), the mean wet evaporation rate calculated from the energy balance residual, $E_{\mathrm{EB}-\mathrm{EC}}$, was $0.28 \mathrm{~mm} \mathrm{~h}^{-1}$ during the day (Fig. 4.3a), 0.07 $\mathrm{mm} \mathrm{h}^{-1}$ during the night (Fig. 4.3b), and $0.20 \mathrm{~mm} \mathrm{~h}^{1}$ for day and night periods combined (Fig. 4.3c). The main sources of evaporation heat (in the equivalent water depth unit) were net radiation $\left(0.07 \mathrm{~mm} \mathrm{~h}^{1}\right)$, sensible heat $\left(0.09 \mathrm{~mm} \mathrm{~h}^{1}\right)$, and the release of stored energy within the canopy $\left(0.03 \mathrm{~mm} \mathrm{~h}^{1}\right)$. Evaporation rates derived from the energy balance residual (for day and night periods) presented a skewed distribution with values ranging from -0.53 to $2.59\left(\mathrm{~mm} \mathrm{~h}^{1}\right)$ with a median value of $0.13\left(\mathrm{~mm} \mathrm{~h}^{1}\right)$.

In order to estimate average wet-canopy evaporation with the Penman-Monteith equation, we first estimated aerodynamic conductance to momentum $g_{\mathrm{a}, \mathrm{M}}\left(\mathrm{m} \mathrm{s}^{-1}\right)$. We estimated the aerodynamic conductance to momentum for the predominant southwesterly wind direction and selected the fluxes coming from the wind direction between 180 and $360^{\circ}$. In this direction, effects of the tower construction on the wind were minimal. The $g_{\mathrm{a}, \mathrm{M}, \mathrm{EC}}$ was estimated by means of the regression between wind speed and friction velocity as $g_{\mathrm{a}, \mathrm{M}, \mathrm{EC}}=0.0318 u$ (Fig. 4.4). When we applied the stability correction for non-neutral hours (Paulson, 1970) and used $\ln \left(z_{0 \mathrm{M}} / z_{0 \mathrm{H}}\right)=2$ (Lankreijer et al., 1993; Moors, 2012), we obtained an aerodynamic conductance to water vapour as $g_{\mathrm{a}, \mathrm{H}, \mathrm{EC}}=0.0303 u$.

For the whole study period, using the estimated $g_{\mathrm{a}, \mathrm{H}, \mathrm{EC}}$, and considering $Q$ and $G$ to be part of the available energy $\left(A=R_{\mathrm{n}}+Q+G\right)$, the mean and median wet evaporation rates estimated by the Penman-Monteith equation $\left(E_{\mathrm{PM}-\mathrm{EC}}\right)$ were 0.13 and $0.10 \mathrm{~mm} \mathrm{~h}^{-1}$, respectively (Fig. 4.3f, Table 4.5). The period 19 June-31 October 2015 presented similar mean and median evaporation rates to the values estimated for the period 1 April-31 October 2016 (Table 4.5).

In general, the mean evaporation rate estimated with the $\mathrm{P}-\mathrm{M}$ equation (using $g_{\mathrm{a}, \mathrm{H}, \mathrm{EC}}=0.0303 u$ ) was $35 \%$ lower than the mean evaporation rate derived from the energy balance residual. Using the water balance measurements with the mean method resulted in an estimated evaporation rate of $0.19 \mathrm{~mm} \mathrm{~h}^{-1}$, which is similar to the mean values of $E_{\mathrm{EB}-\mathrm{EC}}$, although $40 \%$ higher than the estimated values of the median $E_{\mathrm{EB}-\mathrm{EC}}$ used in the Gash model. 
Table 4.4 Average micro-meteorological characteristics for half-hour periods with more than $0.25 \mathrm{~mm}(30 \mathrm{~min})^{-1}$ of $P G$ for day $(07: 00-19: 00 \mathrm{UTC}+1)$ and night conditions (19:00-07:00 UTC+1).

\begin{tabular}{llll}
\hline Parameter & $\begin{array}{l}\text { Day } \\
(n=75) \\
( \pm \mathrm{SD})\end{array}$ & $\begin{array}{l}\text { Night } \\
(n=44) \\
( \pm \mathrm{SD})\end{array}$ & $\begin{array}{l}\text { Day and Night } \\
(n=119) \\
( \pm \mathrm{SD})\end{array}$ \\
\hline Net radiation $\left(\mathrm{W} \mathrm{m}^{-2}\right)$ & $78( \pm 95)$ & $-2( \pm 12)$ & $48( \pm 85)$ \\
Sensible heat flux $\left(\mathrm{W} \mathrm{m}^{-2}\right)$ & $-94( \pm 253)$ & $-25( \pm 77)$ & $-66( \pm 204)$ \\
Total energy storage rate $\left(\mathrm{W} \mathrm{m}^{-2}\right)$ & $-24( \pm 56)$ & $-15( \pm 32)$ & $-20( \pm 48)$ \\
Soil heat flux $\left(\mathrm{W} \mathrm{m}^{-2}\right)$ & $0.5( \pm 3.2)$ & $-2( \pm 3.6)$ & $-0.4( \pm 3.6)$ \\
Air temperature $\left({ }^{\circ} \mathrm{C}\right)$ & $12.7( \pm 4)$ & $11.8( \pm 5)$ & $12( \pm 5)$ \\
Vapour pressure deficit $(\mathrm{hPa})$ & $0.7( \pm 0.8)$ & $0.6( \pm 1.4)$ & $0.7( \pm 0.8)$ \\
Wind speed $\left(\mathrm{m} \mathrm{s}^{-1}\right)$ & $3.7( \pm 1.7)$ & $3.2( \pm 1.0)$ & $3.5( \pm 1.4)$ \\
\hline
\end{tabular}

(a) $E_{E B-E C}$ (day)

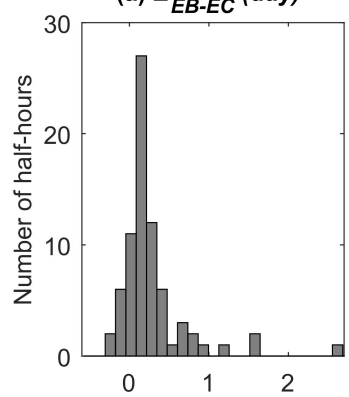

(d) $E_{P M-E C}$ (day)

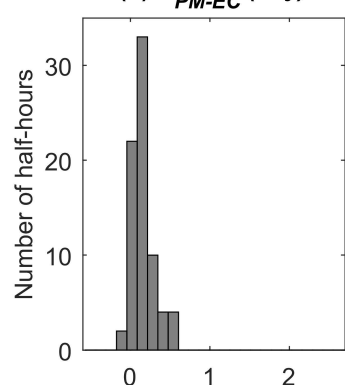

(b) $E_{E B-E C}$ (night)

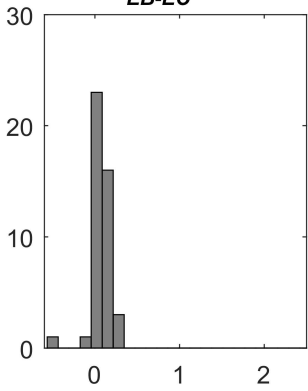

(e) $E_{P M-E C}$ (night)

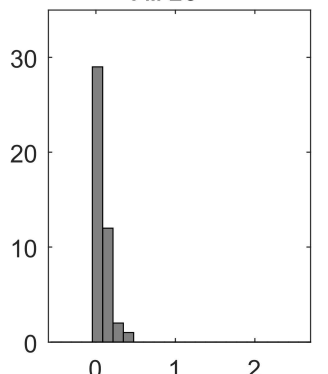

(c) $E_{E B-E C}$ (day and night)

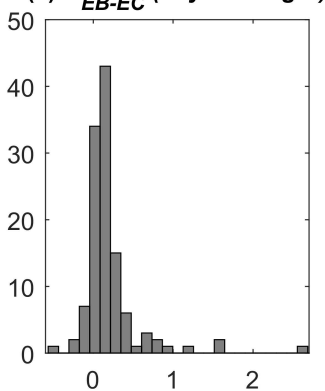

(f) $E_{P M-E C}$ (day and night)

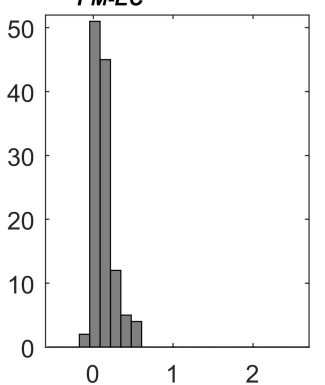

Wet evaporation rate $\left(\mathrm{mm} \mathrm{h}^{-1}\right)$

Figure 4.3 Distributions of wet-canopy evaporation rates during daytime (07:00-19:00 UTC+1), night time (19:00-07:00 UTC+1), and combined day and night. Two different methods applied: (a-C) energy balance residual ( $\left.E_{\mathrm{EB}-\mathrm{EC}}\right)$ and (d-f) Penman-Monteith ( $\left.E_{\mathrm{PM}-\mathrm{EC}}\right)$. 
Table 4.5 Summary statistics for the wet evaporation rates estimated for the study period by different methods: energy balance $\left(\bar{E}_{\mathrm{EB}-\mathrm{EC}}\right)$ and Penman-Monteith equation $\left(\bar{E}_{\mathrm{PM}-\mathrm{EC}}\right)$.

\begin{tabular}{cccccccc}
\hline \multirow{2}{*}{ Method } & \multicolumn{3}{c}{$\begin{array}{c}\text { Energy balance residual } \\
E_{\text {EB-EC }}(\mathrm{mm} \mathrm{h-1)}\end{array}$} & & \multicolumn{3}{c}{$\begin{array}{c}\text { Penman Monteith } \\
E_{\text {PM-EC }}\end{array}$} \\
\cline { 2 - 4 } \cline { 6 - 8 } \cline { 6 - 8 } & $\begin{array}{c}\text { Jun-Oct 2015 } \\
(\mathrm{n}=68)\end{array}$ & $\begin{array}{c}\text { Apr-Oct 2016 } \\
(\mathrm{n}=61)\end{array}$ & $\begin{array}{c}\mathrm{All}^{a} \\
(\mathrm{n}=119)\end{array}$ & & $\begin{array}{c}\text { Jun-Oct 2015 } \\
(n=68)\end{array}$ & $\begin{array}{c}\text { Apr-Oct 2016 } \\
(n=61)\end{array}$ & $\begin{array}{c}\text { All } \\
(n=119)\end{array}$ \\
\hline Mean & 0.23 & 0.16 & 0.20 & & 0.12 & 0.13 & 0.13 \\
Median & 0.12 & 0.12 & 0.12 & & 0.10 & 0.10 & 0.10 \\
Range & {$[-0.53,2.59]$} & {$[-0.26,0.75]$} & {$[-0.53,2.59]$} & & {$[-0.01,0.50]$} & {$[-0.06,0.57]$} & {$[-0.06,0.57]$} \\
\hline
\end{tabular}

a"All" refers to data from both periods together: 19 June to 31 October 2015 and 1 April to 31 October 2016

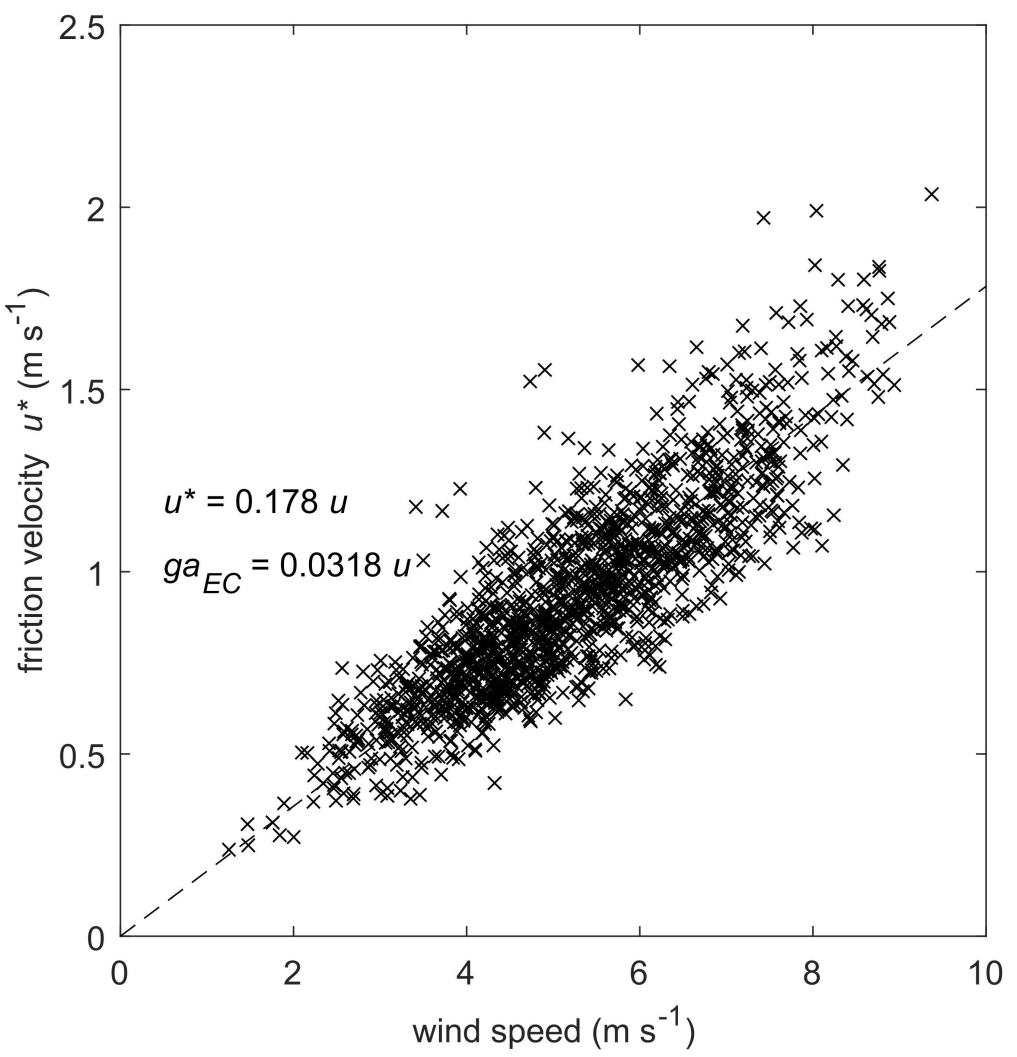

Figure 4.4 Linear regression of friction velocity $u^{*}$ against horizontal wind speed $u$ for near-neutral hours $(-0.02<(z-d) / L<0.02)$ and from a south-westerly wind direction. 


\subsubsection{Modelling rainfall interception}

We used two different parametrizations of the Gash model. In the first parametrization (Run 1) the parameters $S, p$, and $\bar{E} / \bar{R}$ were derived by using the mean method. In the second parametrization (Run 2), the parameters $S$ and $p$ were derived from the IEA; the parameter $\bar{E} / \bar{R}$ was calculated with $\bar{E}$ as the median $E_{\mathrm{EB}-\mathrm{EC}}$ derived from the energy balance residual and $\bar{R}$ as the median rainfall intensity derived from the tipping bucket measurements (Table 4.6).

Run 1 underestimated the interception loss by $3 \%$ with an RMSE of $0.93 \mathrm{~mm}$ for the calibration data set (Table 4.6). The model performance based on the Nash-Sutcliffe (NSE) model efficiency was very good (0.90) (Table 4.6). Run 2, which used the median value of $E_{\text {EB-EC }}\left(0.12 \mathrm{~mm} \mathrm{~h}^{-1}\right)$ and the median $R(0.82$ $\mathrm{mm} \mathrm{h}^{-1}$ ) to obtain parameter $\bar{E} / \bar{R}(0.15)$, underestimated $I$ by about $8 \%$ (166.6 mm modelled, vs. $180.4 \mathrm{~mm}$ measured $I$ ). The RMSE was $1.36 \mathrm{~mm}$ and the performance was lower than that of Run 1 (NSE $=0.79)$. The predicted total interception loss for the validation data set using both Run 1V (V for the validation data set) and Run $2 \mathrm{~V}$ configurations were in good agreement with $I$ derived from the $T F$ and $S F$ measurements, with relative errors of about $1 \%$. In both cases, the RMSE was about $0.79 \mathrm{~mm}$ and the model performance was good, with an NSE of 0.79 .

The interception components that contributed most to the overall evaporation interception loss differ between the two parametrizations of model validation, Run $1 \mathrm{~V}$ and Run $2 \mathrm{~V}$. In the first case, the two largest contributors were evaporation from the saturated canopy during rainfall (37\%) and evaporation loss during the drying phase (34\%). In Run 2, the same two components were the greatest contributors, but in opposite order: evaporation loss during the drying phase was the main contributor (44\%), and evaporation from the saturated canopy during rainfall was the second contributor (24\%). The third largest contribution, in both cases (Run 1 and Run 2), was evaporation from small rainfall events (18 and $24 \%$, respectively), followed by the contribution from the wetting phase ( 7 and $5 \%$, respectively). Evaporation from trunks (during saturated and unsaturated conditions) contributed less than $5 \%$ for both data sets (Table 4.7).

The sensitivity analysis of the Gash model shows that parameter equifinality (Beven and Prophecy, 1993) occurs between $S$ and $\bar{E} / \bar{R}$ (van Dijk et al., 2015), which implies in this case that an underestimation of $S$ is likely to be compensated by overestimation of $\bar{E} / \bar{R}$ (Fig. 4.5). This effect can be seen when modelling the validation data set (Fig. 4.5b): for Run 1 a low value of $S(1.37 \mathrm{~mm})$ may be compensated by a high value of $\bar{E} / \bar{R}(0.23)$, leading to a similar RMSE to Run 2, which used a higher value of $S(1.90 \mathrm{~mm})$ and a lower value of $\bar{E} / \bar{R}$ (0.15). A similar effect is detected when modelling data-set 1 (Fig. $4.5 \mathrm{a}$ ): both parametrizations (Run 1 and Run 2) produce a relative error lower than 10\% (Table 4.6). 
Table 4.6 Comparison of the performance of modelled interception loss using different parametrization. Data-set 1 refers to the period from 19 June to 31 October 2015, and data-set 2 to the period from 1 April to 31 October 2016. Run 1, all parameters derived from the mean method. Run 2, canopy parameters $(S, p)$ derived from IEA and $E$ from the energy balance residual method.

\begin{tabular}{lllllllll}
\hline Description & \multicolumn{3}{l}{ Parametrization } & \multicolumn{3}{c}{$\begin{array}{l}\text { Relative } \\
\text { error }(\%)\end{array}$} & RMSE & $\begin{array}{l}\text { Nash- } \\
\text { Sutcliffe }\end{array}$ \\
\cline { 2 - 6 } & $S$ & $p$ & $\bar{E} / \bar{R}$ & $I(\%)$ & $I(\mathrm{~mm})$ & & & \\
\hline Run 1 & 1.37 & 0.28 & 0.23 & 36.3 & 175.5 & -2.75 & 0.93 & 0.90 \\
Run 2 & 1.90 & 0.17 & 0.15 & 34.4 & 166.6 & -7.70 & 1.36 & 0.79 \\
Measured I & & & & 37.3 & 180.4 & & & \\
Run 1V & 1.37 & 0.28 & 0.23 & 40.43 & 108.66 & -0.77 & 0.78 & 0.79 \\
Run 2V & 1.90 & 0.17 & 0.15 & 40.31 & 108.35 & -1.06 & 0.79 & 0.79 \\
Measured I & & & & 40.74 & 109.5 & & & \\
\hline
\end{tabular}

Table 4.7 Components of interception loss in $\mathrm{mm}$ (and as percentage of total) for data-set 2 (19 June to 31 October 2016) based on the validated Gash analytical original model.

\begin{tabular}{|c|c|c|}
\hline Interception component $\mathrm{mm}(\%)$ & Run 1 & Run 2 \\
\hline $\begin{array}{l}m \text { storms with } P G \text { insufficient } \\
\text { to saturate the canopy } \\
\left(P G<P G^{\prime}\right)\end{array}$ & $18.9 \mathrm{~mm}(17.5 \%)$ & $25.9 \mathrm{~mm}(23.9 \%)$ \\
\hline $\begin{array}{l}\text { Wetting up the canopy with } \mathrm{n} \text { storms } \\
\text { large enough to saturate the canopy } \\
\left(P G \geq P G^{\prime}\right)\end{array}$ & $7.9 \mathrm{~mm}(7.4 \%)$ & $5.1 \mathrm{~mm}(4.7 \%)$ \\
\hline $\begin{array}{l}\text { Evaporation from the saturated } \\
\text { canopy during rainfall }\end{array}$ & $40.53 \mathrm{~mm}(37.3 \%)$ & $25.6 \mathrm{~mm}(23.6 \%)$ \\
\hline Evaporation after rainfall event & $36.9 \mathrm{~mm}(34.1 \%)$ & $47.5 \mathrm{~mm}(43.8 \%)$ \\
\hline $\begin{array}{l}\text { Evaporation from trunks, saturated } \\
\text { and non-saturated conditions }\end{array}$ & $4.2 \mathrm{~mm}(3.8 \%)$ & $4.2 \mathrm{~mm}(3.8 \%)$ \\
\hline
\end{tabular}

\subsection{Discussion}

\subsubsection{Canopy storage capacity}

In the same study area, Klaasen et al. (1998) evaluated the most common indirect methods to derive $S$ from multi-event throughfall measurements. They found that the mean method tended to underestimate $S$ compared to direct microwave transmission 

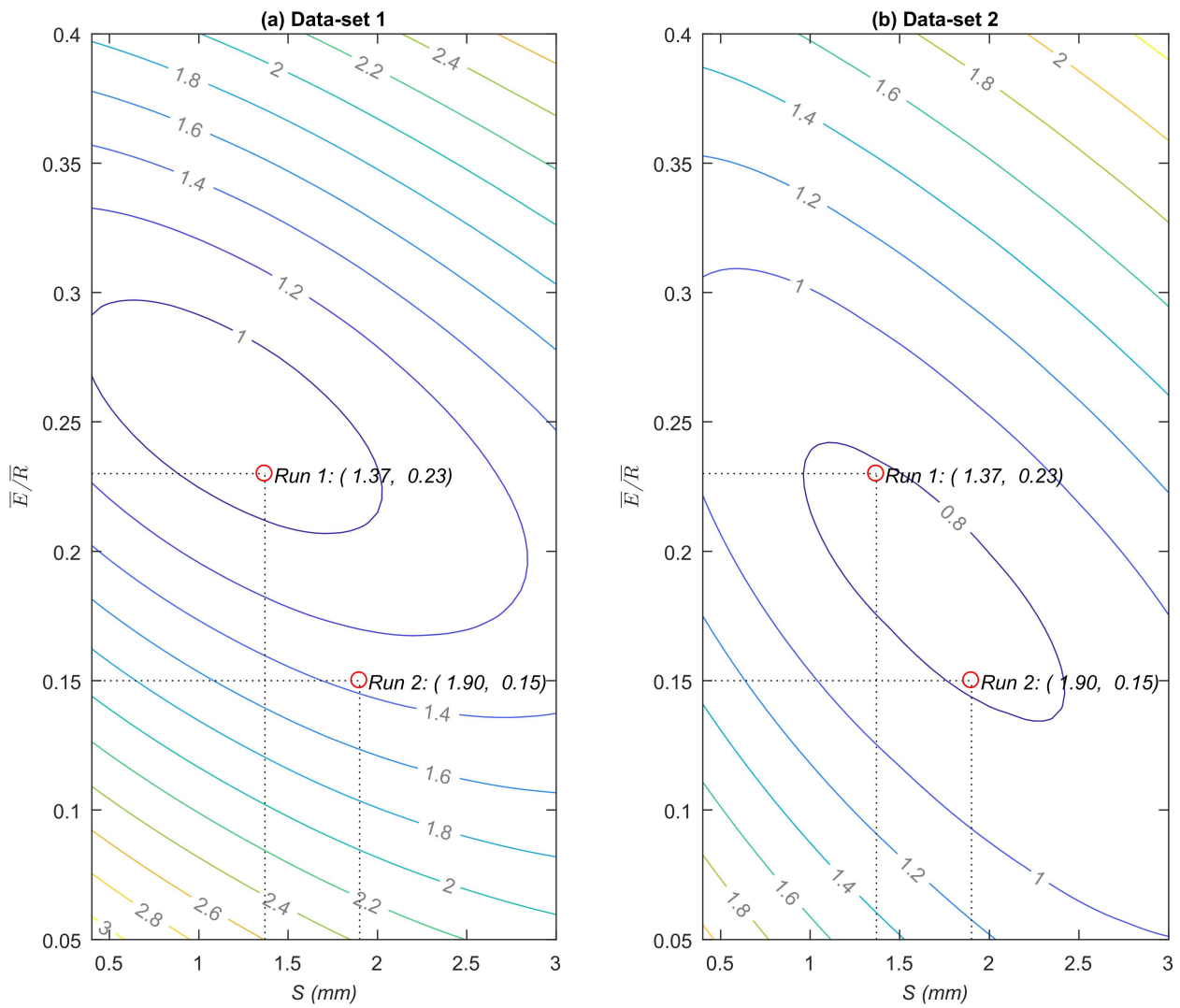

Figure 4.5 Sensitivity analysis of the parametrized original Gash model. Run 1, all parameters derived from the mean method. Run 2, canopy parameters $(S, p)$ derived from IEA and the evaporation rate from the energy balance residual method. Contour lines representing the RMSE for different combinations of the parameters' canopy storage capacity $(S)$ and the ratio $\bar{E} / \bar{R}$. (a) Sensitivity analysis using calibration data-set 1 (19 June to 31 October 2015. (b) Sensitivity analysis using validation data-set 2 (19 June to 31 October 2016). The red circles represent the corresponding parameters used in the model Run 1 and Run 2.

measuring. However, indirect methods are still largely used due to their low cost and simplicity. As an alternative to the multi-event methods, Link et al. (2004) proposed an analysis of individual events. They found that the assumption of a constant $\bar{E} / \bar{R}$ during multiple events was unsustainable, especially during the wetting phase, and might contribute to the underestimation of $S$ in the mean method.

Our findings confirm that $S$ estimated with the mean method is lower (-30\% lower) than $S$ estimated with the IEA. To avoid underestimation caused by incorporating events not preceded by canopy dryness in the regression analysis, we made use of wetness sensors. However, our findings indicate that, despite using the wetness 


\section{The influence of long-term changes in canopy structure on interception loss}

sensors to eliminate certain events, the results remained similar.

The storage capacity at the study site had been reduced compared to in earlier studies, very likely due to the decrease in tree density and LAI over the years. When the stand was 29 years old, the tree density was 992 trees ha ${ }^{-1}$ and LAI was 8 (Table 4.2), while Klaasen et al. (1998) used the principle of microwave attenuation to determine an $S$ of $2.4 \mathrm{~mm}$. At the time of the present study, the tree density as well as the LAI had decreased by about $40 \%$ (Table 4.2). However, the average total storage capacity $\left(S+S_{\mathrm{t}}\right)$ for the study period was reduced much less, only by about $20 \%$, if we considered $S(2.0 \mathrm{~mm})$ derived with the IEA method.

Our estimation of $S$ is comparable with that of other old Douglas fir stands (Table 4.8) and supports the hypothesis that LAI might not be the main predictor of $S$ for Douglas fir forests under temperate climatic conditions. Rutter et al. (1975) reported a total storage capacity of 2.1 ( $S$ equal to $1.2 \mathrm{~mm}$ and $S_{\mathrm{t}}$ of $0.9 \mathrm{~mm}$ ) for Bramshill Forest (UK), a 42-year old Douglas fir stand with similar density but larger LAI (660 trees ha ${ }^{-1}$, LAI = 12). In contrast, Link et al. (2004) applied IEA in a 500-year old mixed Douglas fir and Western hemlock forest (560 trees ha ${ }^{-1}$, LAI = 8.6) located in Washington (USA), and found larger values of $S$ ranging from 2.71 to $4.17 \mathrm{~mm}$. Pypker et al. (2005) in southern-central Washington found significant differences in $S$ for a young (25-year old) Douglas fir forest and an old-growth ( $>450$-year old) mixed Douglas fir and Western hemlock forest, with $S$-young being $1.4 \mathrm{~mm}$ and $S$-old-growth being $3.3 \mathrm{~mm}$. Both forests had a similar LAI (LAI-young $=10.2$; LAI-old-growth $=9.6$ ); however, despite a notable difference in the stem density (young: 2200 tree ha ${ }^{-1}$, old-growth: 441 tree ha $^{-1}$ ), the larger $S$ was found in the old-growth forest. The high $S$ was presumably caused by the changes in species composition (i.e. presence of understory) and the presence of epiphytes, conditions that were not observed at our study site.

Some authors have found that $S$ can be linearly related to the fraction of vegetation cover, which implies an exponential relation between $S$ and LAI (Moors, 2012). However, for closed canopies (LAI > 5) in temperate climate utilizing the fraction of vegetation cover might not be an option (Moors, 2012). The relation between $S$ and the number of trees and their basal area has also been noted to be valid for several sites (Turner and Lambert, 1987; Teklehaimanot et al., 1991). We speculate that for pine species the tree density and basal area imply a direct relation with the amount of bark present in the forest. This amount will increase as the canopy gets older and taller. Recent research in cedar trees in Japan has found high values of $S$, and has shown the bark on the stems providing a major contribution (Iida et al., 2017). We only found a value of $S_{\mathrm{t}}$ of $0.14 \mathrm{~mm}$, but part of the trunks' storage capacity may be hidden in the estimated $S$.

Our results suggest that a long-term decrease in $S$ in a Douglas fir stand does not necessarily imply a decrease in $I$ because the natural process of tree growth as well as forest management practices, such as thinning, all affect other variables that influence the rainfall interception process. Direct extrapolation of $I$ by means of LAI without considering other driving forces (i.e. aerodynamic conductance or change in energy storage) can lead to erroneous approximations of interception loss. 


\subsubsection{Wet-canopy evaporation rate}

Previous investigations have shown that it is possible to estimate sensible heat flux from the sonic anemometer during rainy conditions. Latent heat fluxes derived from the energy balance residual have been shown to be a good approach to derive evaporation rates during rainfall. However, discrepancies with the water budget approach and the Penman-Monteith equation have been reported in several studies (Ringgaard et al., 2014; Schellekens et al., 1999; Holwerda et al., 2012).

The value of $\bar{E}=0.20 \mathrm{~mm} \mathrm{~h}^{-1}$ from the present study was derived from the energy balance residual and is in agreement with the canopy structural changes that occurred in Speulderbos due to natural growth and to management practices causing reduced density. At the Speulderbos study site, when the stand was 29 years old (when canopy height was $18 \mathrm{~m}$ and LAI was $8 \mathrm{~m}^{2} \mathrm{~m}^{-2}$ ), Klaasen et al. (1998) used a combination of eddy correlation and psychrometer profile measurements, and reported a wet-canopy evaporation rate of $0.077 \mathrm{~mm} \mathrm{~h}^{-1}\left(55 \mathrm{~W} \mathrm{~m}^{-2}\right)$. This value was lower than evaporation rates derived at other coniferous forests of the same height and stand configuration and in similar climatic conditions. For example, in the Hafren forest (UK) Stewart (1977) used the Bowen ratio method and found a value of $0.19 \mathrm{~mm} \mathrm{~h}^{-1}$ from daytime measurements, while Gash et al. (1980) used the Penman-Monteith equation and found a similar evaporation rate of 0.13 $\mathrm{mm} \mathrm{h}^{-1}$. Link et al. (2004) reported an average evaporation rate of $0.14 \mathrm{~mm} \mathrm{~h}^{-1}$ using the P-M equation in a 500-year old mixed Douglas fir forest (60 m height) (Table 4.8). In a mixed plantation in western Denmark, Ringgaard et al. (2014) found a wet-canopy evaporation rate of $0.21 \mathrm{~mm} \mathrm{~h}^{-1}$ during the summer season.

In a long-term comparison done by Pypker et al. (2005), similar values of wet evaporation rates were found (young forest: $0.25 \mathrm{~mm} \mathrm{~h}^{-1}$, old-growth forest: 0.21 $\mathrm{mm} \mathrm{h}^{-1}$ ). However, the studied old-growth forest was a mixture of Douglas fir and Western hemlock with understory present, and the young stand had a very high tree density (Table 4.8). Our study site offered the advantage of an unchanged species composition, which allowed us to focus on the long-term effects of the changes in tree density and LAI. Over the past 25 years, tree density and LAI at our study site mainly declined as the result of thinning practices, and to a lesser degree due to natural tree mortality. Moreover, forest height increased by about $16 \mathrm{~m}$. The combination of these changes resulted in an increase in aerodynamic conductance from 0.065 to $0.105 \mathrm{~m} \mathrm{~s}^{-1}$. This change has a direct impact on the exchange of fluxes between the canopy and the atmosphere (Holwerda et al., 2012; Schellekens et al., 1999; Moors, 2012).

$\bar{E}$ (mean) estimated by means of the Penman-Monteith equation was about $35 \%$ lower than with the energy balance residual approach. Several explanations have been proposed in the literature to explain such discrepancies in similar studies. In a comprehensive analysis, van Dijk et al. (2015) pointed out the following possible reasons: (i) underestimation of biomass and heat ground release; (ii) underestimation of aerodynamic conductance; (iii) unaccounted energy advection; (iv) errors in air humidity measurements; (v) mechanical water transport.

In our analysis, we have incorporated estimations of $Q$ and $G$ in our estimate of the available energy $A$ in the $\mathrm{P}-\mathrm{M}$ equation, and therefore disregard the underestimation of biomass and heat ground release as a main cause of the underestimation of the evaporation rate. However, we have to consider the uncertainty in the estimated $Q_{\text {bio. }}$. 
This uncertainty, was calculated as the quadratic sum of the relative errors $\delta m_{\text {bio }}$, $\delta c_{\mathrm{v}}$, and $\delta \Delta T_{\text {bio. }}$. The $\delta m_{\text {bio }}$ is related to the uncertainty of allometric equations ( $18 \%$ for $n=23$, Chave et al., 2004) in combination with the uncertainty in the assumed moisture content (ranging from 44 to $55 \%$ ). The combined uncertainty for $\delta m_{\text {bio }}$ would be about $27 \%$. Regarding $c_{\mathrm{v}}$, the range of values used in studies with similar species is from 2400 to 2928 ( $\mathrm{J} \mathrm{kg}^{-1} \mathrm{~K}^{-1}$ ) (Oliphant et al., 2004), which means a $\delta c_{\mathrm{v}}$ of $22 \% . \Delta T_{\text {bio }}$, here assumed to be equal to $\Delta T_{\text {air }}$ has the largest uncertainty. Based on data presented by Meesters and Vugts (1996) (their Fig. 6) the difference in temperature amplitude between $T_{\text {air }}$ and $T_{\text {bio }}$ would yield to an uncertainty of about $40 \%$. The error propagation of the product of the three variables in Eq. 4.3 yields an uncertainty for $Q_{\text {bio }}$ of $53 \%$.

In the estimation of the aerodynamic conductance, we used $g_{\mathrm{a}, \mathrm{H}}$, calculated using friction velocity derived from the eddy-covariance system, corrected for stability (Paulson, 1970). van Dijk et al. (2015) pointed out that $g_{\mathrm{a}, \mathrm{H}}$ and $g_{\mathrm{a}, \mathrm{M}}$ require the validity of the Monin-Obukhov similarity theory (MOST). MOST assumes that the turbulent flow $\left(u^{*}\right)$ is the only important velocity scale, and that the height above zero-plane of displacement $(z-d)$ and Obukhov length $(L)$ are the only important length scales (van Dijk et al., 2015). In the case of tall canopies, as at the Speulderbos site, the observations are taken in the roughness sub-layer. In this layer, the turbulence is also influenced by length scales related to the surface (i.e. mixing layer instability at the top of the canopy). Corrections for this effect in MOST during rainfall have not been developed and could lead to an underestimation of aerodynamic conductance. Energy advection has also been hypothesized to be a source of unaccounted additional energy (Shuttleworth and Calder, 1979). Although it appeared to occur mainly at maritime sites (Schellekens et al., 1999), Stewart (1977) advocated that the energy does not necessarily need to come from the ocean, and could be supplied by drier and warmer nearby areas. Although vertical energy advection would not invalidate the $\mathrm{P}-\mathrm{M}$ equation, horizontally advected energy occurring below the level of energy balance measurements would not be accounted for, and could influence the underestimation of evaporation rate. Our results suggest that vertical sensible heat flux measured as negative $H$ is the main source of energy that sustains evaporation during rainfall (Table 4.4); however, this situation was not predicted by the $\mathrm{P}-\mathrm{M}$ equation. This could be attributed to errors in air humidity measurements. Wallace and McJannet (2008) estimated that $2 \%$ overestimation in RH already leads to an underestimation of $E_{\mathrm{PM}}$ of $36 \%$. This situation may occur in our case as the accuracy of our RH sensor (CS215, Campbell Sci. Inc.) during wet conditions $(>90 \% \mathrm{RH})$ is low $( \pm 4 \%)$. Likewise, enhanced evaporation of rain droplets splashed from the tree canopy has been mentioned as a possible mechanism allowing high interception losses (Murakami, 2006), but given the low rainfall intensities prevailing in the study area, this is not likely to be important. 
Table 4.8 Summary of canopy properties and interception parameters for Douglas fir forests.

\begin{tabular}{|c|c|c|c|c|c|c|c|c|}
\hline Location & $\begin{array}{l}\text { Age } \\
\text { (year) }\end{array}$ & $\begin{array}{l}\text { Height } \\
\text { (m) }\end{array}$ & $\begin{array}{l}\text { Density } \\
\left(\text { tree ha }^{-1}\right)\end{array}$ & $\begin{array}{l}\text { LAI } \\
\left(\mathrm{m}^{2} \mathrm{~m}^{-2}\right)\end{array}$ & $\begin{array}{l}I \\
(\%)\end{array}$ & $\begin{array}{l}S \\
(\mathrm{~mm})\end{array}$ & $\begin{array}{l}E \\
\left(\mathrm{~mm} \mathrm{~h}^{-1}\right)\end{array}$ & Reference \\
\hline US (north-western Pacific) ${ }^{a}$ & 25 & 20 & 2200 & 10 & 21 & 1.3 & 0.25 & Pypker et al. (2005) \\
\hline Netherlands & 29 & 18 & 992 & $8^{b}$ & 38 & 2.4 & 0.077 & Klaassen et al. (1998) \\
\hline UK & 42 & 24 & 660 & 12 & 39 & 2.1 & NA & Rutter et al. (1975) \\
\hline Netherlands & 55 & 34 & 570 & 4.5 & 34 & 1.7 & 0.20 & This study \\
\hline Belgium & 80 & 41 & 145 & 4.2 & 30 & $\mathrm{NA}^{c}$ & NA & Soubie et al. (2016) \\
\hline US (north-western Pacific) ${ }^{a}$ & $>450$ & 60 & 560 & 8.6 & 24 & $2.7-4.2$ & 0.14 & Link et al. (2004) \\
\hline US (north-western Pacific) ${ }^{a}$ & $>450$ & 39 & 441 & 9.6 & 24 & 3.32 & 0.21 & Pypker et al. (2005) \\
\hline
\end{tabular}

${ }^{a}$ Mixed Douglas fir and Western hemlock

${ }^{b}$ Klaasen et al. (1998) reported an LAI measured by the destructive method, but LAI estimated with Li-COR-2000 was $8 \mathrm{~m}^{2} \mathrm{~m}^{-2}$ ${ }^{c} \mathrm{NA}=$ not available. 


\subsubsection{Rainfall interception}

The interception loss derived for the two consecutive growing seasons of 2015 and 2016 was 37 and $39 \%$ of gross rainfall $(P G)$, respectively. These values are in agreement with other similar studies (Table 4.8). For similar climatic conditions, Rutter et al. (1971) investigated a Douglas fir stand of similar age and stem density in Bramshill Forest (UK) and found an I of 39\% of PG. Soubie et al. (2016) found a value for $I$ of $30 \%$ in a Douglas fir stand in Belgium, which is lower than the value found in the current study and may be attributed to the difference in stem density $\left(145\right.$ tree ha $\left.^{-1}\right)$ since LAI was similar (LAI = 4.2). In a comparison between mixed young and old Douglas fir stands in the north-western Pacific (Washington, US), Pypker et al. (2005) reported similar values of $I$, namely 21 and $24 \%$, respectively. They attributed the slightly larger $I$ in the old stand to the higher $S$ which was also linked to the change in species composition and to the presence of epiphytes.

The other interesting finding in the study by Pypker et al. (2005) is that $\bar{E} / \bar{R}$ was similar for both stands (i.e. young and old). Because the older stand was taller, the aerodynamic conductance may have been larger, with larger expected evaporative rates as a consequence (Teklehaimanot et al., 1991). In contrast, and considering that $\bar{R}$ was not variable (the two stands were close to each other), the evaporative fluxes from the wet canopy were similar. Pypker et al. (2005) observed that the variable species composition at their study site (i.e. Douglas fir mixed with Western hemlocks) increased the gap size and influence on $g_{\mathrm{a}}$. They explained that in this particular situation the use of the average Douglas fir height was likely inappropriate for calculating $d$ and $z_{0}$ and hence $\bar{E} / \bar{R}$.

In the case of Speulderbos at a younger stage, the larger stem density and higher LAI meant a larger $S$ (Klaasen et al., 1998), while, at an older stage (2015-2016), the $\bar{E} / \bar{R}$ was larger mainly as an effect of a larger $g_{\mathrm{a}}$, due to the larger canopy height in combination with lower tree density (Teklehaimanot et al., 1991).

The original version of the Gash (1979) analytical model successfully predicted $I$ for the calibration and validation data sets (Table 4.6). Several studies have demonstrated the validity of the Gash model in temperate coniferous forests (Muzylo et al., 2009)

The performance of the Gash model was as good as that of some more sophisticated models applied in earlier studies at the same site (i.e. Bouten et al., 1996). The difference between observed and predicted values of $I$ was lower than in previous applications of the Gash model in similar climatic conditions (Lankreijer et al., 1999). The model overestimated the total $I$ for all parametrizations (Table 4.6). During the calibration, the relative error of total $I$ was lower than $8 \%$, and for the validation phase, it was lower than $2 \%$.

We used the RMSE as a criterion to evaluate the sensitivity of the model to the two main parameters in the Gash model, $S$ and $\bar{E} / \bar{R}$, considering that the other independently derived parameters have less influence on the model and can be kept fixed. We observed that for calibration (Fig. 4.5a) and validation (Fig. 4.5b) certain combinations of $S$ and $\bar{E} / \bar{R}$ yield an almost equally low RMSE. Such combinations along the major axis of the inner ellipse that encompasses the optimal solution represent the above-mentioned functional equivalence between $S$ and $\bar{E} / \bar{R}$. For instance, in Fig. 4.5b, parametrization for Run 1 presents a higher $\bar{E} / \bar{R}$ (and lower $S$ ) than the one set for Run 2, with a similar RMSE of below $0.8 \mathrm{~mm}$. This confirms 
that it is necessary to reduce the uncertainty in one of the parameters ( $S$ or $\bar{E}$ ) by independent measurements, before optimizing the second one (i.e. Gash et al., 1980; Ringgaard et al., 2014). The independent estimations of $S$ and $\bar{E}$ by means of the IEA and the energy balance residual give us the confidence to select the parametrization of Run 2 as the most realistic in the case of Speulderbos.

\subsubsection{Conclusion}

Rainfall interception loss $(I)$ was quantified and modelled for a mature Douglas fir stand (ca. 55 years old) in the centre of the Netherlands for two growing seasons in 2015 and 2016. Over the study period, the interception loss was $38 \%$ of gross precipitation. This value was similar to the value reported for the same stand when the forest was 29 years old, indicating the changes in forest structure may not always result in changes in interception loss. Tree density as well as LAI were reduced by about $40 \%$ in comparison with the former study by Klaassen et al. (1998). However, the change in canopy storage capacity $(S)$ was much less (a reduction of about 20 $\%$ ). Canopy storage capacity remained relatively stable largely due to the increase in the total biomass, and more specifically in stem bark surface. The reduction in stem density and the growth of canopy height resulted in a larger surface roughness and in consequence enhanced the evaporation rate during rainfall.

The main sources of energy supply that sustain evaporation of intercepted rainfall were net radiation ( $35 \%)$, sensible heat flux (45\%), and change in energy stored in air and canopy biomass (15\%). Downward sensible heat fluxes estimated by means of the eddy-covariance technique were larger than those predicted by the $\mathrm{P}-\mathrm{M}$ equation, possibly due to inaccuracies in the measurement of the relative humidity in the air.

The Gash model was able to simulate I reasonably well, with relative errors of less than $10 \%$. A sensitivity analysis of interception losses simulated with the Gash model shows that the presently higher $\bar{E} / \bar{R}$ can indeed compensate for the lower $S$, confirming the parameter equifinality effect.

Our results confirm that even after a reduction in tree densities old growth stands can maintain similarly high rates of interception. This finding will be useful to improve long-term model predictions that involve structural changes or planned management practices in forested ecosystems. 



\section{Modelling rainfall interception loss with SCOPE}

This chapter is based on: Cisneros Vaca, C., van der Tol, C., 2018. Modelling rainfall interception loss with SCOPE. Under review. Agricultural and Forest Meteorology 


\begin{abstract}
The evaporation of intercepted rainwater by forests is a significant contribution to both the water and energy budget of the Earth. A number of physically based models for rainfall interception have been developed and applied at a plot scale, but the effects of canopy structure has often been represented by simple empirical parameters. The consideration of canopy structure in rainfall interception models is required for spatially resolved and spatially representative interception estimates. In the present study, the integrated radiative transfer and energy balance model SCOPE (Soil Canopy Observation, Photochemistry and Energy fluxes) (van der Tol et al., 2009), originally developed for remote sensing applications, was extended with a module for the interception, storage and dripping of precipitation. The interception of water was modelled in analogy to the interception of light. The model was validated against Eddy-covariance fluxes, throughfall and canopy wetness data of a mature Douglas-fir stand in the Netherlands during the summer of 2015. Our results showed modelled time series of throughfall were in good agreement with the measurements. The Nash-Sutcliffe efficiency coefficient (NSE) was 0.75. The model was also able to simulate large downward sensible heat fluxes predominant during wet canopy conditions and night time dew formation. The timing of canopy drying was longer than data of wetness sensors installed in the canopy foliage suggest, probably because of overestimation in the canopy water storage capacity. Interception loss was underestimated by $\sim 6 \%$ which suggests that water and energy stored in the trunk biomass needs to be incorporated into the energy and water balance modules in SCOPE. The coupled radiation, energy and water budget in the model has potential for remote sensing estimates of rainfall interception and wet canopy evaporation at larger scales.
\end{abstract}

\title{
5.1 Introduction
}

Forested areas play an important role in regulating the hydrological cycle, mainly due to their capacity to intercept, store and evaporate precipitation. Rainfall interception loss is the fraction of rainwater that is temporally stored in the canopy and subsequently evaporated, thus returning to the atmosphere. The interception loss is a large component of the water budget. Research on rainfall interception loss in different forest types has shown that it represents around $10-45 \%$ of gross rainfall $(P G)$ (Rutter et al., 1975; Gash et al., 1980; Crockford and Richardson, 2000; Carlyle-Moses and Gash, 2011). In addition, the variability of rainfall interception loss is influenced by other factors as rainfall characteristics and meteorological conditions that control evaporative fluxes during and after rainfall events (Rutter and Morton, 1977; Brutsaert, 2005).

The importance of rainfall interception loss has led to the development of a variety of models (Muzylo et al., 2009), most of them applied at plot scales. Those models vary from simple empirical models (Horton, 1919; Helvey and Patric, 1965), to probabilistic (Calder, 1986) to physically based models (Gash, 1979; Rutter et al., 1971). Muzylo et al. (2009) found that the most commonly used models for rainfall interception loss are the original and sparse Gash model (Gash, 1979; Gash et al., 1995) and the original and sparse Rutter model (Rutter et al., 1971; Valente et al., 1997). These two models, expressed in the form of differential equation (Rutter) 
or the analytical form (Gash) are based on a running balance in time between gross rainfall, the rate of change in water storage inside the canopy, evaporation, throughfall, and stemflow. Both models have been used across the globe in different forest ecosystems and presented satisfactory results (Muzylo et al., 2009).

A limitation of these models is that they require some empirical parameters that lack a physically based link with canopy structure. For a better understanding of the dependence of rainfall interception on canopy structure, forest type, and tree density, it is necessary to establish this link.

Several models have advanced in this direction by linking canopy structure with the physical nature of the interception loss by including a multilayer approach (i.e. Sellers and Lockwood, 1981; Liu, 1988; Watanabe and Mizutani, 1996). Sellers and Lockwood (1981) numerate the main advantages of a multilayer modelling approach as i) the leaf/needle drainage and the distribution of rainwater within the canopy are better described, ii) the capability of simulate change in location of heat and vapour is improved (sink/sources), iii) the canopy energy balance improves because of the differentiation of dry and wet canopy elements. Sellers and Lockwood (1981) adapted Rutter's water balance model into a multilayer model and concluded that it became more realistic. Liu (1988) proposed a theoretical model, different from the classical approaches, that resolves equations for infinitely thin layers and that includes the shading effects between branches and leaves. Similarly, Watanabe and Mizutani (1996) developed and validated a 40-layer canopy model that calculates interception loss and transpiration loss based on a leaf energy budget equation. These approaches have not been frequently used because are demanding regarding data and parametrization. However, nowadays data availability has mostly improved, and technologies as remote sensing, flux tower networks, reliable and open access meteorological data (high temporal resolution), allow us to investigate new approaches that include the detailed process such as the vertical and the spatial variability of interception loss.

Published methods for global estimates of interception loss from remote sensing data do not use these layered models, but they are based on the original or sparse Gash or Rutter models. For instance, Miralles et al. (2010) were the first to extend the revised version of Gash analytical model (Valente et al., 1997) to a global scale. Their model is driven by remote sensing data of precipitation, lighting frequency (as a proxy of rainfall intensity), and canopy fraction. However, not all Miralles' model parameters were derived from satellite data, some important parameters as canopy storage capacity and mean evaporation rate were set as averages values from the literature. Similarly, at the basin scale, Vegas Galdos et al. (2012), and Cui and Jia (2014) adapted Rutter and Gash type models respectively to remote sensing applications. Vegas Galdos et al. (2012) parametrized a simplified version of the original Rutter model (at daily temporal scale), combining meteorological data with Moderate Resolution Imaging Spectroradiometer (MODIS) products (normal derived vegetation index: NDVI, leaf area index: LAI) to map interception loss. Evaporation of a wet canopy is calculated using Rutter's approach (Rutter et al., 1971) with the Penman-Monteith (PM) equation and surface resistance set to zero. They used leaf area index (LAI) as a predictor of canopy storage capacity.

Similarly, Cui and Jia (2014) followed the sparse version of Gash model (Valente et al., 1997) to implement a remote sensing model for rainfall interception loss. They used a similar proxy to determine storage capacity, notably the vegetation area index 
(VAI). Evaporation was also calculated using the PM equation, but using fractional vegetation cover (FVC) as a proxy to the canopy cover parameter of the Gash sparse model.

Thus, the state-of-the-art for spatially distributed estimates of rainfall interception is to use spectral indices of vegetation reflectance in lumped rainfall interception models. Improving these methods, it is necessary to develop models that (i) describe a physically based link between canopy structure and rainfall interception, and (ii) can be fed with remote sensing data.

This paper addresses the first need and provides some ideas for the second. The central idea is to develop an internally consistent model by combining rainfall interception with light interception via a radiative transfer model and linking the water budget of the vegetation with a canopy energy budget model. We assumed that such a model might be more realistic in simulating both the process of wetting of the canopy during rainfall and the canopy drying process after rains.

For this purpose, we extended the 'Soil-Canopy-Observation of Photosynthesis and Energy fluxes (SCOPE) model (van der Tol et al., 2009) with a rainfall interception and wet canopy evaporation module. SCOPE couples radiative transfer in the optical and thermal domain with leaf photosynthesis and gas exchange and turbulent heat fluxes. SCOPE produces vertical within-canopy heat fluxes, aerodynamic resistance, and hyperspectral outgoing radiances as output. The performance of SCOPE to estimate turbulent fluxes from different 'dry' canopies has been tested (Timmermans et al., 2013). The implementation of evaporation from a partially wet canopy required only minor modification of the model, as presented in this paper. We evaluated several features of the model using data collected from a mature Douglas-fir plantation located in the centre of the Netherlands. The objectives of this study were: i) To prepare the SCOPE model for remote sensing based application of rainfall interception, by incorporating a water budget routine that includes the rainfall interception loss. ii) To validate the water balance routine against energy and water fluxes, canopy wetness and sap flux density in a well-instrumented forest stand. iii) To study the effect of age-related changes in vegetation height and density, on the processes of interception and evaporation, using model simulation.

\subsection{Materials and Methods}

\subsubsection{The water budget model}

The essence of our approach was to extend the radiation budget and the energy budget with a foliage water budget. The canopy architecture as represented in SCOPE model was used for this purpose. The water budget of the leaves or needles (1) is written as:

$$
C_{\mathrm{l}}(t+\Delta t)=C_{\mathrm{l}}(t)+\left(I_{\mathrm{g}}(t)-D_{\mathrm{l}}(t)-E_{\mathrm{l}}(t)\right) \Delta t
$$

Where $C_{1}$ is the water storage on the leaves (depth per unit LAI), $I_{\mathrm{g}}$ is gross interception, $D_{1}$ is drip and $E_{1}$ evaporation of intercepted water (depth per unit LAI per unit of time). This water budget is resolved for leaf layers as well as leaf orientations (zenith and azimuth angles). Here we use $I_{\mathrm{g}}$ to describe the process 
of rainwater captured in the canopy foliage. We will use the symbol $I_{\mathrm{n}}$ to refer to interception loss, denoted as: $I_{\mathrm{n}}=\int_{0}^{t} E_{1} d t$.

In the following, equations for the components of the water balance are derived.

The canopy is assumed to be a homogeneous structure in the horizontal direction. Therefore it is a 1-D (vertical) representation. For numerical calculations, it is defined by 60 elementary layers of equal optical depth (or LAI). Numerically, 13 discrete leaf (or needle) inclinations $\left(\theta_{1}\right)$ are used in SCOPE, and the uniform leaf azimuth $\left(\varphi_{1}\right)$ distribution is also discretized to 36 angles of $5,15, \ldots, 355^{\circ}$ relative to the solar azimuth. In the new water budget module, each leaf is considered as an individual shallow reservoir where water storage increases by interception of direct rainfall, drainage from foliage located above and condensation, while it decreases by evaporation and drainage as in Eq. 5.1. Because a separate water budget is calculated for leaf layers and leaf orientations, drip can occur before the canopy is completely saturated. Drip from a partially wet canopy appears if any leaf class reaches the saturation. This is different from lumped models. Lumped models treat the canopy as a whole and drip only occurs after saturation of the whole canopy. The maximum storage capacity per leaf area used in our model, $S_{\max }$, is therefore conceptually different from the maximum storage capacity traditionally used in, for example, the Rutter model, which is a canopy effective storage capacity.

The fraction of $P G$ going directly through the canopy without interaction with the foliage elements is known as 'free' or 'primary' throughfall $\left(T F_{\mathrm{p}}\right)$. Primary throughfall is calculated by using the probability of the foliage layers and soil being observed through direct line-of-sight by an observer above the canopy. An analogy to Beer's law describes the probability for leaves (needles) in the layer $j$ (i.e., $j$ from 1 to 60 ) or the soil (i.e., $j=61$ ) as:

$$
P_{\mathrm{p}}(j)=\exp (-\kappa \Delta L j)
$$

Where $\kappa$ is the extinction coefficient in the zenith direction of incident rainfall, $\Delta L$ is leaf area index per layer $(L / 60)$. The formulation of $P_{\mathrm{p}}$ is identical to the formulation of the existing SCOPE state variable $P_{\mathrm{o}}$, which is the gap fraction in observation direction. $P_{\mathrm{p}}$ hereinafter will be the gap fraction in the zenith direction of incident rainfall.

The extinction coefficient $\kappa$ is a function of the leaf or needle inclination distribution and the precipitation incident angle. In this study, we used vertical rainfall, but the concept can be applied to any inclination angle of incident rainfall.

The primary (free) throughfall equation is denoted as:

$$
T F_{\mathrm{p}}=P_{\mathrm{p}}(61) P G
$$

The remaining part of $P G$, notably $P G-T F_{\mathrm{p}}$, is intercepted by the canopy $\left(P G_{\mathrm{I}}\right)$ :

$$
P G_{\mathrm{I}}=P G-T F_{\mathrm{p}}=\left(1-P_{\mathrm{p}}(61)\right) P G
$$


The intercepted precipitation is distributed over the canopy layers and over the leaf area $L\left(I_{\mathrm{g}}\right)$ :

$$
I_{\mathrm{g}}(j)=x_{\mathrm{P}}(j) P G_{I}
$$

Where $x_{\mathrm{P}}$ quantifies the portion of the intercepted rainfall arriving at layer $j$, per unit of $L$ :

$$
x_{\mathrm{P}}(j)=\frac{P_{\mathrm{p}}(j)}{\sum_{i=1}^{60} P_{\mathrm{p}}(i)} \frac{1}{\Delta L}
$$

By using the canopy mean $P_{\mathrm{p}}$ as: $\overline{P_{\mathrm{p}}}=\sum_{i=1}^{60} P_{\mathrm{p}}(i) / 60$ and $\Delta L=L / 60$ :

$$
x_{\mathrm{P}}(j)=\frac{P_{\mathrm{p}}(j)}{\overline{P_{\mathrm{p}}} L}
$$

The intercepted precipitation is equally distributed over the 468 leaf inclination (leaf zenith and azimuth) classes within a layer in SCOPE. Differentiating these classes is relevant in sunny conditions during the drying period after rainfall, when evaporation rates depend on the exposure of the leaves to sunlight. Dripping occurs when the storage of water on the leaves or needles exceeds the storage capacity, and due to wind-induced friction and movements. The effects of wind on the drip are not included in our model, and we used a constant storage capacity per unit leaf area. The dripping of the canopy layers $(D(j))$ is calculated from the top to the bottom layer. If the stored water in any leaf orientation class is larger than a threshold defined as the maximum storage capacity per leaf area $\left(S_{\max }\right)$, then the excess water drips vertically downward. The drip per layer is calculated as the total drip from all leaf inclination classes, weighted with the probability that these leaf inclination classes occur $\left(P\left(\theta_{1}\right)\right.$ for the zenith angle, and uniform for the 36 leaf azimuth classes). The drip from the top layer $(j=1)$ is:

$$
D(1)=\sum_{\varphi_{1}} \sum_{\theta_{1}} \max \left(0,\left(C(1, \varphi, \theta)-S_{\max }\right)\right) P\left(\theta_{1}\right) / 36
$$

The drip is incident to the lower layers. Part of the drip reaches the soil directly, herein after referred as the 'secondary' throughfall $T F_{\mathrm{s}}$ :

$$
T F_{\mathrm{s}}(j)=P_{\perp}(60-j) D(j)
$$

were $P_{\perp}$ is the gap fraction as defined in Eq 5.2 for the vertical direction. The complementary part, notably $D(j)-T F_{\mathrm{s}}(j)$, is intercepted by the layers $k \in[j+1,60]$ below, and it is distributed over these lower layers as:

$$
x_{\mathrm{D}}(k)=\frac{P_{\perp}(k)}{\sum_{i=1}^{j} P_{\perp}(i)} \frac{1}{\Delta L}
$$


The rainwater intercepted by layer $k$ of drip originating from layer $j$ is:

$$
I_{\mathrm{D}}(k, j)=x_{\mathrm{D}}(k) D(j)
$$

Now the drip from the second layer below the top can be calculated as:

$$
D(2)=\sum_{\varphi_{1}} \sum_{\theta_{1}} \max \left(0,\left(C(2, \varphi, \theta)+I_{\mathrm{D}}(2,1)-S_{\max }\right)\right) P\left(\theta_{1}\right) / 36
$$

And for the following layers:

$$
D(j)=\sum_{\varphi_{1}} \sum_{\theta_{1}} \max \left(0,\left(C(j, \varphi, \theta)+\sum_{i=1}^{j-1} I_{\mathrm{D}}(j, 1)-S_{\max }\right)\right) P\left(\theta_{\mathrm{l}}\right) / 36
$$

The total secondary throughfall is:

$$
T F_{\mathrm{s}, \mathrm{tot}}=\sum_{j=1}^{60} T F_{\mathrm{s}, j}
$$

The total of water stored in the canopy is defined as:

$$
C_{\text {tot }}=\sum_{j=1}^{60} \sum_{\varphi_{1}} \sum_{\theta_{1}} C_{1} P\left(\theta_{1}\right) \frac{1}{36} \frac{1}{60} L
$$

Evaporation is calculated from the vapour gradient between the foliage and the air above the canopy, and the aerodynamic resistance over this path (van der Tol et al., 2009). The vapour gradient not only depends on the atmospheric vapour pressure but also on the skin temperature of the foliage. The skin temperature is calculated using the energy balance module. The energy balance module calculates the fate of net radiation per surface element (leaf and the soil) (van der Tol et al., 2009). For the foliage elements, the energy balance is (for brevity, the index referring to the layer and leaf angles are omitted in these equations):

$$
R_{\mathrm{n}}=H+\lambda E
$$

and for the sunlit and shaded soil:

$$
R_{\mathrm{n}}=H+\lambda E+G
$$

Where $R_{\mathrm{n}}$ is the net radiation, $\lambda E$ is the latent heat flux, $H$ is the sensible heat flux, and $G$ is the change in the soil heat storage, all the terms are expressed in W $\mathrm{m}^{-2}$. Storage of energy in the canopy and energy involved in chemical processes are not included in the balance. Turbulent fluxes $H$ and $\lambda E$ are calculated from the vertical gradients of temperature and humidity for soil or foliage in analogy to 
Ohm's law (van der Tol et al., 2009). Aerodynamic resistance is calculated using the two source model of Wallace and Verhoef (2000). Temperature and humidity are calculated at soil and leaf surfaces, at the in-canopy mixing point and the top of the roughness sub-layer only. Soil heat flux at the surface is calculated by the forcerestore method (Bhumralkar, 1975). The energy balance is closed in an iterative manner by adjusting skin temperatures of leaf and soil, separately for the sunlit and the shaded portion of the soil and the canopy, until radiative and non-radiative fluxes balance. The skin temperatures and the turbulent fluxes are calculated for all leaf angles and layers separately. The air temperature is used as the initial estimate of the skin temperature. In each iteration step, the energy fluxes $(\lambda E, H, G)$ and a new estimation of surface temperature are calculated for each element. Aerodynamic and stomatal resistances are included in the iteration, because atmospheric stability and biochemical process are affected by leaf temperatures. The iteration ends when the energy balance closure is less than the required accuracy for all surface elements (i.e. standard $1 \mathrm{~W} \mathrm{~m}^{-2}$ ). The energy balance routine thus provides 60 values of evaporation (1 per layer) for the shaded fraction of the canopy, and $60 \times 13 \times 36$ values for the sunlit fraction. If there is only diffuse irradiance, then the shaded and sunlit evaporation are equal, but for direct solar irradiance, they differ. In the case of wet leaves $\left(C_{1}>0\right)$, the stomatal resistance is set to zero in the energy balance module, and the calculated evaporation rate is the evaporation of intercepted water $\left(E_{\mathrm{I}}=E\right)$. For dry leaves $\left(C_{1}=0\right)$, the stomatal resistance is calculated as in the original SCOPE model, and the transpiration is calculated $\left(E_{\mathrm{T}}=E\right)$. After each time step, the water budget of the leaf elements is updated according to Eq.5.1.

\subsubsection{Canopy experiment}

\subsubsection{Study area}

The study site is located in the forested area of 'Speulderbos' $\left(52^{\circ} 15^{\prime} 04^{\prime \prime} \mathrm{N}, 05^{\circ}\right.$ $41^{\prime} 25^{\prime \prime} \mathrm{E}$ ), near the settlement of Garderen, the Netherlands (Fig. 2.1). The 2.5 ha evergreen Douglas-fir (Pseudotsuga menziesii) stand was planted with twoyear-old seedlings in 1962. The site has a $47 \mathrm{~m}$ tall scaffolding tower, which supports measurement of a variety of micrometeorological parameters. The climate is classified as temperate-humid. The mean $( \pm$ SD) annual precipitation for the period 2000-2015 was $864( \pm 92) \mathrm{mm}$. July is the wettest month with about 12 $\%$ of the annual rainfall and April the driest month with $4 \%$ of the yearly rainfall. The mean annual temperature was $10.6^{\circ} \mathrm{C}( \pm 0.6)$ with January being the coldest month $\left(3.7 \pm 2{ }^{\circ} \mathrm{C}\right)$ and July the warmest month $\left(18.2 \pm 1.6{ }^{\circ} \mathrm{C}\right)(\mathrm{KNMI}, 2015)$. Canopy height was about $34 \mathrm{~m}$, whereas stem density was 571 trees ha $^{-1}$, and mean diameter at breast height $(\mathrm{DBH})$ was $34.8( \pm 8.9) \mathrm{cm}$. Leaf area index of the plot (estimated with an LI-COR LAI 2000 Plant Canopy Analyser) was $4.5 \mathrm{~m}^{2} \mathrm{~m}^{-2}$ (士 0.38) (Fig. 2.1b). The stand was mono-species, and understory was mostly absent (Fig. 2.1c). We used micro-meteorological data collected in the Speulderbos tower (Table 2.1) to validate the water budget model incorporated in SCOPE. 
Table 5.1 Input parameters in SCOPE used to model energy fluxes time series.

\begin{tabular}{llll}
\hline Paramter & \multicolumn{1}{c}{ Description } & \multicolumn{1}{c}{ Unit } & Value \\
\hline$C_{a b}$ & Chlorophyll AB content & $\mathrm{mg} \mathrm{cm}^{-2}$ & 70 \\
$C_{d m}$ & Dry matter content & $\mathrm{g} \mathrm{cm}^{-2}$ & 0.08 \\
$C_{w}$ & Leaf water equivalent layer & $\mathrm{g} \mathrm{cm}^{-2}$ & 0.02 \\
$V_{c m o}$ & Maximum carboxylation capacity & $\mu \mathrm{mol} \mathrm{m}^{-2}$ & 60 \\
$m$ & Ball-Berry stomatal conductance & - & 7 \\
$L A I$ & Leaf area index & $\mathrm{m} \mathrm{m}^{2} \mathrm{~m}^{-2}$ & 4.5 \\
$h_{\mathrm{c}}$ & Vegetation height & $\mathrm{m}$ & 34 \\
$L I D F a^{a}$ & Leaf inclination distribution parameter & - & 1 \\
$L I D F b$ & Bi-modality of of the leaf inclination distribution & - & 0 \\
$z_{0}$ & Roughness length for momentum of the canopy & $\mathrm{m}$ & 4.2 \\
$d$ & Displacement height & $\mathrm{m}$ & 23 \\
$t t o$ & Observation zenith angle & $\mathrm{deg}$ & 0 \\
\hline
\end{tabular}

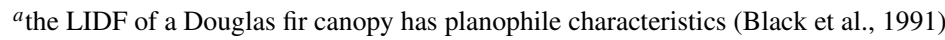

\subsubsection{Turbulent heat fluxes and net radiation}

To test the water budget module incorporated in SCOPE, we ran the model from 29 June 2015 to 2 August 2015. The main parameters used in SCOPE are listed in Table 5.1. We compared the modelled fluxes obtained from SCOPE with the fluxes from the eddy-covariance system. Turbulent heat fluxes, sensible $(H)$ and latent $(\lambda E)$ heat flux, were estimated by the eddy-covariance technique with a sonic anemometer (CSAT3, Campbell Sci. Inc.) and an open path gas analyser (LI7500, LI-COR Biosciences) mounted at $47 \mathrm{~m}$. Thirty-minute turbulent fluxes were processed with the EddyUH software ver. 1.7 (University of Helsinki, https://www.atm. helsinki.fi/Eddy_Covariance/EddyUHsoftware.php). As initial estimates for EddyUH, a displacement height $(d)$ of 0.7 of canopy height $\left(h_{\mathrm{c}}\right)$ (Stull, 2012), and a roughness length $\left(z_{0}\right)$ of $0.06 * h_{\mathrm{c}}$ (Weligepolage et al., 2012) were used. Furthermore, the following corrections were performed: de-spiking, 2D coordinate rotation, cross-wind correction to sonic temperature according to Liu et al. (2001), high frequency spectral corrections according to Moncrieff et al. (1997) and Aubinet et al. (2000), low frequency spectral corrections according to Rannik and Vesala (1999), correction for humidity effect on sonic heat flux according to Schotanus et al. (1983), and WPL correction according to Webb et al. (1980). We disregarded turbulence data with an overall quality flag above 2 in accordance with the Foken et al. (2005) quality flag system.

\subsubsection{Net radiation and soil heat flux}

Similarly to the turbulent heat fluxes, we also compared the SCOPE modelled values of net radiation, $R_{\mathrm{n}}$, to measured values in the study plot. $R_{\mathrm{n}}$ was measured by a four-component net radiometer (model CNR1, Kipp and Zonen) mounted at $35 \mathrm{~m}$ above ground (Table 2.1), and averages were stored at 10-minute intervals. Note that the measured in incoming fluxes were also used as input for SCOPE. 


\subsubsection{Water balance}

Interception loss was estimated using a water balance approach. Throughfall ( $T F$, $\mathrm{mm})$ and stemflow $(S F)$ were collected below the canopy by different sampling strategies that guarantee the spatial representativeness of the measurements, as described below (and in further detail by Cisneros Vaca et al. (2018b)). The measurements do not differentiate between primary and secondary throughfall (Eq. 5.3 and Eq. 5.14), and therefore, the measurements represent the total throughfall by the whole stand. We assumed that $S F$, which is not simulated by the model, is implicitly included in the simulated $T F$. This assumption is not critical because $S F$ appeared to be a minor term in the water budget $T F$ (Cisneros Vaca et al., 2018b).

The total net interception loss $\left(I_{\mathrm{n}}\right)$ by the whole stand, which is gross precipitation less throughfall less stemflow, was calculated from the measurements as:

$$
I_{\mathrm{n}}=P G-T F-S F
$$

Gross rainfall $P G$ was measured in a nearby well-exposed clearing (ca. 250 $\mathrm{m}$ from the centre of the study plot) using two tipping bucket rain gauges (Rain Collector II, Davis Instruments, USA) with a resolution of $0.2 \mathrm{~mm}$ per tip. The orifice of the rain gauge was positioned at $1.5 \mathrm{~m}$ above the ground to avoid groundsplash effects. The automatically recorded data were stored by a HOBO event logger at $1 \mathrm{~min}$ intervals (Onset Computer Corporation, USA). Gross rainfall was also collected at the top of the $47 \mathrm{~m}$ scaffolding tower operated by University of Twente (ITC-UT), using a tipping bucket rain gauge (Onset HOBO-RG3, resolution $0.2 \mathrm{~mm}$ ). The data collected at the top of the tower were only used to fill gaps in the data from the clearing (from 23 July 2015 to 12 August 2015) using a linear regression equation linking $10 \mathrm{~min}$ rainfall totals of the two locations $\left(R^{2}=0.93, n\right.$ $=500$ ). Throughfall measurements were collected by an automated gutter system and validated by an arrangement of manual (roving sampling) funnel-type collectors. The automated gutter system consisted of four stainless steel gutters $(200 \mathrm{~cm} \mathrm{x} 30$ $\mathrm{cm}$ each) randomly located in the plot and connected by pairs to two tipping buckets (V2A UP Umweltanalytische Produkte $\mathrm{GmbH}$ ). The gutters were mounted on a wooden frame, about $60 \mathrm{~cm}$ from the forest floor and at an inclination of $10 \%$ to facilitate drainage to the tipping buckets. Combining two gutters and correcting for the inclination provided a total catchment area of $1.2 \mathrm{~m}^{2}$ yielding $0.084 \mathrm{~mm}$ per tip. The tipping buckets were connected to a data logger (CR23X, Campbell Scientific Ltd.) and tip pulses were recorded at a $1 \mathrm{~min}$ resolution. The gutters and the tubes were cleaned every 7 to 15 days to avoid clogging due to falling litter. Also, TF was measured using a roving arrangement of funnel-type collectors. The manual array of collectors was operated from 17 February 2015 to 02 November 2015. A stratified random sampling approach was used to ensure an even spread of sampling locations (Cisneros Vaca et al., 2018b). Throughfall measurements were used to calibrate the parameter $S_{\max }$ of the water balance model, by repeated simulations in the range of from $2.0 \mathrm{~mm}$ to $5.0 \mathrm{~mm}$, and adopting the simulation with the highest Nash-Sutcliffe efficiency value (NSE). 


\subsubsection{Canopy drying time and evaporative fluxes}

The canopy storage $C$ was evaluated employing measurements of the wetness and the canopy drying time (CDT) with leaf wetness sensors (LWSs) and thermal dissipation probes (TDPs). Two LWSs (Model 237, Campbell Sci. Inc.) were installed at 20 and $26 \mathrm{~m}$ height, in the middle of the living crown. The sensors were placed over the needles in the middle of the branches and tilted about $60^{\circ}$ to avoid rainwater puddling on the electrodes. An LWS consists of a circuit board that emulates the leaf surface, with interlacing gold-plated fingers on it. The LWS estimates foliage wetness by determining the electrical resistance on the surface of the sensor.

Besides, three thermal dissipation probes (TDP) (UP GmbH, Munich, Germany) were installed in different trees. One of the TDP sensors was installed in a tree next to the scaffolding tower, in the same tree where the LWSs were placed, while the others TDPs were set in trees around the tower at a distance not longer than $25 \mathrm{~m}$. The sensors were placed on the northern side of the trunks to avoid sunexposure and they were insulated using a radiation shield to prevent any externally induced heat influence. TDP sensors are widely used to evaluate tree transpiration by measuring xylem sap flux density $\left(J_{p}\right)$ and multiplying by the sapwood area $\left(A_{x}\right)$ (Granier, 1985). It has been demonstrated that sap flux density (SFD) can be used to monitor the canopy drying time, as sap flux is interrupted when the canopy is wet and resumes as the canopy dries up and transpiration starts (Kume et al., 2006, 2008a). Natural thermal gradients (NTG) as measured in the instrumented trunks were always less than $0.2{ }^{\circ} \mathrm{C}$. Temperature differences between the upper and the lower probes were sampled every $30 \mathrm{~s}$, and $10 \mathrm{~min}$ averages were recorded on a data logger (CR23X, Campbell Scientific Ltd.). The recorded temperature differences were converted to sap flux density using the expression proposed by Granier (1985). We used the SFD to qualitatively check the onset of tree transpiration $\left(E_{\mathrm{T}}\right)$ after canopy drying. This approach is limited to rainfall events that ended during daylight hours when transpiration is active.

We evaluated the canopy drying time (CDT), which is defined as the time after the end of a rainfall event when the canopy storage $(C)$ reaches zero. The CDT can be defined for the whole stand, or for individual layers. In this study, we compared the time when LWS indicated completely dry, with the simulated time of depletion of the storage at the corresponding optical depth in the canopy of the sensor, and report the root mean squared error (RMSE). To estimate the RMSE we used the lower sensor located at $20 \mathrm{~m}$ because the upper one could be less reliable due to winds shaking effects that are not considered in the water budget model.

\subsubsection{Numerical simulations}

One of the advantages of the numerical model is the capability to create hypothetical scenarios. We investigated three scenarios with different canopy height and storage capacity, representing the actual history of the forest and a hypothetical future. The three scenarios represented the past of the Speulderbos (SCN1), based on studies carried out when the stand was 29 years old (Klaasen et al., 1998), the present scenario on 2015 (described in the canopy experiment section) (SCN2), and the third scenario, a future scenario, with taller trees but with lower LAI due to decreasing 
Table 5.2 Description of canopy parameters used in the numerical simulations.

\begin{tabular}{ccccc}
\hline Scenario & Age (years) & LAI $\left(\mathrm{m}^{2} \mathrm{~m}^{-2}\right)$ & Canopy height $(\mathrm{m})$ & $S_{\max }(\mathrm{mm})$ \\
\hline SCN1 & 29 & 8 & 18 & 6.8 \\
SCN2 & 55 & 4.5 & 34 & 3.8 \\
SCN3 & 60 & 3 & 37 & 2.5 \\
\hline
\end{tabular}

stand density (SCN3). This third scenario is an extrapolation of the height increase (0.6 $\mathrm{m} \mathrm{y}^{-1}$, Bond et al. (2007)) and density decrease of the last decades. We assumed a decline of $1.5 \mathrm{~m}^{2} \mathrm{~m}^{-2}$ in 5 years for the SCN3. The parameters adopted for the simulations are shown in Table 5.2. In all the scenarios the meteorological conditions as observed between 29 June 2015 and 2 August 2015 in Speulderbos were used. The scenarios enabled us to understand better the changes in the rainfall interception process as forest stand ages, as discussed using actual measurements for this specific forest in a previous study by Cisneros Vaca et al. (2018b).

\subsection{Results}

\subsubsection{Energy fluxes}

In this section, we compared modelled to measured energy fluxes. The results demonstrate the capabilities of the implemented water budget model to determine micro-meteorological features during the rainfall interception process. To compare the estimated energy fluxes, we used the processed 30-minutes fluxes from the eddy covariance system deployed in Speulderbos. The energy balance ratio (EBR) defined as the sum of $H+\lambda E$ divided by $R_{\mathrm{n}}-G$ was 0.98 for the complete period (i.e. wet and dry). However, it is noticeable that during rainfall this value can be biased due to data incompleteness.

Thirty minutes modelled fluxes of net radiation $\left(R_{\mathrm{n}}\right)$, latent heat flux $(\lambda E)$, and sensible heat flux $(H)$ during dry conditions $\left(C_{\text {tot }}=0\right)$ were in good agreement with the measured fluxes at the tower site. Their respective root mean square error (RMSE) were: $18 \mathrm{~W} \mathrm{~m}^{-2}, 62 \mathrm{~W} \mathrm{~m}^{-2}$ and $74 \mathrm{~W} \mathrm{~m}^{-2}$; and bias $-2.7 \%, 1.2 \%$, and $-3.1 \%$. However, for wet $\left(C_{\text {tot }}>0\right)$ periods the RMSEs were higher as: $4.7 \mathrm{~W} \mathrm{~m}^{-2}$, $248 \mathrm{~W} \mathrm{~m}^{-2}$ and $138 \mathrm{~W} \mathrm{~m}^{-2}$; and bias $2.9 \%, 71.9 \%$, and $-4.4 \%$, respectively. It is noticeable that the model performance differed among storms.

Figure 5.1 shows a comparison of modelled versus measured sensible heat flux $(H)$ for two dates on 2 July 2015 and 27 July 2015. On 2 July 2015, rainfall started around 18:00, and the highest rainfall intensity of $11 \mathrm{~mm}(30 \mathrm{~min})^{-1}$ occurred at 21:30 (Fig. 5.1a). Good agreement was found between the diurnal variation of sensible heat flux modelled and measured on the 2 July 2015 (note that strict quality filtering was applied to the measured fluxes), and both the magnitude and sign of $H$ was accurately modelled. The downward $H$ was larger (larger negative values) at the beginning of the rainfall event because the temperature differences between canopy surface and air were more substantial at that time.

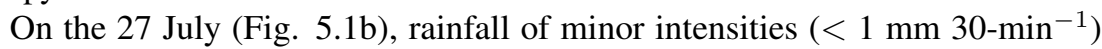
was observed early in the morning, contrasting with high rainfall intensities (16

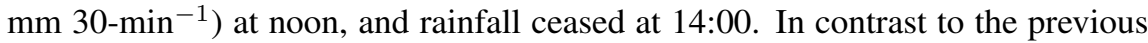


case, there was no agreement between the modelled and observed fluxes. The large downward sensible heat fluxes were not predicted by the model during the early drizzly morning, and the small downward $H$ observed after rainfall diminished, and although the direction was correct, the model overestimated the magnitude of $H$.

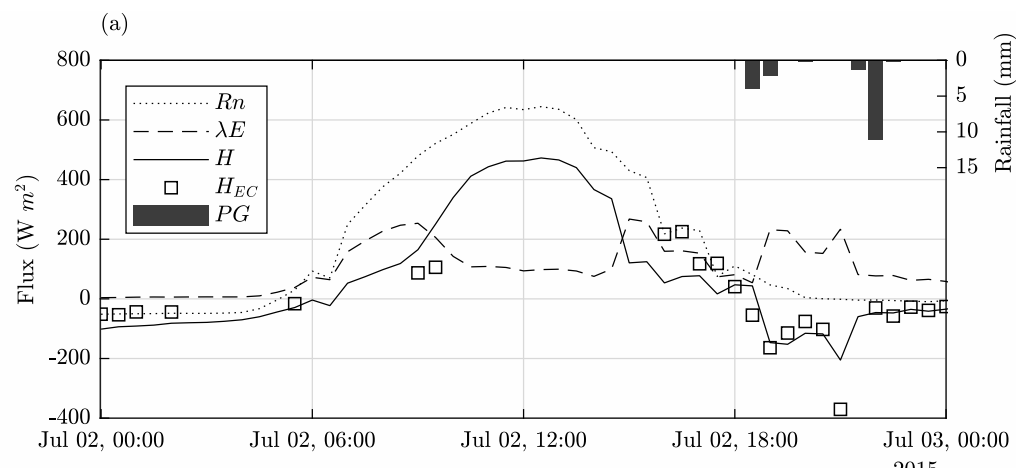

(b)

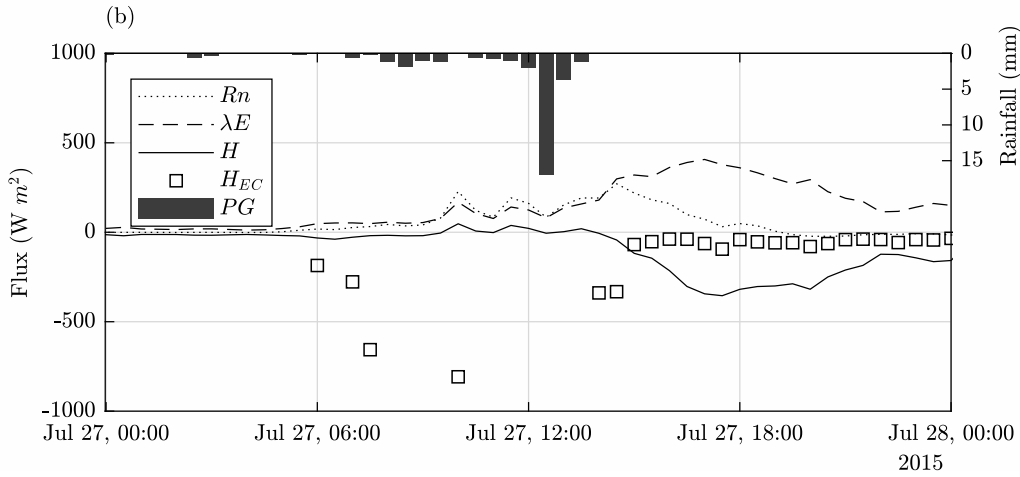

Figure 5.1 Modelled fluxes of net radiation $\left(R_{\mathrm{n}}\right)$, latent heat $(\lambda E)$ and sensible heat $(H)$ for (a) 2 July 2015, and (b) 27 July 2015. Black plotted points ( $\square$ ) denoted estimated values of sensible heat by the eddy covariance technique $\left(H_{E C}\right)$ 
Figure 5.2 Time series of throughfall observed $\left(T F_{\mathrm{Obs}}\right)$ and predicted $\left(T F_{\text {Tot }}\right)$ during the period 2 July to 30 July 2015. 


\subsubsection{Modelled water balance}

From 29 June 2015 (DOY 180) to 2 August 2015 (DOY 214) a total of $150.4 \mathrm{~mm}$ of gross precipitation was measured. Observed throughfall $\left(T F_{\mathrm{Obs}}\right)$ for the same period was $90.4 \mathrm{~mm}\left(I_{\mathrm{n}}\right.$ equal to $40 \%$ of $\left.P G\right)$. Modelled total throughfall $\left(T F_{\text {Mod }}\right)$ was 98.7 $\mathrm{mm}$, resulting in a lower value for $I_{\mathrm{n}}(34 \%$ of $P G)$. The best model performance based on the Nash-Sutcliffe model efficiency (NSE $=0.75$ ) was obtained by using a $S_{\max }$ equal to $3.8 \mathrm{~mm}$. Time series plots of $T F_{\text {Obs }}$ and $T F_{\text {Mod }}$ showed that the model overestimates $T F$ during events with high rainfall intensities (Fig. 5.2). To analyse rainfall interception at event scale, we separated the time series into events $\left(\min \left(C_{1}\right)>0\right)$, separated by periods in which $C_{\text {tot }}=0$. In this way, 11 events were delimited for the modelled period. The respective event based mean (median) of $P G, T F_{\text {Obs }}, T F_{\text {Mod }}$ were 12.9 (8.2) mm, 7.9 (4.9) mm, 8.8 (3.2) mm. At event scale, there was good agreement between $T F$ modelled and observed, $R^{2}=0.97(p<$ 0.01) (Fig. 5.3), but this high correlation is driven mostly by $P G$.

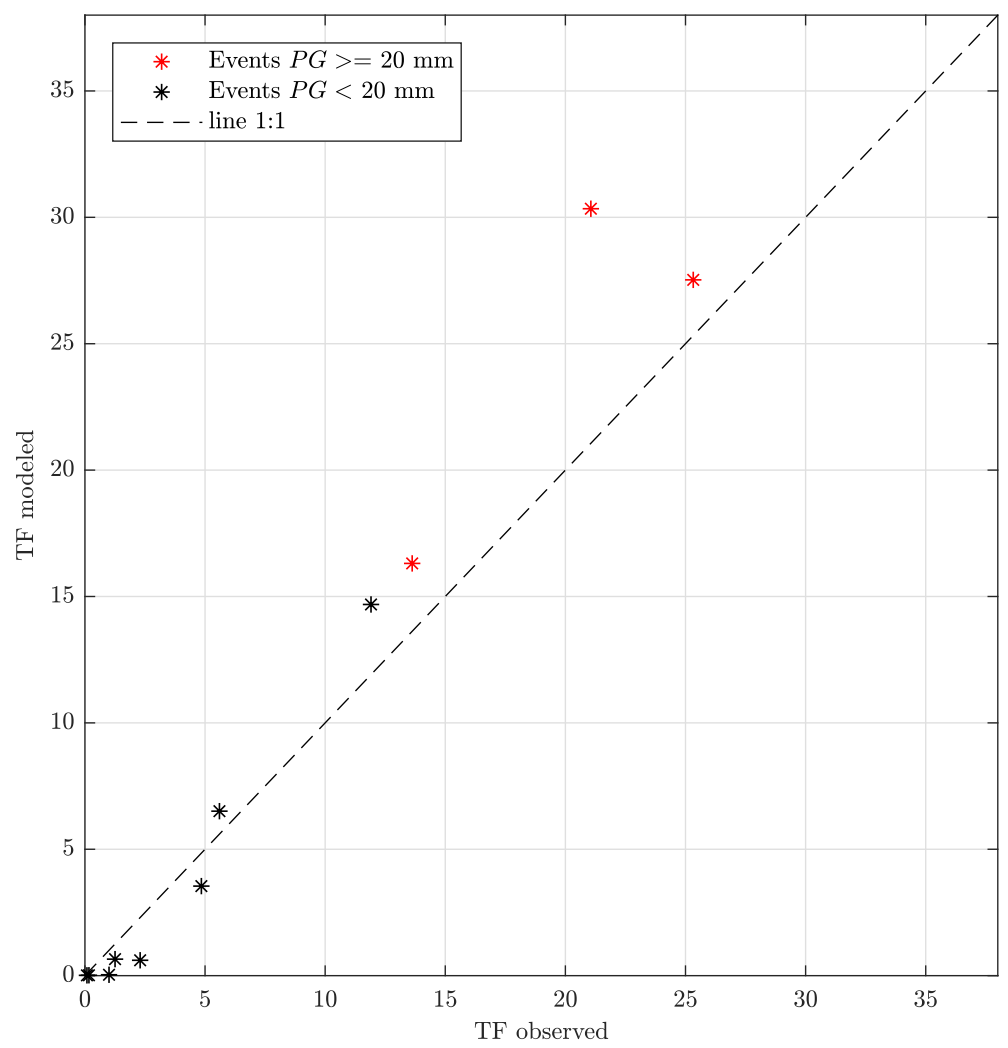

Figure 5.3 Scatter plot of $T F$ observed vs $T F$ modelled per rainfall event.

\subsubsection{Canopy drying time and evaporative fluxes}

In this section, we first illustrate some of the model outputs as evaporation of intercepted water $\left(E_{\mathrm{I}}\right)$, transpiration $\left(E_{\mathrm{T}}\right)$, vertical profiles of turbulent fluxes $(\lambda E$, 
$H)$, leaf temperatures and water storage. Then, we present a validation of the canopy drying time by comparing the modelled water stored in the canopy to drying time according to the LWS. Model outputs during a typical sequence of wetting up and drying are shown for the period from 13 July 2018 to 15 July 2015 (Fig. 5.4). The rainfall in the early morning of 13 July gradually fills up the storage from top to bottom, but it takes until the afternoon before the canopy fully saturates. Evaporation of intercepted water starts at the onset of precipitation, peaks shortly after the end of the rainfall in the afternoon, and diminishes at night. Rainfall during night time causes the canopy to saturate again fully. On the following day, the canopy dries up, and transpiration resumes in the afternoon of 14 July. The drying at the top is more rapid than the drying at the bottom of the canopy, due to the larger amount of energy available at the top (net radiation and negative sensible heat flux). Vertical profiles of the drying process are illustrated in Fig. 5.5. During the night of 15 July, the water storage in the upper layers of the canopy increases slightly from zero in the absence of precipitation. This effect is dew formation (negative $\lambda E$ ) associated with the radiative cooling.

(a)

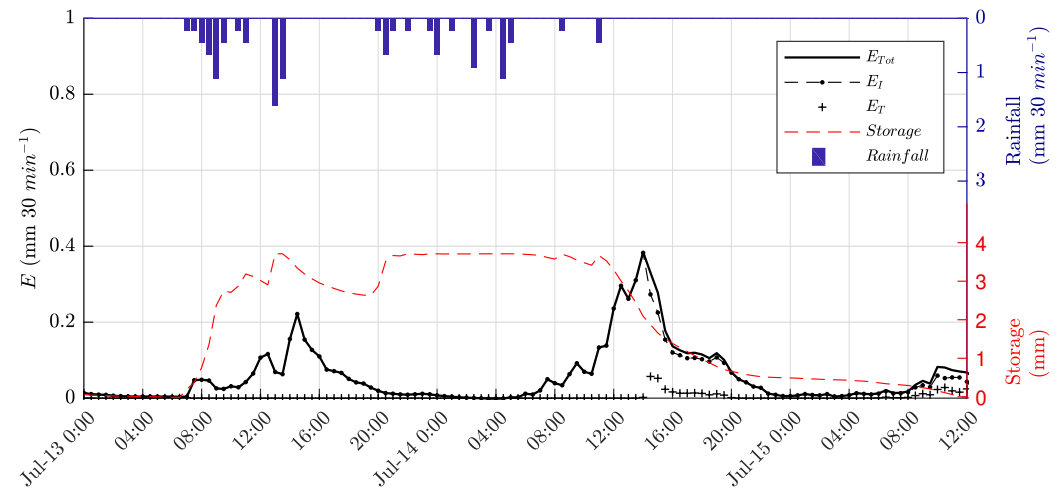

(b)

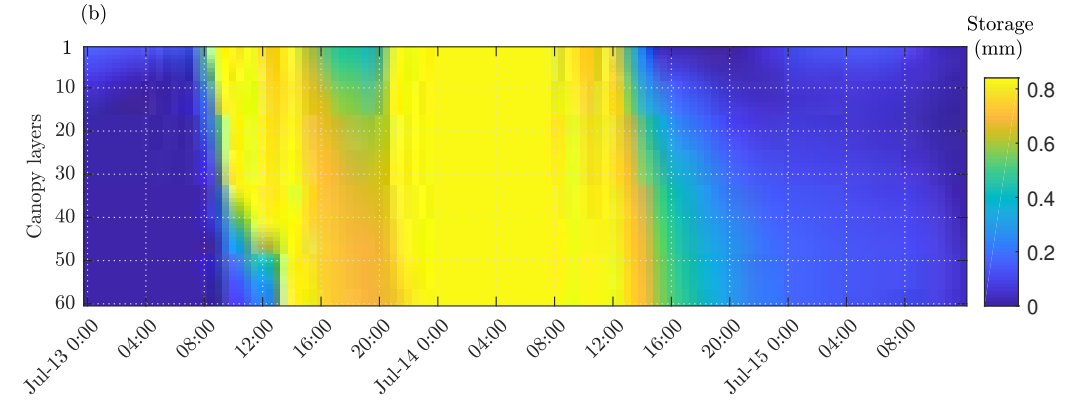

Figure 5.4 Temporal distribution of: (a) Estimated evaporative fluxes of intercepted precipitation $\left(E_{\mathrm{I}}\right)$, transpiration $\left(E_{\mathrm{T}}\right)$, total Evapotranspiration $\left(E_{\mathrm{Tot}}\right)$, rainwater storage $(S)$ and (b) rainwater stored in the vertical profile (60 layers) for the period 13 July 2018 to 15 July 2015.

We also plotted simulated leaf temperatures profiles averaged per layer (Fig. 5.5b) and turbulent heat fluxes (Fig. 5.6) for 14 July 2015 from 12:00 to 24:00H. The upper part of the canopy heats up by intercepted radiation (12:00 to 16:00), and 
foliage temperatures increase with height in the canopy. The temperature profile gradually reverses from an hour before sunset (20:00), to a completely inverted profile at night. During the night, the foliage temperature drops below the air temperature, and this causes negative (downward) sensible heat fluxes (Fig. 5.6) and high aerodynamic resistance.

(a)

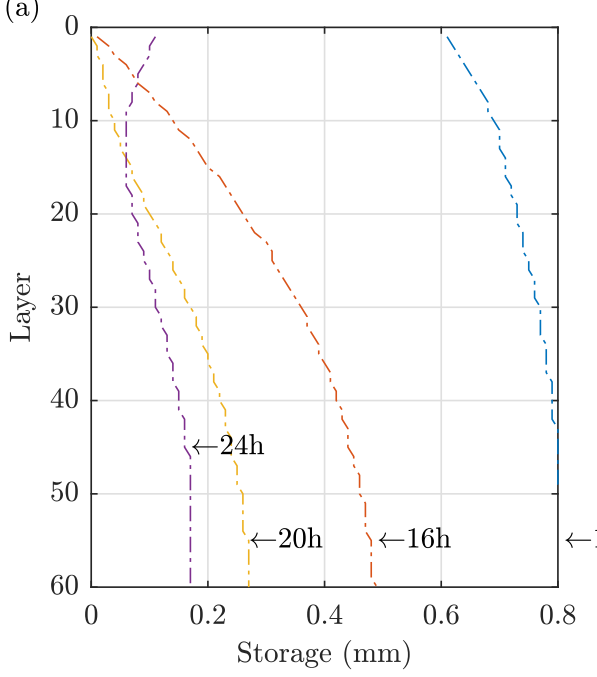

(b)

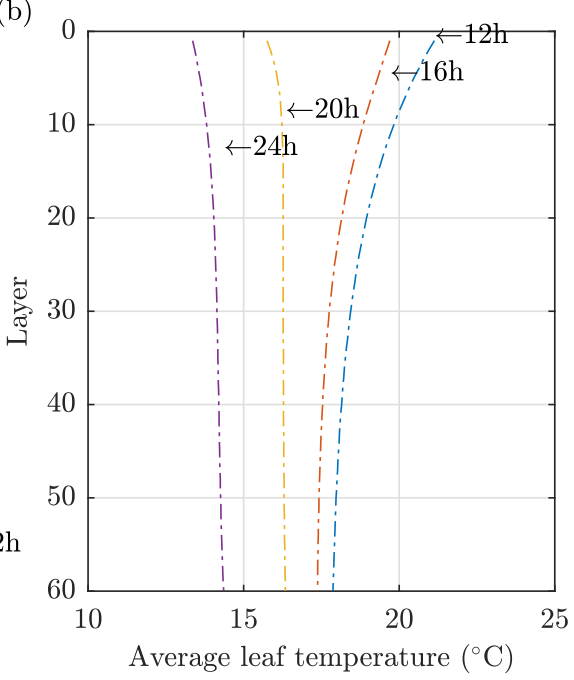

Figure 5.5 Vertical profiles of (a) rainwater storage and (b) leaf temperature (average per layer) on 14 July 2015 (DOY 195, from 12h to $24 \mathrm{~h}$ ).
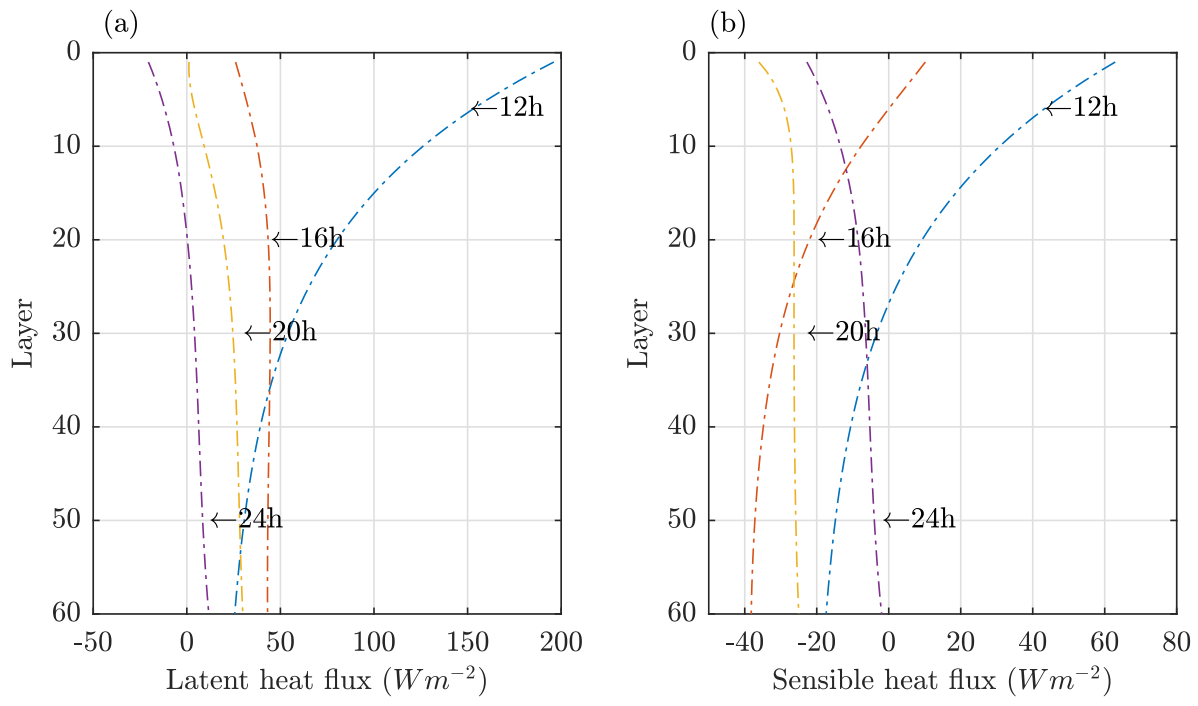

Figure 5.6 Vertical profiles (average per layers) of (a) latent heat flux $(\lambda E)$, (b) sensible heat flux $(H)$ during the canopy drying phase on 14 July 2015 (from $12 \mathrm{~h}$ to 24h). 
Consistent with the net radiation, the simulated latent heat fluxes were more significant in the upper layers during the drying phase on 14 July 2018 at 12:00, and they gradually decreased with depth from $200 \mathrm{~W} \mathrm{~m}^{-2}$ to $25 \mathrm{~W} \mathrm{~m}^{-2}$ (Fig 5.6a). At 16:00, the trend was inverted: Latent heat fluxes of upper layers were $\sim 20 \mathrm{~W} \mathrm{~m}^{-2}$ in the upper layers and $\sim 40 \mathrm{~W} \mathrm{~m}^{-2}$ in the lower ones, despite the higher net radiation at the top (Fig 5.6a). The smaller $\lambda E$ at the top was because the top layers were already dry (Fig. 5.5). Approaching sunset (20:00), both $H$ and $\lambda E$ were close to zero, with $H$ negative and $\lambda E$ positive. Dew formation occurs at midnight in the upper third of the canopy.

The measurements with the leaf water sensors (LWS) confirmed the presence of dew in clear nights. For example, when the model simulated dew formation on 6 of July 2015, the LWSs in the canopy indeed recorded wetness (on a unit-less scale from wet to dry), first the highest sensor in the canopy $(26 \mathrm{~m})$ at midnight, followed by the lower sensor $(20 \mathrm{~m})$ at 2:30. Shortly after sunrise, both LWSs indicate the canopy was dry again. This example confirms that the storage due to dew quickly depletes due to early morning wet canopy evaporation (Figure 5.7).
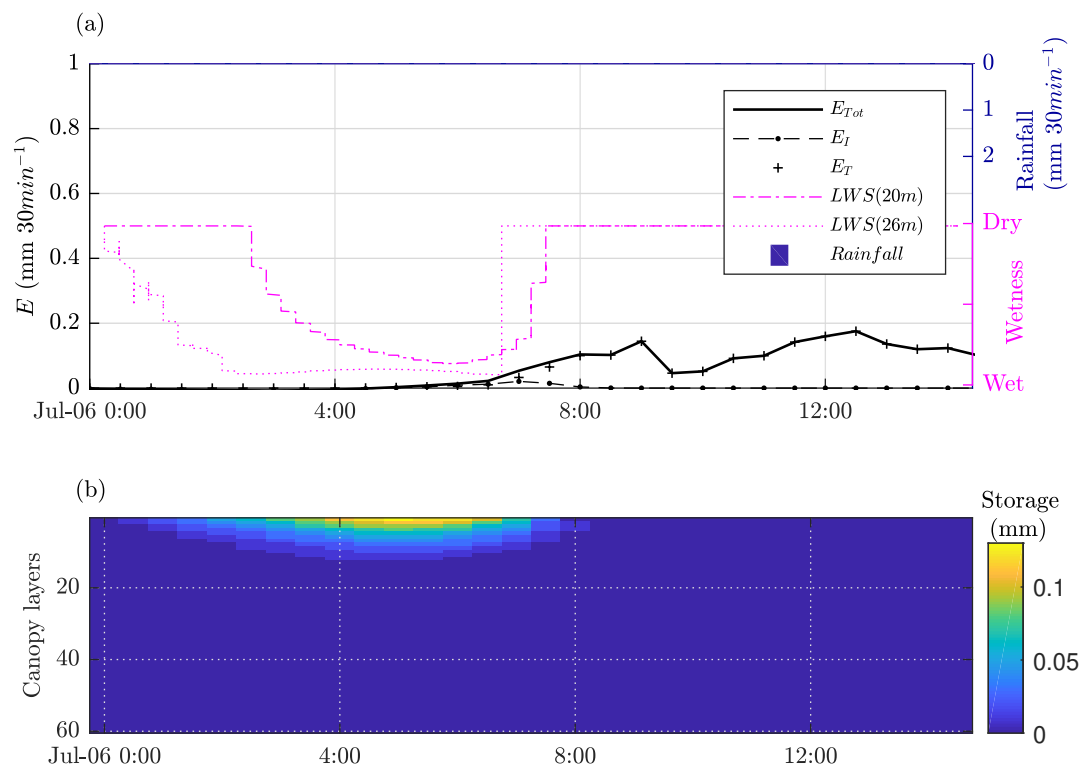

Figure 5.7 Dew formation (a) detected by 2 leaf wetness sensors (LWS) located at $20 \mathrm{~m}$ and $26 \mathrm{~m}$ height within the canopy during 6th of July 2015 (DOY 187), no rain was observed during that day. (b) Dew formation modelled at the top layers of the canopy.

Data collected by the TDPs sensors were further used to evaluate the ability of the model to simulate the drying process. Fig. 5.8 shows the sap flux density (SFD, $\mathrm{ml} \mathrm{cm}{ }^{-2} \mathrm{~min}^{-1}$ ) of the three sensors along with the simulated time series of $E_{\mathrm{I}}$ and $E_{\mathrm{T}}$, as well as rainfall and measured wetness. The timing when rainfall started and the LWSs detected canopy wetness matched pretty well (upper part of the Fig. 5.8). When the canopy was wet (from 5:00 to 11:00), the values of sap flux density and $E_{\mathrm{T}}$ were close to zero. As the canopy gradually dried, $E_{\mathrm{T}}$ resumed. The decrease of 
wetness recorded with LWS2 matches with the gradual drying and sap flux started upon complete dryness of the canopy. At 10:00 all three SFD sensors showed a rapid increase.

For validation of the model, we compared the drying time of the LWS2 (at $20 \mathrm{~m}$ ) to the simulated drying time of the equivalent model layer $(j=24)$ for all 11 rainfall events detected during the modelled period. The resulting RMSE was $6.0 \mathrm{~h}$. The estimated average $E_{\mathrm{I}}( \pm \mathrm{SD})$ event based was $0.19 \mathrm{~mm} \mathrm{~h}^{-1}( \pm 0.09)$, while the $E_{\mathrm{I}}$ rate during rain and drying period were $0.13( \pm 0.05) \mathrm{mm} \mathrm{h}^{-1}$ and $0.32( \pm 0.23)$ $\mathrm{mm} \mathrm{h}^{-1}$ respectively.

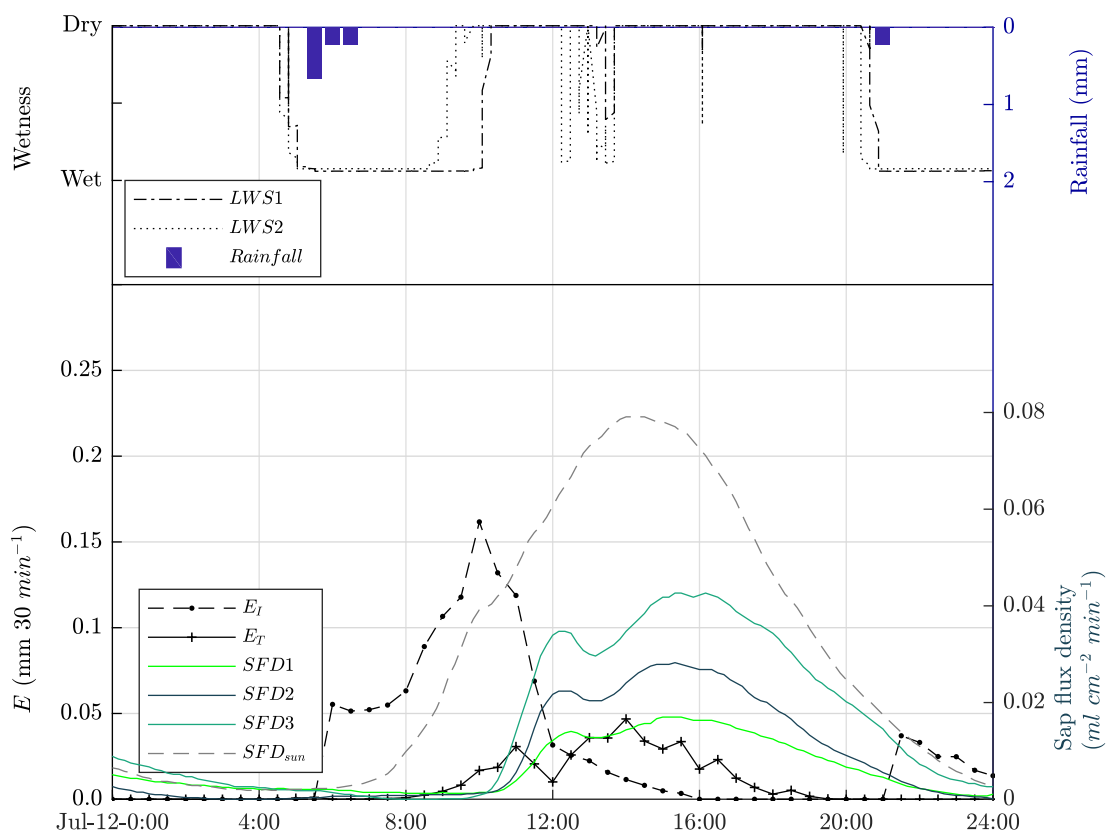

Figure 5.8 Daily distribution of transpiration flux $\left(E_{\mathrm{T}}\right)$. After a rainfall event starting at 5:00, the canopy is wet (also detected by the LWS), around 11:00 the canopy is getting dry and transpiration is beginning. The time when transpiration flux has started is compared with three thermal dissipation probes (TDP; installed in three different trees) and it matches with the modelled transpiration flux. The dashed gray line represent a diurnal cycle of SFD during a sunny day $\left(\mathrm{SFD}_{\text {sun }}\right)$

\subsubsection{Numerical simulations}

Rainfall interception loss as a percentage of $P G$, for the three scenarios (SCN), were $45.1 \%, 34.4 \%$ and $25.7 \%$ for the SCN1, SCN2 and SCN3, respectively. A lower number of events, seven in total, were identified for SCN1 in comparison with eleven events identified for both SCN2 and SCN3. This difference can be explained by the higher canopy storage capacity set for SCN1 which made that contiguous rainfall events were grouped into single events. In consequence, the average event duration is larger for the SCN1 $(32.4 \mathrm{~h})$, in comparison with SCN2 $(21.0 \mathrm{~h})$ and $\mathrm{SCN} 3(18.5 \mathrm{~h})$. Average evaporation rate of intercepted rainfall $\left(E_{\mathrm{I}}\right)$ for the full 
Table 5.3 Results from numerical simulations for the three proposed scenarios $(\mathrm{SCN})($ mean $\pm \mathrm{SD})$.

\begin{tabular}{lccccccc}
\hline Scenario & $\begin{array}{c}I_{\mathrm{n}} \\
(\% P G)\end{array}$ & $\begin{array}{c}T F_{\text {Mod }} \\
(\mathrm{mm})\end{array}$ & $\begin{array}{c}\text { Events } \\
(\#)\end{array}$ & $\begin{array}{c}\text { Event duration } \\
(\mathrm{h})\end{array}$ & $\begin{array}{c}E_{\mathrm{I}, \text { wet }} \\
\left(\mathrm{mm} \mathrm{h}^{-1}\right)\end{array}$ & $\begin{array}{c}E_{\mathrm{I}, \mathrm{dry}} \\
\left(\mathrm{mm} \mathrm{h}^{-1}\right)\end{array}$ & $\begin{array}{c}E_{\mathrm{I}} \\
\left(\mathrm{mm} \mathrm{h}^{-1}\right)\end{array}$ \\
\hline SCN1 & 45.1 & 82.6 & 7 & $32.4 \pm 26.0$ & $0.14 \pm 0.07$ & $0.25 \pm 0.16$ & $0.19 \pm 0.08$ \\
SCN2 & 34.4 & 98.7 & 11 & $21.0 \pm 14.2$ & $0.13 \pm 0.06$ & $0.32 \pm 0.23$ & $0.20 \pm 0.01$ \\
SCN3 & 25.7 & 111.8 & 11 & $18.5 \pm 11.3$ & $0.11 \pm 0.05$ & $0.29 \pm 0.18$ & $0.16 \pm 0.08$ \\
\hline
\end{tabular}

duration of the events (wetting and drying phases) were similar for the SCN1 and SCN2 $\left(\sim 0.20 \mathrm{~mm} \mathrm{~h}^{-1}\right)$, and slightly lower for the SCN3 $\left(0.16 \mathrm{~mm} \mathrm{~h}^{-1}\right)$ (Table 5.3). Those rates are related to the canopy storage capacity and the aerodynamic resistance. In Figure 5.9 we compared the aerodynamic resistances $\left(r_{a a}\right)$ among the three scenarios. SCN1 showed the highest $r_{a a}$, and SCN3 the lowest.

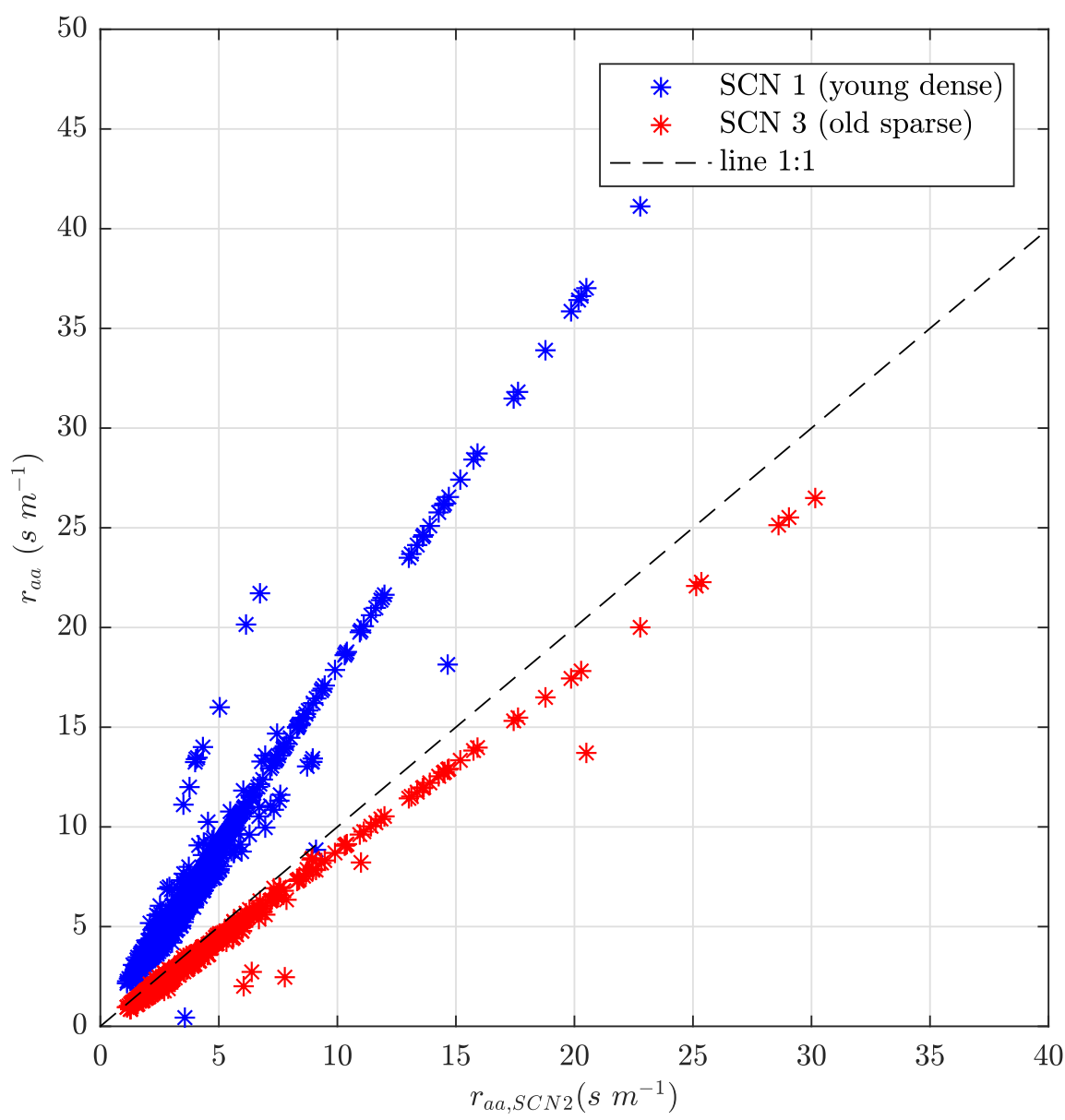

Figure 5.9 Inter-comparison of modelled aerodynamic resistance for the proposed scenarios representing past (SCN1), and future $(\mathrm{SCN} 3)$ in relation to the present scenario (SCN2, line 1:1), 
As an example, the drying phase of 14 July 2018 was analysed for the three scenarios. For tall and sparse canopy (SCN3), drying was much faster than in dense and shorter canopy scenarios (SCN1) (Fig. 5.10a). Although $E_{\mathrm{I}}$ is slightly lower in the case of $\mathrm{SCN} 3$, the lower storage capacity of $\mathrm{SCN} 3$ resulted in a shorter canopy drying time in comparison with SCN1 and SCN2 (Fig. 5.10 b).

(a)
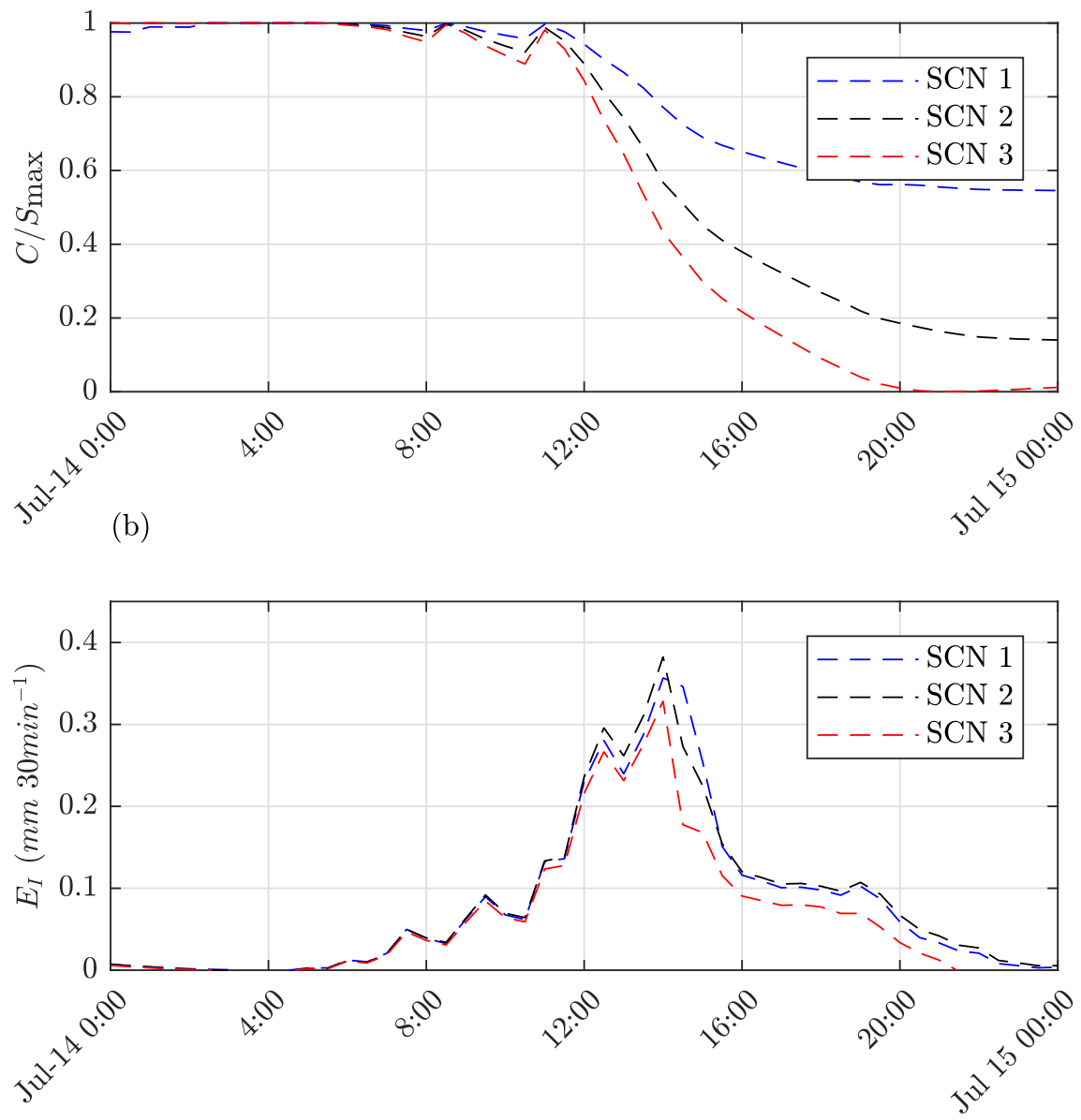

Figure 5.10 Ilustration of the drying phase for the three proposed scenarios representing past (SCN1), present (SCN2), and future (SCN3). (a) Comparison of water stored in the canopy normalized to $S_{\max }$ for the three scenarios. (b) Comparison of $E_{\mathrm{I}}$ for the three scenarios along the drying phase on 14 July 2018. 


\subsection{Discussion}

\subsubsection{Energy fluxes}

To our knowledge, few models incorporate a multi-layer approach to solving the energy budget and estimating evaporation of intercepted rainfall. Other multi-layer models as the proposed by Sellers and Lockwood (1981) use the PM equation to estimate $E_{\mathrm{I}}$, while the theoretical model of Liu (1988) treats the evaporation rate as a constant value along storms. The model proposed by Watanabe and Mizutani (1996) solves the energy budget equation in order to obtain leaf temperature, $H, E_{\mathrm{I}}$, and $E_{\mathrm{T}}$ at leaf level. Although Watanabe and Mizutani (1996) only tested the model for short periods of time, their results showed a good agreement between estimated sensible heat fluxes at canopy level and the fluxes measured by an eddy-covariance system. Our model resolves the radiative transfer in the canopy in addition.

The model could nevertheless not reproduce all observed variability in energy fluxes. During dry conditions, simulated $\lambda E$ and $H$ were close to the measured values (RMSE of $65 \mathrm{~W} \mathrm{~m}^{-2}$ and $74 \mathrm{~W} \mathrm{~m}^{-2}$, respectively), but during wet conditions, the errors were more than double (RMSE of $138 \mathrm{~W} \mathrm{~m}^{-2}$ and $248 \mathrm{~W} \mathrm{~m}^{-2}$, respectively). This can partly be attributed to the uncertainty of measurements during wet conditions and the apparently random fluctuations of the turbulent fluxes, which is larger than during dry conditions. However, we used strict quality filtering, and sonic anemometers, which are built with hydrophobic materials, have been successfully used in wet conditions in earlier studies (Mizutani et al., 1997; Gash et al., 1999; van der Tol et al., 2003; Cisneros Vaca et al., 2018b). Therefore, model limitations must be responsible for the lower agreement with measurements too. The timing of modelled downward $H$ did not always match with the observations and it was hard to explain some of the large negative downward $H$ by any of the synoptic weather input variables directly. Nevertheless, mean observed $H$ during wet $(C>0)$ periods $\left(-48 \mathrm{~W} \mathrm{~m}^{-2}\right)$ is consistent with the mean modelled $H(-46 \mathrm{~W}$ $\left.\mathrm{m}^{-2}\right)$ for the periods when good quality data $(H$ quality flag $\leq 2)$ were available.

The model can also be improved if change in energy stored in the canopy ( $Q$; in air and biomass) is included. $Q$ is an important component in the energy balance of tall forest with a high amount of biomass (Michiles and Gielow, 2008). Additionally, horizontal net fluxes (advection) below the height of the sensor could not be accounted for by our measurement setup (Stewart, 1977), and that could also influence our results.

\subsubsection{Water balance}

The performance of SCOPE in terms of the whole stand water budget is comparable to, but not better than a calibrated Gash model. For a longer period of modelling (19 June 2015 to 31 October 2015), Cisneros Vaca et al. (2018b) using the Gash analytical model found a similar value of $T F$ ( $66 \%$ of $P G)$, which was an overestimate of $3 \%$ of $P G$ (compared to $6 \%$ of $P G$ in the present study). Although our present model does not necessarily perform better than a calibrated Gash model regarding total volume of $T F$, it has the an advantages that it does not depend on an average evaporation rate parameter, and, that we simulate the total canopy storage 
and aerodynamic resistance as functions of canopy structure parameters as leaf area, leaf inclination, and vegetation height.

In general there was a good agreement between measured $T F$ and modelled $T F$ with SCOPE, however, we observed that the water balance model from SCOPE tends to overestimate $T F$ during the periods with high rainfall intensities (Fig. 5.2e and Fig. 5.2f), and in some cases it underestimates $T F$ at the beginning of the event (Fig. 5.2b, 5.2c, and 5.2g). A possible explanation is the implemented drip routine: there is no drip if the storage of a vegetation element is below $S_{\max }$, and all excess water above this threshold drips without time delay. In the literature, the term 'dynamic storage' has been introduced (Keim et al., 2006; Reid and Lewis, 2009), which means that storage capacity increases with rainfall intensity and water that 'survives' evaporation will be delayed in transit to the ground. This introduces differences in interception due to rainfall intensity.

Other factors related to high-intensity storms are the shaking effect due to high wind speed as well as the rainfall inclination which can vary during a storm. The effect of rainfall inclination has not been tested in the present study, although the model can use different rainfall incident angles.

Another critical component that influences the running water balance is the parameter $S_{\max }$, the resultant value of $3.8 \mathrm{~mm}$ derived from the calibration, probably includes the storage capacity of the stem. Trunk or stem storage is relatively large in species with a thick bark (as a mature Douglas fir). The water storage capacity in the bark of a Japanese cedar tree was estimates as $4.4 \mathrm{~mm}$ by Iida et al. (2017). Even though the mechanisms of rainwater storage in the tree bark are not fully understood, and considering that the bark experiment procedures are different to natural conditions (cf. Levia and Herwitz, 2005), such results indicate the large capacity of bark can be in many cases underestimated.

\subsubsection{Canopy drying time and evaporative fluxes}

Estimates of evaporation from wet canopies are needed in interception models. They are usually estimated by means of the PM equation. These estimates are sensitive to the air temperature and relative humidity measured above the canopy, and these measurement may not be sufficiently accurate during the humid conditions prevalent during rainfall episodes. Alternatively, indirect approaches derive $E_{\mathrm{I}}$ from a plot of $T F$ versus $P G$ measurements (i.e. Klaasen et al., 1998). The use of sonic anemometers to obtain evaporation as the residual from the energy balance is considered as a third acceptable approach (Gash et al., 1999; Mizutani et al., 1997). In the study area and using the energy balance residual approach Cisneros Vaca et al. (2018b) found that the average $E_{\mathrm{I}}$ was $0.20 \mathrm{~mm} \mathrm{~h}^{-1}$ for the period from 19 June 2015 to 31 October 2015. Modelled mean event-based $E_{\mathrm{I}}$ in the present study resulted in a similar value $0.19 \mathrm{~mm} \mathrm{~h}^{-1}$. These two estimates were obtained independently: in the first case, $30 \mathrm{~min} E_{\mathrm{I}}$ values from fluxes resultant from the energy balance residual were used, in the second case $E_{\mathrm{I}}$ values were averaged along the duration of the rainfall event and based on modeled $C$ (event is defined for the period when $C_{\text {tot }}>0$ ). Our results indicate that mean $E_{\mathrm{I}}$ during the wet-canopy period was about $60 \%$ lower than during the drying period $\left(0.13 \mathrm{~mm} \mathrm{~h}^{-1}\right.$ during rain versus $0.32 \mathrm{~mm} \mathrm{~h}^{-1}$ during the drying phase). Resultant values are comparable 
with other studies performed for Douglas-fir stands ranging from 0.07 to $0.25 \mathrm{~mm}$ $\mathrm{h}^{-1}$ (Klaasen et al., 1998; Link et al., 2004; Pypker et al., 2005)

Storage capacity is also firmly (positively) related to the canopy drying time. The model shows that the drying time can vary substantially within the canopy, which makes it difficult to validate with a limited number of leaf wetness sensors. Considering that $E_{\mathrm{I}}$ rates during rainfall are relatively low, the most critical forest characteristic that influences rainfall interception loss is $S_{\max }$. This parameter is still an empirical one that required calibration. Our contribution is that the gap fraction, the total canopy storage capacity, and the evaporation rate during and after rainfall are now functions of the canopy structure. This is a step towards a more complete model of rainfall interception and wet canopy evaporation. Other aspects that need to be included in the future are the water and energy storage of trunks and crown clumping.

\subsubsection{Numerical simulations}

The simulations of interception losses for the past and the present (SCN1 and $\mathrm{SCN} 2$ ) can be compared to measurements. Historic measurements showed a rainfall interception loss of about $\sim 39 \%$, which is equal to the present time interception loss (cf. Klaasen et al., 1998; Cisneros Vaca et al., 2018b). In our previous study we showed using historic measurements, that the storage capacity in the past was higher and the aerodynamic conductance lower than presently. The negative effect of thinning on the storage capacity is compensated by a greater aerodynamic roughness, and therefore a higher evaporation rate of the wet canopy (Cisneros Vaca et al., 2018b). Our model reproduces both effects: higher storage capacity and higher aerodynamic resistance in SCN1 (past) compared to the present (SCN2). During low radiation conditions, the aerodynamic resistances is the main determining factor for evaporation (Stewart, 1977). The model simulated the aerodynamic resistances adequately. Figure 5.9 showed the relative comparison of the aerodynamic resistance for SCN1 (young dense) and SCN3 (old sparse) versus the resistances estimated for SCN2 (present). It was observed that aerodynamic resistance in the past (SCN1) was significantly lower than in the present (SCN2), and aerodynamic resistances for the future scenario was slightly reduced, resulting in more rapid drying of the canopy (Fig. 5.10).

However, by assuming canopy storage capacity is proportional to LAI, the effect of thinning on the canopy water storage is amplified. Measurements show that the (relative) decrease of storage capacity after thinning is smaller than the decline in LAI (cf. Klaasen et al., 1998; Cisneros Vaca et al., 2018b). This issue is related to the earlier mentioned lack of simulation of the effects of stems and branches. For this reason, the decreasing aerodynamic resistance does not adequately compensate for the (overestimated) decline in storage capacity as the forest ages in our simulations.

\subsubsection{Potential input from remote sensing observations}

The implementation of the water budget module in SCOPE was straightforward, because the analogy of light interception could be used. The rainfall distribution within the canopy in analogy to Beer's law has been tested earlier by Calder (1986) in a two-layer stochastic model. The present multi-layer approach not only allowed 
us to improve the representation of the drainage/storage process (i.e. Fig. 5.4 and Fig. 5.5), but also improves the knowledge on the storage location, which is an advantage versus other models as Rutter type which only consider the canopy as a single layer. Because SCOPE simulates the energy and water balance per foliage element, evaporation from a partially wet canopy can also be simulated.

The meteorological input requirements are equal to that of the model of Rutter et al. (1971), and include incoming short wave and long wave radiation, gross precipitation, air temperature, air pressure, vapour pressure, wind speed above the canopy.

Other relevant parameters used in SCOPE as emissivity, maximum carboxylation capacity, Ball-Berry stomatal conductance could be obtained from the literature, while other parameters, such as the Chlorophyll AB content, LAI and LIDF can be retrieved from satellite data by model inversion (i.e. Jacquemoud et al., 2009).

Critical parameters that define the surface characteristics as canopy height and surface roughness could be derived from active remote sensing technologies like laser scanning (i.e. LiDAR) (Maltamo et al., 2014) or SAR (Synthetic aperture radar). This last one has been applied mainly with missions as ALOS PALSAR (Rosenqvist et al., 2007) and Terra SAR X (Krieger et al., 2007), and most recently with the incorporation of the Sentinel-1 mission from the European Space Agency (ESA). Other future mission as BIOMASS (Le Toan et al., 2011) may also provide useful data for estimating the water storage capacity, and change in energy storage.

Although air and surface temperatures could be more difficult to retrieve from remote sensing during overcast conditions, there are still opportunities to have reliable data during the drying period. The high temporal resolution of MODIS on board both the Terra and Aqua satellites (Hou et al., 2014), or Sea and Land Surface Temperature Radiometer (SLSTR) (Donlon et al., 2012) on the Sentinel-3 satellites, may provide temperature data required to constrain the evaporation rates of the SCOPE model.

Similarly there is a high potential of improvement on other relevant parameters in the process of evaporation of interception. In a near future, 3D wind fields will be provided at global coverage by ESAs ADM Aeolus mission (Stoffelen et al., 2005). The potential of using global precipitation measurements from the Global Precipitation Measurements (GPM) mission (Hou et al., 2014) can largely improve estimations of rainfall interception loss at global scale not only because the improvements on accuracy of total precipitation, but also because GPM has been extended to provide rain intensity estimates.

Probably one of the most difficult parameters to obtain for rainfall interception modelling is the maximum storage capacity. The study form De Jong et al. (2000) was one of the few attempts to retrieve water storage capacity from remote sensing SAR observations. They used observations from ERS-satellite (Attema et al., 1998) to evaluate the sensitivity to quantify rainwater stored in forest canopies. Although they concluded that the accuracy from the ERSs instruments was not enough for those purposes, improvements as multiple polarizations and high temporal resolutions on the new generation of satellites (i.e. Sentinel-1) could overcome the limitations presented in ERS observations. At the moment, few studes have focused on analysing the potential of Sentinel-1 C-band for estimating water storage capacity of vegetation canopies, and this is a field to be considered. 


\subsection{Conclusions}

We have extended the SCOPE model with a water budget routine that allowed us to estimate rainfall interception loss. The water budget routine has been linked with the canopy energy budget consistently by using the concept of light interception defined in the radiative transfer model of SCOPE. We have presented in detail the equations that describe the process of rainfall distribution within the canopy, primary throughfall (freely) crossing the canopy, and the dripping function. The model provides a physically based link between canopy structure and rainfall interception process, albeit with the limitation that stems and trunks are not included yet.

We have validated the newly implemented routine in a well-instrumented plot by using measurements of turbulent fluxes derived from an eddy-covariance system in combination with meteorological measurements. The results showed that the model underestimates the interception loss by $6 \%$ of gross precipitation, and the performance of the model had an NSE value of 0.75 , which is similar to the accuracy of the Gash analytical model evaluated in the same plot earlier (Cisneros Vaca et al., 2018 b). However, the multilayer structure of SCOPE improves the description of the vertical process of dripping and water storage in the canopy layers and provides extra information about the vertical location of water storage, heat and vapour. The model was also capable of reproducing dew formation.

Numerical simulations allowed us to study interception loss in the past, present and future scenarios. Those results were consistent with previous measurements and with the proposed hypothesis for the future. Simulations for a denser but lower canopy in the past (SCN1, young dense canopy) resulted in a higher aerodynamic resistance, a higher storage capacity and a larger value $I_{\mathrm{n}}$ of about $45 \%$ of $P G$. In the present (SCN2), the aerodynamic resistance decreased because the canopy has grown about $10 \mathrm{~m}$ in height while storage capacity reduced, resuting in $I_{\mathrm{n}}$ was $34 \%$ of $P G$. For the future (SCN3, old sparse canopy), the amount of $I_{\mathrm{n}}$ has decreased to $26 \%$ of $P G$, as a result of a drastic decrease of LAI hence on $S_{\mathrm{n}}$. However, these simulations do not include the positive effects of trunks on the water storage capacity.

This extension of SCOPE is a step towards better spatially resolved rainfall interception estimates driven by remote sensing data. We expect that this model will facilitate the integration of satellite data into quantitative estimates of rainfall interception losses. 


\section{Synthesis}


Forests ecosystems are essential regulators of water and climate. Globally, the amount and availability of water control primary productivity and other physiological processes in the land surface. In consequence, partitioning gross rainfall into throughfall, stemflow and rainfall interception loss is a critical factor within the eco-hydrological studies.

In the near future, forest ecosystems will be altered in structure and function due to increase in temperatures, changes in precipitation regimes, a higher concentration of atmospheric $\mathrm{CO}_{2}$, higher deposition of nitrogen, and increasing demand for ecosystem services. Some of the effects would result in altered species composition, changes in the distribution of forest structure, and changes of spatial patterns across different scales (Vose et al., 2012). It is essential to understand how these changes affect the components of the hydrological cycle.

At first glance, rainfall interception loss seems to be a minor component of the hydrological cycle. However, it is not as small as it looks. The interception in forested ecosystems has been estimated as 10 to $50 \%$ of the incident precipitation (Carlyle-Moses and Gash, 2011). The exclusion of rainfall interception loss can increase the uncertainties in the estimation of other components of the hydrological cycle as total Evapotranspiration (Coenders-Gerrits et al., 2014; Savenije, 2005). There is abundant literature on interception loss available since the 1960's: A search in the databases of Scopus and Web of Science, with the keywords "rainfall interception", returns almost 1800 peer-reviewed articles. These studies cover different forest types under different climatic conditions around the world, but most of them focus on the plot level. Studies that address rainfall interception loss at larger spatial scales (i.e. regional or global) comprise only a small fraction of these studies. Examples of these studies are Miralles et al. (2010) Cui et al. (2015), who presented the first spatially distributed estimates of rainfall interception loss at global and local scale, respectively. However, those approaches are extensions of lumped models (conceptually designed for plot level) and did not contain not explicitly links to the structural properties of the canopy. Thus, there has been a need for new approaches with the capability of assimilating remote sensing data to realistically represent vegetation changes and predict variations of energy and water fluxes more accurate, and this thesis is a step into this direction.

The objective was to evaluate the effects of long-term changes in forest canopy structure on the rainfall interception loss process and to model these changes in a physically based way. This objective can help us to improve understanding of the rainfall interception process, its dependence on canopy structure due to natural growing and management practices (i.e. thinning), and on the sources of energy that sustain the evaporation of intercepted rainfall. Implementing these processes in a model meant for remote sensing applications is a first step towards estimating rainfall interception loss at larger scales.

\subsection{Summary of the research results}

\subsubsection{Spatial patterns and temporal stability of throughfall}

The spatial variability and temporal persistence of $T F$ were evaluated at a finespatial scale in the Speulderbos study site. The spatial variability of throughfall 
is known to affect the accuracy of estimates of stand-scale interception losses (Shinohara et al., 2009; Holwerda et al., 2006; van Dijk et al., 2015). The 2.5 ha of Douglas fir in Speulderbos has a long history of measurements which made a comparison with the situation of 25 years ago possible.

To evaluate the spatial variability of throughfall, in Chapter 3 a randomly stratified sampling strategy was carried out. From February to November 2015 throughfall measurements were collected every 15 days on average. For the first ten collections of throughfall a roving sample technique was applied and for the last five collections a stationary sampling technique. This scheme allowed to collect data from 320 different positions on the forest floor.

In order to map the spatial patterns of throughfall the methodology proposed by Sterk and Stein (1997) was used. This methodology is meant to extend the spatial analysis into the space-time domain and join data from multiple periods of measurements. Time stability plots were used to evaluate the temporal persistence of the throughfall patterns.

The results showed that for the full period of measurements throughfall represented the $61 \%$ of $P G$ which was almost the same value estimated 25 years ago (Bouten et al., 1992). That is an interesting finding considering that the forest density decreased ( 900 trees ha ${ }^{-1}$ in 1989 vs 570 trees ha ${ }^{-1}$ in 2015) and the stand height grew by about $10 \mathrm{~m}$ during this period. The spatial variability of the measurements was relatively low (16\%) compared with similar studies (i.e. Staelens et al., 2006). The coefficient of variation evaluated by Raat et al. (2002) was $~ 5 \%$ higher for the same plot. A possible cause of the reduction in the $\mathrm{CV}$ of throughfall is the thinning that took place in the winter of 1995-1996. As an effect of thinning/pruning, the storage capacity of the canopy can be reduced, and the throughfall rates increase facilitating a more the homogeneous distribution of $T F$ (Sun et al., 2015). The temporal resolution of the measurements, which is another important determining factor for the CV, was similar between the present study and that of Raat et al. (2002).

A geostatistical analysis of the spatial patterns of $T F$ showed that the longterm changes in the canopy structure due to thinning and natural growing had homogenised the spatial distribution of $T F$ in the forest floor of the mature Douglas fir stand. Spatial correlation lengths of $12 \mathrm{~m}$ and $8 \mathrm{~m}$ were found for spring and summer seasons respectively, which allowed creating maps of the spatial distribution of $T F$.

Furthermore, the detected spatial patterns of $T F$ were stable during the study period, slightly more stable than 25 years ago (Raat et al., 2002). This stability has consequences for root zone soil moisture, soil microflora distribution and root water uptake.

\subsubsection{Sources of energy driving evaporation of intercepted rainfall}

Results from different studies have shown a discrepancy in the water and energy budget: Often the energy needed for the actual evaporation is larger than the available energy supplied by net radiation (Stewart, 1977). In the study area of Speulderbos, measurements of eddy-covariance fluxes, net radiation (4 components), soil heat flux and changes of energy stored in the canopy (air and biomass) were collected to quantify the sources of energy driving the evaporation of intercepted rainfall. 
The performance of the sonic anemometer under wet conditions was tested as a pre-requirement before using the estimated sensible heat fluxes derived from the eddy-covariance system. The energy balance residual equation (Eq. 4.4) was used to evaluate the values of latent heat during wet conditions. Additionally, values of sensible heat fluxes with a quality flag higher than two (according to the Foken et al. (2005)) were filtered out.

The increased wet-canopy evaporation rate of $0.20 \mathrm{~mm} \mathrm{~h}^{-1}$ in comparison with the reported value of wet-canopy evaporation rate of $0.077 \mathrm{~mm} \mathrm{~h}^{-1}$ when the stand was 29 years old (canopy height was $18 \mathrm{~m}$, and LAI was $8 \mathrm{~m}^{2} \mathrm{~m}^{-2}$ ) is a result of the canopy structural changes that occurred in Speulderbos due to natural growth and to management practices that reduced the stand density. Over the past 25 years, tree density and LAI at our study site mainly declined as the result of thinning practices, but also due to natural tree mortality. The combination of these changes resulted in an increase in aerodynamic conductance from 0.065 to $0.105 \mathrm{~m} \mathrm{~s}^{-1}$. This change has a direct impact on the exchange of fluxes between the canopy and the atmosphere and is a crucial factor to consider for modelling purposes. It highlights the importance to not only consider vegetation cover or LAI in models, but also the structure and tree height.

The Penman-Monteith (PM) equation was also used to estimate wet-canopy evaporation. The aerodynamic conductance to momentum for the predominant southwesterly wind direction $\left(g_{\mathrm{a}, \mathrm{M}, \mathrm{EC}}\right)$ was estimated by means of the regression between wind speed and friction velocity derived from the eddy-covariance system as $g_{\mathrm{a}, \mathrm{M}, \mathrm{EC}}$ $=0.0318 u$. After applying stability correction for non-neutral hours (Paulson, 1970), the aerodynamic conductance to water vapour was $g_{\mathrm{a}, \mathrm{H}, \mathrm{EC}}=0.0303 u$. The mean evaporation rate estimated with the $\mathrm{P}-\mathrm{M}$ equation was $35 \%$ lower than the mean evaporation rate derived from the energy balance residual.

Underestimation of the canopy (biomass and air) and heat ground release, as well as underestimation of aerodynamic conductances, were discarded as potential reasons of the discrepancies between the results of PM equation and the energy balance residual. In the case of the Speulderbos stand, the most likely candidate explanation for the underestimate is errors in air humidity measurements, to which the PM equation is highly sensitive. Other aspects that need more attention are the unaccounted energy advection (below the level of measurements) and the mechanical liquid water transport (fog).

\subsubsection{Effects of natural growing and thinning in the rainfall interception loss process}

The long-term establishment of the study site in Speulderbos provided a unique opportunity to re-evaluate the process of rainfall interception loss and evaluate the effects of the structural changes of the stand. There are few studies in the literature evaluating this situation, the closest experiences are focused on assessing two stands of different age simultaneously (i.e. Pypker et al., 2005), but there have been other factors as forest composition or presence of epiphytes that can distort the results.

Two variables are of key importance for the rainfall interception process: the water storage capacity of the forest, and the evaporation rate of the wet canopy. The hypothesis that thinning the forest stand together with an increase in height due to natural growth, would alter the forest roughness and increase the evaporation rates, 
was confirmed. The storage capacity of the forest stand has decreased in comparison with the past, in agreement (but not proportional to) the decrease in tree density and LAI over the years. The IEA (individual event analysis) appeared to be a practical way to obtain an approximation of the storage capacity in this case of $2.0 \mathrm{~mm}$. The small decrease in the storage capacity of the forest was not expected considering the significant reduction in tree density and LAI. Such small variation in $S$ can be explained by a substantial increase of bark area due to the natural growth of the trees. Several experimental studies confirm that the capacity of water storage in bark can be in the order of 3 millimetres (i.e. Iida et al., 2017). This contribution is far from negligible, and the topic needs more attention in future studies.

The original version of the Gash (1979) model was calibrated and validated successfully (Table 4.6). The performance of the model was good, during the calibration, the relative error of total $I$ was lower than $8 \%$, and for the validation phase, it was lower than $2 \%$. The sensitivity of the model to the most influencing parameters, $S$ and $\bar{E} / \bar{R}$, was studied. We observed that certain combinations of both parameters yield to optimise the objective function almost equally, due to the functional equivalence between $S$ and $\bar{E} / \bar{R}$. This confirms the necessity to reduce the uncertainty in one of the parameters by independent measurements, before optimising the second one. It is recommended to investigate new methods to study the process of water storage in the canopy by a combination of microwave sensors (nowadays more accessible) with technologies as LiDAR that can give more details about the canopy structure.

\subsubsection{A new multilayer modelling approach to estimate rainfall interception loss}

The integrated radiative transfer and energy balance model SCOPE (Soil Canopy Observation, Photochemistry and Energy fluxes) (van der Tol et al., 2009), originally developed for remote sensing applications, was extended with a module for the interception, storage and dripping of intercepted rainfall. The equations in Chapter 5 describe how the concept of light interception from SCOPE was adapted to rainfall interception.

The distribution of rainfall within the canopy was determined in analogy to Beer's law and using the 60 layer canopy structure from SCOPE. By using the multilayer approach the representation of the drainage/storage process was improved, as well as the knowledge about change in location of heat and vapour along the vertical dimension. Those aspects are an advantage versus other lumped models that consider the canopy as a single layer.

The adapted version of SCOPE model required as inputs time series of incoming short and longwave radiation, gross precipitation, air temperature, air pressure, vapour pressure, and wind speed, if it is possible, measured above the canopy. For calibration, time series of throughfall can be used, and the RMSE optimised to get the best value of $S_{\max }$.

The model was tested in the Speulderbos study site. There was a reasonable agreement not only between measured and modelled $T F$ and also for the turbulent fluxes. The model was also useful in predicting dew formation and was able to simulate vertical profiles of heat and vapour during wet-canopy conditions. 
Another application of the model was in numerical simulation of different scenarios. Three scenarios (past, present and future) of varying canopy forest structure were tested in Speulderbos. Several features of rainfall interception process could be reproduced by the model, such as the increasing roughness of the canopy, change on evaporation rates, differences in the vertical distribution of storage, the difference in drying times. The model presented several advantages, but it can be improved in the way that maximum storage capacity was parametrised.

\subsection{Perspectives}

Estimating evaporation of intercepted rainfall through the energy balance can overcome several issues discussed in previous studies. Modelling tools are also an excellent tool to study the process of rainfall interception at larger scales. The use of several sources of remote sensing data in combination with models that can assimilate them could help to extend the analysis to larger scales.

Evaluating evaporation of intercepted rainfall using energy balance supported by air and surface temperatures derived from remote sensing can be very challenging, but there are still opportunities to exploit the available data. The high temporal resolution such as MODIS and Sentinel-3 missions could improve the chance to get more data for drying periods. The VNIR spectral shape as observed with for example OLCI on Sentinel-3 could help retrieve leaf inclination distributions or gap fractions, while SLSTR may provide thermal data during drying episodes. Other variables as wind speed can also be evaluated for larger scales by using the recently launched ADM Aeolus mission (Stoffelen et al., 2005).

Other canopy structural parameters as canopy height and surface roughness could be derived from active remote sensing technologies as LiDAR or SAR. These data have been already tested to be useful in other applications related to forest management. The study of rainfall interception loss can take advantage of these techniques.

Regarding remote sensing data of precipitation, for instance, data from the Global Precipitation Map mission (GPM) are already available and could contribute to evaluating rainfall interception loss at larger scales. The GPM mission has the advantage that provides not only total precipitation values but also rainfall intensity measurements.

Finally, and probably one of the most difficult parameters to obtain for rainfall interception modelling, the maximum storage capacity, can also be better estimated from remote sensing. The study form De Jong et al. (2000) was one of the few attempts to retrieve water storage capacity from remote sensing SAR observations. They used observations from ERS-satellite (Attema et al., 1998) to evaluate the sensitivity to quantify rainwater stored in forest canopies. This study needs to be updated by using the new generation of Sentinel-1 satellites. The availability of remote sensing data still increases, and this generates the need for physically based models that can assimilate them. Exploration of new methods supported by field observations can help to solve the remaining questions about the rainfall interception process. 


\section{List of abbreviations and symbols}

$\begin{array}{ll}\text { Abbreviations } & \\ \text { CV } & \text { coefficient of variation } \\ \text { CDT } & \text { canopy drying time } \\ \text { DNT } & \text { distance to the nearest tree } \\ \text { ESA } & \text { European Space Agency } \\ \text { EBR } & \text { energy balance ratio } \\ \text { IDW } & \text { inverse distance weighted } \\ \text { IEA } & \text { individual event analysis } \\ \text { LAI } & \text { leaf area index } \\ \text { LIDF } & \text { leaf inclination distribution function } \\ \text { LWS } & \text { leaf wetness sensor } \\ \text { MAE } & \text { mean absolute error } \\ \text { MoM } & \text { Method-of-moments } \\ \text { MOST } & \text { Monin-Obukhov similarity theory } \\ \text { NSE } & \text { Nash-Sutcliffe model efficiency } \\ \text { NTG } & \text { Natural thermal gradients } \\ \text { P-M } & \text { Penman-Monteith } \\ \text { RMSE } & \text { root mean square error } \\ \text { SAR } & \text { synthetic aperture radar } \\ \text { SCN } & \text { scenario } \\ \text { SCOPE } & \text { Soil Canopy Observation, Photochemistry and Energy } \\ & \text { fluxes (model) } \\ \text { SFD } & \text { sap flux density } \\ \text { TDP } & \text { thermal dissipation probes } \\ \text { TSP } & \text { time stability plots } \\ \text { WAI } & \text { wood area index } \\ & \end{array}$




\section{Symbols}

A

$A_{x}$

$b$

$b_{1}$

$b_{2}$

$c_{\mathrm{p}}$

$c_{\mathrm{V}}$

C

C

$C_{0}$

$C_{1}$

$C_{\text {tot }}$

$\Delta$

$\Delta L$

$d$

$D$

$D_{1}$

$D(j)$

$\epsilon$

$e$

$e_{s}$

$E_{\mathrm{EB}-\mathrm{EC}}$

$E_{\mathrm{I}}$

$E_{1}$

$E_{\mathrm{P}}$

$E_{\mathrm{PM}-\mathrm{EC}}$

$E_{\mathrm{t}}$

$E_{\mathrm{T}}$

$\gamma^{\prime}$

$\gamma$

$\gamma(h)$

$g_{\mathrm{a}, \mathrm{M}}$

$g_{\mathrm{a}, \mathrm{H}}$

$g_{\mathrm{a}, \mathrm{M}, \mathrm{EC}}$

$g_{\mathrm{a}, \mathrm{H}, \mathrm{EC}}$

$g_{\mathrm{s}}$

available energy $\left(\mathrm{W} \mathrm{m}^{-2}\right)$

sapwood area $\left(\mathrm{cm}^{2}\right)$

empirical coefficient of the drainage function in Ch. 1

slope of the linear regression between interception versus rainfall

interception coefficient of the linear regression between interception versus rainfall

specific heat of air $\left(\mathrm{J} \mathrm{kg}^{-1} \mathrm{~K}^{-1}\right)$

specific heat of the vegetation $\left(\mathrm{J} \mathrm{kg}^{-1} \mathrm{~K}^{-1}\right)$

stock or interception storage $(\mathrm{mm})$

sill parameter in Ch. 3

the nugget effect parameter in Ch. 3

water storage on the leaves/needles (mm per unit LAI)

total integrated storage among the canopy layers ( $\mathrm{mm}$ )

slope of the saturated water vapour pressure curve $(\mathrm{hPa}$ $\mathrm{K}^{-1}$ )

is leaf area index per layer in Ch. 5

displacement height $(\mathrm{m})$

rate of drainage from the canopy

rate of drip from the leaves

drip from the layer $(j)$

coefficient of proportionality between the rate of evaporation from saturated trunks and the evaporation of the saturated canopy

actual vapour pressure $(\mathrm{hPa})$

specific heat of air at constant pressure (hPa)

wet-canopy evaporation rate calculated from the energy

balance residual

evaporation rate of intercepted rainfall $\left(\mathrm{mm} \mathrm{h}^{-1}\right)$

evaporation of intercepted water (depth per unit LAI per unit of time)

potential evaporation rate from wet-canopy

wet-canopy evaporation rate estimated with the $\mathrm{P}-\mathrm{M}$ equation in Ch. 4

evaporation rate of the water stored on the trunks $\left(\mathrm{mm} \mathrm{h}^{-1}\right)$ tree transpiration rate $\left(\mathrm{mm} \mathrm{h}^{-1}\right)$

adjusted psychrometric constant $\left(\mathrm{hPa} \mathrm{K}^{-1}\right)$

original psychrometric constant $\left(\mathrm{hPa} \mathrm{K}^{-1}\right)$

semi variance in $\mathrm{Ch} .3$

aerodynamic conductance to momentum $\left(\mathrm{m} \mathrm{s}^{-1}\right)$

aerodynamic conductance to heat $\left(\mathrm{m} \mathrm{s}^{-1}\right)$

aerodynamic conductance to momentum for the predominant wind direction at the eddy-covariance tower $\left(\mathrm{m} \mathrm{s}^{-1}\right)$

aerodynamic conductance to heat for the predominant wind direction at the eddy-covariance tower $\left(\mathrm{m} \mathrm{s}^{-1}\right)$

surface conductance $\left(\mathrm{m} \mathrm{s}^{-1}\right)$ 
G

$h$

$h_{\mathrm{c}}$

H

I

I

$I_{\mathrm{n}}$

$I_{\mathrm{g}}$

$J_{p}$

$\lambda$

$L$

$L$

$m$

$m_{\text {bio }}$

$n$

$N$

$\phi_{o}$

$\varphi_{1}$

$p$

$p_{\mathrm{t}}$

$P G$

$P G^{\prime}$

$P G_{\mathrm{I}}$

$P_{\perp}$

$P_{\mathrm{p}}$

$Q$

$Q_{\text {air }}$

$Q_{\text {bio }}$

$Q_{\mathrm{br}}$

$Q_{\text {nd }}$

$Q_{\mathrm{q}}$

$Q_{\mathrm{T}}$

$Q_{\mathrm{tr}}$

$\rho$

$R$

$R_{\mathrm{n}}$

$\sigma w$

$S$

$S_{\max }$

$S_{t}$

$S F$

$\theta_{o}$

soil heat flux $\left(\mathrm{W} \mathrm{m}^{-2}\right)$

lag distance (m) in Ch. 3

canopy height $(\mathrm{m})$

sensible heat flux $\left(\mathrm{W} \mathrm{m}^{-2}\right)$

rainfall interception loss $\left[\mathrm{L} \mathrm{T}^{-1}\right]$ in $\mathrm{Ch} .1$

net interception loss integrated in a period of time $(\mathrm{mm}, \%$ $P G)$ in Ch. 4

net interception loss integrated in a period of time $(\mathrm{mm}, \%$ $P G)$ in Ch. 5

gross interception captured in the canopy (depth per unit LAI per unit of time) in Ch. 5

xylem sap flux density $\left(\mathrm{ml} \mathrm{cm} \mathrm{cm}^{-2} \mathrm{~min}^{-1}\right.$ )

the extinction coefficient in Ch. 5

Latent heat of vaporization $\left(\mathrm{J} \mathrm{g}^{-1}\right)$

Obukhov length in Ch. 4

leaf area index in Ch. 5

number of storms not large enough to saturate the canopy

biomass per unit of horizontal area $\left(\mathrm{kg} \mathrm{m}^{-2}\right)$

number of storms large enough to saturate the canopy

number of pairs of observations within a class distance

observation azimuth angle

leaf azimuth

the free throughfall coefficient

the stemflow partitioning coefficient

gross rainfall $(\mathrm{mm})$

amount of rainfall necessary to saturate the canopy $(\mathrm{mm})$

rainfall intercepted by the canopy in $\mathrm{Ch} .5$

gap fraction in the vertical direction

gap fraction in the zenith direction of incident rainfall.

energy storage rate in the forest $\left(\mathrm{W} \mathrm{m}^{-2}\right)$

energy storage rate in the canopy air $\left(\mathrm{W} \mathrm{m}^{-2}\right)$

energy storage rate in the canopy biomass $\left(\mathrm{W} \mathrm{m}^{-2}\right)$

energy storage rate in the branches $\left(\mathrm{W} \mathrm{m}^{-2}\right)$

energy storage rate in the needles $\left(\mathrm{W} \mathrm{m}^{-2}\right)$

energy storage rate in the air related to the specific humidity variations $\left(\mathrm{W} \mathrm{m}^{-2}\right)$

energy storage rate in the air related to the temperature variations $\left(\mathrm{W} \mathrm{m}^{-2}\right)$

energy storage rate in the trunks $\left(\mathrm{W} \mathrm{m}^{-2}\right)$

density of air $\left(\mathrm{kg} \mathrm{m}^{-3}\right)$

rainfall intensity $\left(\mathrm{mm} \mathrm{h}^{-1}\right)$

net radiation $\left(\mathrm{W} \mathrm{m}^{-2}\right)$

standard deviation of the vertical wind speed

canopy storage capacity (mm)

maximum storage capacity per leaf area

trunk storage capacity $(\mathrm{mm})$

stemflow (mm)

observation zenith angle 
A. List of abbreviations and symbols

$\begin{array}{ll}\theta_{1} & \text { leaf (or needle) inclinations } \\ T_{\text {air }} & \text { air temperature }(\mathrm{K}) \\ T_{\text {bio }} & \text { biomass temperature }(\mathrm{K}) \\ T F & \text { throughfall }(\mathrm{mm}) \\ T F-\mathrm{p} & \text { throughfall }(\% P G) \\ u & \text { wind speed }\left(\mathrm{m} \mathrm{s}^{-1}\right) \\ u^{*} & \text { friction velocity }\left(\mathrm{m} \mathrm{s}^{-1}\right) \\ z_{0} & \text { roughness length }(\mathrm{m})\end{array}$




\section{Bibliography}

Anniballe, R., Bonafoni, S., Pichierri, M., 2014. Spatial and temporal trends of the surface and air heat island over Milan using MODIS data. Remote Sensing of Environment 150,163-171. doi:10.1016/J.RSE.2014.05.005.

Attema, E., Duchossois, G., Kohlhammer, G., 1998. ERS-1/2 SAR land applications: overview and main results, in: IGARSS '98. Sensing and Managing the Environment. 1998 IEEE International Geoscience and Remote Sensing. Symposium Proceedings. (Cat. No.98CH36174), IEEE. pp. 1796-1798 vol.4. URL: http://ieeexplore.ieee.org/document/703655/, doi:10.1109/IGARSS.1998.703655.

Aubinet, M., Grelle, A., Ibrom, A., Rannik, Ü., Moncrieff, J., Foken, T., Kowalski, A.S., Martin, P.H., Berbigier, P., Bernhofer, C., Clement, R., Elbers, J., Granier, A., Grünwald, T., Morgenstern, K., Pilegaard, K., Rebmann, C., Snijders, W., Valentini, R., Vesala, T., 2000. Estimates of the annual net carbon and water exchange of forests: the EUROFLUX methodology. Advances in Ecological Research 30,113-175. doi:10.1016/S0065-2504(08) 60018-5.

Bartelink, H.H., 1996. Allometric relationships on biomass and needle area of Douglas-fir. Forest Ecology and Management 86, 193-203. doi:10.1016/ S0378-1127 (96)03783-8.

Bellot, J., Escarre, A., 1998. Stemflow and throughfall determination in a resprouted Mediterranean holm-oak forest. Annales des Sciences Forestieres 55, 847-865. doi:10.1051/forest: 19980708 .

Beven, K.J., Prophecy, 1993. Reality and Uncertainty in Distributed Hydrological Modelling. Adv. Water Resour. 16, 41-51.

Bhumralkar, C.M., 1975. Numerical Experiments on the Computation of Ground Surface Temperature in an Atmospheric General Circulation Model. Journal of Applied Meteorology 14, 1246-1258. doi:10.1175/1520-0450 (1975) $014<1246$ : neotco>2.0.co; 2 .

Black, T.A., Chen, J.M., Lee, X., Sagar, R.M., 1991. Characteristics of shortwave and longwave irradiances under a Douglas-fir forest stand. Canadian Journal of Forest Research 21, 1020-1028. doi:10.1139/x91-140.

Bond, B.J., Czarnomski, N.M., Cooper, C., Day, M.E., Greenwood, M.S., 2007. Developmental decline in height growth in Douglas-fir. Tree Physiology 27, 441-453. doi:10.1093/treephys/27.3.441. 
Bormann, B.T., Darbyshire, R.L., Homann, P.S., Morrissette, B.A., Little, S.N., 2015. Managing early succession for biodiversity and long-term productivity of conifer forests in southwestern Oregon. Forest Ecology and Management 340, 114-125. doi:10.1016/j.foreco.2014.12.016.

Bosveld, F., Bouten, W., 2001. Evaluation of transpiration models with observations over a Douglas-fir forest. Agricultural and Forest Meteorology 108, 247-264. doi:10.1016/S0168-1923(01)00251-9.

Bouten, W., Heimovaara, T.J., Tiktak, A., 1992. Spatial patterns of throughfall and soil water dynamics in a Douglas fir stand. Water Resources Research 28, 3227-3233. doi:10.1029/92WR01764.

Bouten, W., Schaap, M.G., Aerts, J., Vermetten, A.W., 1996. Monitoring and modelling canopy water storage amounts in support of atmospheric deposition studies. Journal of Hydrology 181, 305-321. doi:10 . 1016/0022-1694 (95) 02907-9.

Bouten, W., Swart, P.J., De Water, E., 1991. Microwave transmission, a new tool in forest hydrological research. Journal of Hydrology 124, 119-130. doi:10 . 1016/0022-1694(91)90009-7.

Brutsaert, W., 2005. Hydrology: An Introduction. Cambridge University Press.

Bui, E.N., Box, J.E., 1992. Stemflow, rain throughfall, and erosion under canopies of corn and sorghum. Soil Science Society of America Journal 56, 242. doi:10 . $2136 /$ sssaj1992.03615995005600010037x.

Burba, G.G., Mcdermitt, D.K., Anderson, D.J., Furtaw, M.D., Eckles, R.D., 2010. Novel design of an enclosed $\mathrm{CO} 2 / \mathrm{H} 2 \mathrm{O}$ gas analyser for eddy covariance flux measurements. Tellus B: Chemical and Physical Meteorology 62, 743-748. doi:10.1111/j.1600-0889.2010.00468.x.

Calder, I.R., 1986. A stochastic model of rainfall interception. Journal of Hydrology 89, 65-71. doi:10.1016/0022-1694(86) 90143-5.

Calder, I.R., 1996. Dependence of rainfall interception on drop size: 1. Development of the two-layer stochastic model. Journal of Hydrology 185, 363-378. doi:10 . 1016/0022-1694(95)02998-2.

Calder, I.R., Wright, I.R., 1986. Gamma ray attenuation studies of interception from sitka spruce: some evidence for an additional transport mechanism. Water Resources Research 22,409-417. doi:10.1029/WR022i 003 p00409.

Carlyle-Moses, D.E., Gash, J.H.C., 2011. Rainfall interception loss by forest canopies, in: Levia, D.F., Carlyle-Moses, D., Tanaka, T. (Eds.), Forest Hydrology and Biogeochemistry. Springer, Dordrecht. volume 216 of Ecological Studies, pp. 407-423. doi:10.1007/978-94-007-1363-5_20.

Carlyle-Moses, D.E., Lishman, C.E., McKee, A.J., 2014. A preliminary evaluation of throughfall sampling techniques in a mature coniferous forest. Journal of Forestry Research 25, 407-413. doi:10 .1007/s11676-014-0468-8.

Carlyle-Moses, D.E., Price, A.G., 1999. An evaluation of the Gash interception model in a northern hardwood stand. Journal of Hydrology 214, 103-110. doi:10 . 1016/s0022-1694(98)00274-1. 
Carlyle-Moses, D.E., Price, A.G., 2007. Modelling canopy interception loss from a Madrean pine-oak stand, northeastern Mexico. Hydrological Processes 21, 2572-2580. doi:10.1002/hyp. 6790.

Carnol, M., Ineson, P., 1999. Environmental factors controlling NO3- leaching, N2O emissions and numbers of NH4+ oxidisers in a coniferous forest soil. Soil Biology and Biochemistry 31,979-990. doi:10 .1016/S0038-0717 (99) $00007-3$.

Chave, J., Condit, R., Aguilar, S., Hernandez, A., Lao, S., Perez, R., 2004. Error propagation and scaling for tropical forest biomass estimates. Philosophical Transactions of the Royal Society B: Biological Sciences 359, 409-420. doi:10 . 1098 /rstb.2003.1425.

Cisneros, C., 2018. Water and energy fluxes measurement in Speulderbos. URL: https://easy.dans.knaw.nl/ui/datasets/id/ easy-dataset : 104514 , doi:10.17026/dans-zvq-dq4w.

Cisneros Vaca, C., Ghimire, C., van der Tol, C., 2018a. Spatial Patterns and Temporal Stability of Throughfall in a Mature Douglas-fir Forest. Water 10, 317. doi:10.3390/w10030317.

Cisneros Vaca, C., van der Tol, C., Ghimire, C.P., 2018b. The influence of longterm changes in canopy structure on rainfall interception loss: a case study in Speulderbos, the Netherlands. Hydrol. Earth Syst. Sci 22, 3701-3719. doi:10 . 5194/hess-22-3701-2018.

Coenders-Gerrits, A.M.J., van der Ent, R.J., Bogaard, T.A., Wang-Erlandsson, L., Hrachowitz, M., Savenije, H.H.G., 2014. Uncertainties in transpiration estimates. Nature 506, E1-E2. doi:10.1038/nature12925.

Crockford, R.H., Richardson, D.P., 2000. Partitioning of rainfall into throughfall, stemflow and interception: effect of forest type, ground cover and climate. Hydrological Processes 14, 2903-2920.

Cuartas, L.A., Tomasella, J., Nobre, A.D., Hodnett, M.G., Waterloo, M.J., Múnera, J.C., 2007. Interception water-partitioning dynamics for a pristine rainforest in Central Amazonia: Marked differences between normal and dry years. Agricultural and Forest Meteorology 145, 69-83. doi:10 .1016/J.AGRFORMET . 2007.04 .008 .

Cui, Y., Jia, L., 2014. A modified Gash model for estimating rainfall interception loss of forest using remote sensing observations at regional scale. Water 6, 993-1012. doi:10.3390/w6040993.

Cui, Y., Jia, L., Hu, G., Zhou, J., 2015. Mapping of Interception Loss of Vegetation in the Heihe River Basin of China Using Remote Sensing Observations. IEEE Geoscience and Remote Sensing Letters 12, 1-5. doi:10.1109/LGRS . 2014 . 2324635 .

Dawson, T.E., Goldsmith, G.R., 2018. The value of wet leaves. New Phytologist 219, 1156-1169. doi:10.1111/nph.15307.

De Jong, J.J.M., Klaassen, W., Ballast, A., 2000. Rain storage in forests detected with ERS tandem mission SAR. Remote Sensing of Environment 72, 170-180. doi:10.1016/S0034-4257(99)00100-5. 
De Jong, J.J.M., Klaassen, W., Kuiper, P.J.C., 2002. Monitoring of Rain Water Storage in Forests With Satellite Radar. IEEE Transactions on Geoscience and Remote Sensing 40, 338-347.

Deguchi, A., Hattori, S., Park, H.T., 2006. The influence of seasonal changes in canopy structure on interception loss: Application of the revised Gash model. Journal of Hydrology 318, 80-102. doi:10 .1016/j . jhydrol . 2005.06. 005.

van Dijk, A.I., Bruijnzeel, L.A., 2001. Modelling rainfall interception by vegetation of variable density using an adapted analytical model. Part 1 . model description. Journal of Hydrology 247, 230-238.

van Dijk, A.I., Gash, J.H., van Gorsel, E., Blanken, P.D., Cescatti, A., Emmel, C., Gielen, B., Harman, I.N., Kiely, G., Merbold, L., Montagnani, L., Moors, E., Sottocornola, M., Varlagin, A., Williams, C.A., Wohlfahrt, G., 2015. Rainfall interception and the coupled surface water and energy balance. Agricultural and Forest Meteorology 214-215, 402-415. doi:10.1016/j . agrformet . 2015 . 09.006 .

Dolman, A.J., 1987. Summer and winter rainfall interception in an oak forest. Predictions with an analytical and a numerical simulation model. Journal of Hydrology 90, 1-9. doi:10 .1016/0022-1694 (87) 90169-7.

Donlon, C., Berruti, B., Buongiorno, A., Ferreira, M.H., Féménias, P., Frerick, J., Goryl, P., Klein, U., Laur, H., Mavrocordatos, C., Nieke, J., Rebhan, H., Seitz, B., Stroede, J., Sciarra, R., 2012. The Global Monitoring for Environment and Security (GMES) Sentinel-3 mission. Remote Sensing of Environment 120, 37-57. doi:10.1016/j.rse.2011.07.024.

Dunin, F.X., O'Loughlin, E.M., Reyenga, W., 1988. Interception loss from eucalypt forest: Lysimeter determination of hourly rates for long term evaluation. Hydrological Processes 2, 315-329. doi:10 .1002/hyp.3360020403.

van Emmerik, T., Steele-Dunne, S., Hut, R., Gentine, P., Guerin, M., Oliveira, R., Wagner, J., Selker, J., van de Giesen, N., 2017. Measuring Tree Properties and Responses Using Low-Cost Accelerometers. Sensors 17, 1098. doi:10.3390/ s17051098.

Evers, P., Bouten, W., van Grinsven, J., Steingrver, E., 1991. CORRELACI, Identification of traditional and air pollution related stress factors in a Douglas fir ecosystem: the ACIFORN stands. Technical Report 623. ACIFORN. Wageningen.

Fathizadeh, O., Attarod, P., Keim, R.F., Stein, A., Amiri, G.Z., Darvishsefat, A.A., 2014. Spatial heterogeneity and temporal stability of throughfall under individual Quercus brantii trees. Hydrological Processes 28, 1124-1136. doi:10.1002/ hyp. 9638.

Foken, T., Göockede, M., Mauder, M., Mahrt, L., Amiro, B., Munger, W., Mathias, G., Mauder, M., Mahrt, L., Amiro, B., Munger, W., 2005. Post-Field Data Quality Control, in: Lee, X., Massman, W., Law, B. (Eds.), Handbook of Micrometeorology: A Guide for Surface Flux Measurement and Analysis. Springer Netherlands, Dordrecht. 1988, pp. 181-208. doi:10.1007/1-4020-2265-4_9. 
Ford, E.D., Deans, J.D., 1978. The Effects of Canopy Structure on Stemflow, Throughfall and Interception Loss in a Young Sitka Spruce Plantation. The Journal of Applied Ecology 15, 905. doi:10.2307/2402786.

Franklin, J.F., Lindenmayer, D., Thornburgh, D., Pelt, R.V., Chen, J., Spies, T., Carey, A.B., Shaw, D.C., Berg, D.R., Harmon, M.E., Keeton, W.S., Bible, K., 2002. Disturbances and structural development of natural forest ecosystems with silvicultural implications, using Douglas-fir forests as an example. Forest Ecology and Management 155, 399-423. doi:10.1016/S0378-1127(01) $00575-8$.

Freund, J.A., Franklin, J.F., Lutz, J.A., 2015. Structure of early old-growth Douglasfir forests in the Pacific Northwest. Forest Ecology and Management 335, 11-25. doi:10.1016/j. foreco.2014.08.023.

Friesen, J., van Beek, C., Selker, J., Savenije, H.H.G., van de Giesen, N., 2008. Tree rainfall interception measured by stem compression. Water Resources Research 44. doi:10.1029/2008WR007074.

Friesen, J., Lundquist, J., Van Stan, J.T., 2015. Evolution of forest precipitation water storage measurement methods. Hydrological Processes 29, 2504-2520. doi:10.1002/hyp.10376.

Garratt, J.R., Francey, R.J., 1978. Bulk characteristics of heat transfer in the unstable, baroclinic atmospheric boundary layer. Boundary-Layer Meteorology 15, 399421.

Gash, J.H., Morton, A.J., 1978. An application of the Rutter model to the estimation of the interception loss from Thetford Forest. Journal of Hydrology 38, 49-58. doi:10.1016/0022-1694(78)90131-2.

Gash, J.H., Wright, I.R., Lloyd, C.R., 1980. Comparative estimates of interception loss from three coniferous forests in Great Britain. Journal of Hydrology 48, 89-105. doi:10.1016/0022-1694 (80) 90068-2.

Gash, J.H.C., 1979. An analytical model of rainfall interception by forests. Quarterly Journal of the Royal Meteorological Society 105, 43-55. doi:10.1002/qj . 49710544304.

Gash, J.H.C., Lloyd, C.R., Lachaud, G., 1995. Estimating sparse forest rainfall interception with an analytical model. Journal of Hydrology 170, 79-86. doi:10 . 1016/0022-1694(95) 02697-N.

Gash, J.H.C., Shuttleworth, W.J., 2007. Evaporation. IAHS Press, Wallingford.

Gash, J.H.C., Valente, F., David, J.S., 1999. Estimates and measurements of evaporation from wet, sparse pine forest in Portugal. Agricultural and Forest Meteorology 94, 149-158. doi:10.1016/S0168-1923(99)00008-8.

Gómez, J.A., Vanderlinden, K., Giráldez, J.V., Fereres, E., 2002. Rainfall concentration under olive trees. Agricultural Water Management 55, 53-70. doi:10.1016/S0378-3774(01)00181-0.

Granier, A., 1985. Une nouvelle méthode pour la mesure du flux de sève brute dans le tronc des arbres. Ann. For. Sci. 42, 193-200.

Hassan, S.M., Ghimire, C.P., Lubczynski, M.W., 2017. Remote sensing upscaling of interception loss from isolated oaks: Sardon catchment case study, Spain. Journal of Hydrology 555, 489-505. doi:10.1016/j.jhydrol.2017.08.016. 
Heij, G.J., Schneider, T., 1991. Acidification research in the Netherlands: final report of the Dutch Priority Programme on Acidification. Elsevier Science Publishers BV, Amsterdam.

Helvey, J.D., Patric, J.H., 1965. Canopy and litter interception of rainfall by hardwoods of eastern United States. Water Resources Research .

Herbst, M., Rosier, P.T.W., McNeil, D.D., Harding, R.J., Gowing, D.J., 2008. Seasonal variability of interception evaporation from the canopy of a mixed deciduous forest. Agricultural and Forest Meteorology 148, 1655-1667. doi:10 . $1016 / j$.agrformet.2008.05.011.

Holwerda, F., Bruijnzeel, L.A., Scatena, F.N., Vugts, H.F., Meesters, A.G., 2012. Wet canopy evaporation from a Puerto Rican lower montane rain forest: The importance of realistically estimated aerodynamic conductance. Journal of Hydrology 414-415, 1-15. doi:10.1016/j.jhydrol.2011.07.033.

Holwerda, F., Scatena, F.N., Bruijnzeel, L.A., 2006. Throughfall in a Puerto Rican lower montane rain forest: A comparison of sampling strategies. Journal of Hydrology 327, 592-602. doi:10.1016/j. jhydrol.2005.12.014.

Horton, R.E., 1919. Rainfall Interception. Monthly Weather Review 47, 603-623.

Hou, A.Y., Kakar, R.K., Neeck, S., Azarbarzin, A.A., Kummerow, C.D., Kojima, M. Oki, R., Nakamura, K., Iguchi, T., 2014. The Global Precipitation Measurement Mission. Bulletin of the American Meteorological Society 95, 701-722. doi:10 . 1175 /BAMS-D-13-00164.1.

Hsueh, Y.H., Allen, S.T., Keim, R.F., 2016. Fine-scale spatial variability of throughfall amount and isotopic composition under a hardwood forest canopy. Hydrological Processes 30, 1796-1803. doi:10.1002/hyp. 10772.

Huber, L., Gillespie, T.J., 1992. Modeling Leaf Wetness in Relation to Plant Disease Epidemiology. Annual Review of Phytopathology 30, 553-577. doi:10.1146/ annurev.py.30.090192.003005.

Iida, S., Levia, D.F., Shimizu, A., Shimizu, T., Tamai, K., Nobuhiro, T., Kabeya, N., Noguchi, S., Sawano, S., Araki, M., 2017. Intrastorm scale rainfall interception dynamics in a mature coniferous forest stand. Journal of Hydrology 548, 770-783. doi:10.1016/j.jhydrol.2017.03.009.

Jackson, N., 2000. Measured and modelled rainfall interception loss from an agroforestry system in Kenya. Agricultural and Forest Meteorology 100, 323 336. doi:10.1016/S0168-1923 (99)00145-8.

Jacquemoud, S., Verhoef, W., Baret, F., Bacour, C., Zarco-Tejada, P.J., Asner, G.P., François, C., 2009. PROSPECT + SAIL models: A review of use for vegetation characterization. Remote Sensing of Environment 113, S56-S66. doi:10.1016/J.RSE.2008.01.026.

Jasechko, S., Sharp, Z.D., Gibson, J.J., Birks, S.J., Yi, Y., Fawcett, P.J., 2013. Terrestrial water fluxes dominated by transpiration. Nature 496, 347-350. doi:10 . 1038 / nature11983.

Johnson, R.C., 1990. The interception, throughfall and stemflow in a forest in Highland Scotland and the comparison with other upland forests in the U.K. Journal of Hydrology 118, 281-287. doi:10 .1016/0022-1694 (90) 90263-W. 
Journel, A.G., Huijbregts, C.J., 1978. Mining geostatistics. Academic Press.

Kaspari, M., Weiser, M.D., 2000. Ant Activity along Moisture Gradients in a Neotropical Forest. Biotropica 32, 703-711. doi:10.1646/0006-3606 (2000) 032.

Kato, H., Onda, Y., Nanko, K., Gomi, T., Yamanaka, T., Kawaguchi, S., 2013. Effect of canopy interception on spatial variability and isotopic composition of throughfall in Japanese cypress plantations. Journal of Hydrology 504, 1-11. doi:10.1016/j.jhydrol.2013.09.028.

Keim, R.F., Skaugset, A.E., Weiler, M., 2005. Temporal persistence of spatial patterns in throughfall. Journal of Hydrology 314, 263-274. doi:10.1016/j. jhydrol.2005.03.021.

Keim, R.F., Skaugset, A.E., Weiler, M., 2006. Storage of water on vegetation under simulated rainfall of varying intensity. Advances in Water Resources 29, 974-986. doi:10.1016/j.advwatres.2005.07.017.

Kimmins, J.P., 1973. Some Statistical Aspects of Sampling Throughfall Precipitation in Nutrient Cycling Studies in British Columbian Coastal Forests. Ecology 54, 1008-1019. doi:10.2307/1935567.

Klaasen, W., Bosveld, F., de Water, E., 1998. Water storage and evoporation as constituents of rainfall interception. Journal of Hydrology 212-213, 36-50. doi:10.1016/S0022-1694(98)00200-5.

Klaassen, W., 2001. Evaporation from rain-wetted forest in relation to canopy wetness, canopy cover, and net radiation. Water Resources Research 37, $3227-$ 3236. doi:10.1029/2001WR000480; doi:10.102.

Klamerus-Iwan, A., Witek, W., Klamerus-Iwan, A., Witek, W., 2018. Variability in the Wettability and Water Storage Capacity of Common Oak Leaves (Quercus robur L.). Water 10, 695. doi:10.3390/w10060695.

KNMI, 2015. Climatology. URL: http://www.knmi.nl/nederland-nu/ klimatologie/.

Kozak, J.A., Ahuja, L.R., Green, T.R., Ma, L., 2007. Modelling crop canopy and residue rainfall interception effects on soil hydrological components for semi-arid agriculture. Hydrological Processes 21, 229-241. doi:10.1002/hyp. 6235.

Krieger, G., Moreira, A., Fiedler, H., Hajnsek, I., Werner, M., Younis, M., Zink, M., 2007. TanDEM-X: A Satellite Formation for High-Resolution SAR Interferometry. IEEE Transactions on Geoscience and Remote Sensing 45, 33173341. URL: http://ieeexplore. ieee.org/document/4373373/, doi:10.1109/TGRS.2007.900693.

Kume, T., Kuraji, K., Yoshifuji, N., Morooka, T., Sawano, S., Chong, L., Suzuki, M., 2006. Estimation of canopy drying time after rainfall using sap flow measurements in an emergent tree in a lowland mixed-dipterocarp forest in Sarawak, Malaysia. Hydrological Processes 20, 565-578. doi:10.1002/hyp. 5924.

Kume, T., Manfroi, O.J., Kuraji, K., Tanaka, N., Horiuchi, T., Suzuki, M., Kumagai, T., 2008a. Estimation of canopy water storage capacity from sap flow measurements in a Bornean tropical rainforest. Journal of Hydrology 352, 288-295. doi:10.1016/j.jhydrol.2008.01.020. 
Kume, T., Manfroi, O.J., Suzuki, M., Tanaka, K., Kuraji, K., Nakagawa, M., Komatsu, H., Kumagai, T., 2008b. Estimation of vertical profiles of leaf drying times after daytime rainfall within a Bornean tropical rainforest. Hydrological Processes 22, 3689-3696. doi:10.1002/hyp.6972.

Lankreijer, H.J.M., Hendriks, M., Klaassen, W., 1993. A comparison of models simulating rainfall interception of forests. Agricultural and Forest Meteorology 64, 187-199. doi:10.1016/0168-1923 (93) 90028-G.

Lankreijer, H.J.M., Lundberg, A., Grelle, A., Lindroth, A., Seibert, J., 1999. Evaporation and storage of intercepted rain analyzed by comparing two models applied to a boreal forest. Agricultural and Forest Meteorology 98-99, 595-604. doi:10.1016/S0168-1923(99)00126-4.

Le Toan, T., Quegan, S., Davidson, M., Balzter, H., Paillou, P., Papathanassiou, K., Plummer, S., Rocca, F., Saatchi, S., Shugart, H., Ulander, L., 2011. The BIOMASS mission: Mapping global forest biomass to better understand the terrestrial carbon cycle. Remote Sensing of Environment 115, 2850-2860. doi:10 . $1016 /$ J.RSE. 2011.03 .020$.

Levia, D., Herwitz, S., 2005. Interspecific variation of bark water storage capacity of three deciduous tree species in relation to stemflow yield and solute flux to forest soils. CATENA 64, 117-137. doi:10.1016/J.CATENA. 2005.08.001.

Levia, D.F., Frost, E.E., 2006. Variability of throughfall volume and solute inputs in wooded ecosystems. Progress in Physical Geography 30, 605-632. doi:10 . $1177 / 0309133306071145$.

Levia, D.F., Germer, S., 2015. A review of stemflow generation dynamics and stemflow-environment interactions in forests and shrublands. Reviews of Geophysics 53, 673-714. doi:10.1002/2015RG000479.

Levia, D.F., Keim, R.F., Carlyle-Moses, D.E., Frost, E.E., 2011. Throughfall and Stemflow in Wooded Ecosystems, in: Forest Hydrology and Biogeochemistry. Springer, Dordrecht, pp. 425-443. doi:10 .1007/978-94-007-1363-5_ 21.

Link, T.E., Unsworth, M., Marks, D., 2004. The dynamics of rainfall interception by a seasonal temperate rainforest. Agricultural and Forest Meteorology 124, 171-191. doi:10.1016/j.agrformet.2004.01.010.

Liu, H., Peters, G., Foken, T., 2001. New equations for sonic temperature variance and buoyancy heat flux with an omnidirectional sonic anemometer. BoundaryLayer Meteorology 100,459-468. doi:10.1023/a:1019207031397.

Liu, J., 1988. A theoretical model of the process of rainfall interception in forest canopy. Journal of Hydrology 42, 111-123.

Liu, L., Liu, J., 2008. A rainfall interception model for inhomogeneous forest canopy. Frontiers of Forestry in China 3, 50-57. doi:10.1007/ s11461-008-0019-6.

Liu, S., 1997. A new model for the prediction of rainfall interception in forest canopies. Ecological Modelling 99, 151-159. doi:10.1016/S0304-3800 (97) 01948-0. 
Llorens, P., Domingo, F., 2007. Rainfall partitioning by vegetation under Mediterranean conditions. A review of studies in Europe. Journal of Hydrology 335, 37-54. doi:10.1016/j.jhydrol.2006.10.032.

Llorens, P., Poch, R., Latron, J., Gallart, F., 1997. Rainfall interception by a Pinus sylvestris forest patch overgrown in a Mediterranean mountainous abandoned area I. Monitoring design and results down to the event scale. Journal of Hydrology 199, 331-345. doi:10.1016/S0022-1694(96)03334-3.

Lloyd, C.R., Marques, A., 1988. Spatial variability of throughfall and stemflow measuremntes in a amazonian rainforest. Agricultural and Forest Meteorology $42,63-73$.

Loustau, D., Berbigier, P., Granier, A., 1992. Interception Loss, Throughfall and Stemflow in a Maritime Pine Stand .2. An Application of Gash Analytical Model of Interception. Journal of Hydrology 138, 469-485. doi:10.1016/ 0022-1694 (92) 90130-N.

Maltamo, M., Næsset, E., Vauhkonen, J. (Eds.), 2014. Forestry Applications of Airborne Laser Scanning. volume 27 of Managing Forest Ecosystems. Springer Netherlands, Dordrecht. doi:10.1007/978-94-017-8663-8.

Massman, W.J., 1983. The derivation and validation of a new model for the interception of rainfall by forests. Agricultural Meteorology 28, 261-286. doi:10.1016/0002-1571(83)90031-6.

Matheron, G., 1962. Traite de geostatistique applique. Editions Technip, Paris.

McCaughey, J.H., 1985. Energy balance storage terms in a mature mixed forest at Petawawa, Ontario: A case study. Boundary-Layer Meteorology 31, 89-101. doi:10.1007/BF00120036.

Meesters, A.G.C.A., Vugts, H.F., 1996. Calculation of heat storage in stems. Agricultural and Forest Meteorology 78, 181-202.

Michiles, A.A.d.S., Gielow, R., 2008. Above-ground thermal energy storage rates, trunk heat fluxes and surface energy balance in a central Amazonian rainforest. Agricultural and Forest Meteorology 148, 917-930. doi:10.1016/j. agrformet.2008.01.001.

Miralles, D.G., Gash, J.H., Holmes, T.R.H., de Jeu, R.A.M., Dolman, A.J., 2010. Global canopy interception from satellite observations. Journal of Geophysical Research: Atmospheres 115, D16122. doi:10.1029/200 9JD013530.

Miralles, D.G., Holmes, T.R., De Jeu, R.A., Gash, J.H., Meesters, A.G., Dolman, A.J., 2011. Global land-surface evaporation estimated from satellitebased observations. Hydrology and Earth System Sciences 15, 453-469. doi:10.5194/hess-15-453-2011.

Mizutani, K., Yamanoi, K., Iketa, T., Watanabe, T., 1997. Appilicability of the eddy correlation method to measure sensible heat transfer to forest under rainfall conditions. Agricultural and Forest Meteorology 86, 193-203.

Moncrieff, J.B., Massheder, J.M., de Bruin, H., Elbers, J., Friborg, T., Heusinkveld, B., Kabat, P., Scott, S., Soegaard, H., Verhoef, A., 1997. A system to measure surface fluxes of momentum, sensible heat, water vapour and carbon dioxide. Journal of Hydrology 188, 589-611. doi:10.1016/S0022-1694 (96) 03194-0. 
Monteith, J.L., 1981. Evaporation and surface temperature. Quarterly Journal of the Royal Meteorological Society 107, 1-27. doi:doi:10.1002/qj. 49710745102.

Moors, E.J., 2012. Ph. D. Thesis: Water Use of Forests in the Netherlands. Ph.D. thesis. de Vrije Universiteit Amsterdam.

Mulder, J.P.M., 1985. Simulating Interception Loss Using Standard Meteorological Data, in: The Forest-Atmosphere Interaction. Springer Netherlands, Dordrecht, pp. 177-196. doi:10.1007/978-94-009-5305-5_12.

Murakami, S., 2006. A proposal for a new forest canopy interception mechanism: Splash droplet evaporation. Journal of Hydrology 319, 72-82. doi:10 . $1016 / \mathrm{j}$. jhydrol.2005.07.002.

Muzylo, A., Llorens, P., Valente, F., Keizer, J.J., Domingo, F., Gash, J.H.C., 2009. A review of rainfall interception modelling. Journal of Hydrology 370, 191-206. doi:10.1016/j.jhydrol.2009.02.058.

Muzylo, A., Valente, F., Domingo, F., Llorens, P., 2012. Modelling rainfall partitioning with sparse Gash and Rutter models in a downy oak stand in leafed and leafless periods. Hydrological Processes 26, 3161-3173. doi:10 .1002/hyp. 8401.

Nord-Larsen, T., Nielsen, A.T., 2015. Biomass, stem basic density and expansion factor functions for five exotic conifers grown in Denmark. Scandinavian Journal of Forest Research 30, 135-153. doi:10.1080/02827581.2014.986519.

Oliphant, A.J., Grimmond, C.S.B., Zutter, H.N., Schmid, H.P., Su, H.B., Scott, S.L., Offerle, B., Randolph, J.C., Ehman, J., 2004. Heat storage and energy balance fluxes for a temperate deciduous forest. Agricultural and Forest Meteorology 126, 185-201. doi:10.1016/j.agrformet.2004.07.003.

Paulson, C.A., 1970. The Mathematical Representation of Wind Speed and Temperature Profiles in the Unstable Atmospheric Surface Layer. doi:10.1175/ 1520-0450 (1970) 009<0857:TMROWS >2.0.CO; 2.

Pebesma, E.J., 2004. Multivariable geostatistics in S: the gstat package. Computers \& Geosciences 30,683-691. doi:10.1016/J.CAGEO.2004.03.012.

Penman, H.L., 1952. The physical bases of irrigation control. The physical bases of irrigation control. .

Pitman, J.I., 1989. Rainfall interception by bracken in open habitats - Relations between leaf area, canopy storage and drainage rate. Journal of Hydrology 105, 317-334. doi:10.1016/0022-1694 (89) 90111-X.

Price, A.G., Carlyle-Moses, D.E., 2003. Measurement and modelling of growingseason canopy water fluxes in a mature mixed deciduous forest stand, southern Ontario, Canada. Agricultural and Forest Meteorology 119, 69-85. doi:10 . 1016/S0168-1923(03)00117-5.

Pypker, T.G., Bond, B.J., Link, T.E., Marks, D., Unsworth, M.H., 2005. The importance of canopy structure in controlling the interception loss of rainfall: Examples from a young and an old-growth Douglas-fir forest. Agricultural and Forest Meteorology 130,113-129. doi:10.1016/j.agrformet.2005.03. 003 . 
Raat, K.J., Draaijers, G.P.J., Schaap, M.G., Tietema, A., Verstraten, J.M., 2002. Spatial variability of throughfall water and chemistry and forest floor water content in a Douglas fir forest stand. Hydrology and Earth System Sciences 6, 363-374. doi:10.5194/hess-6-363-2002.

Rannik, Ü., Vesala, T., 1999. Autoregressive filtering versus linear detrending in estimation of fluxes by the eddy covariance method. Boundary-Layer Meteorology 91, 259-280. doi:10.1023/A:1001840416858.

Reid, L.M., Lewis, J., 2009. Rates, timing, and mechanisms of rainfall interception loss in a coastal redwood forest. Journal of Hydrology 375, 459-470. doi:10 . $1016 / j \cdot j h y d r o l .2009 .06 .048$.

Ringgaard, R., Herbst, M., Friborg, T., 2014. Partitioning forest evapotranspiration: Interception evaporation and the impact of canopy structure, local and regional advection. Journal of Hydrology 517, 677-690. doi:10 .1016/j . jhydrol . 2014.06 .007 .

Ritter, A., Regalado, C.M., 2014. Roving revisited, towards an optimum throughfall sampling design. Hydrological Processes 28, 123-133. doi:10.1002/hyp. 9561.

Robson, A.J., Neal, C., Ryland, G.P., Harrow, M., 1994. Spatial variations in throughfall chemistry at the small plot scale. Journal of Hydrology 158, 107-122. doi:10.1016/0022-1694(94) 90048-5.

Rosenqvist, A., Shimada, M., Ito, N., Watanabe, M., 2007. ALOS PALSAR: A Pathfinder Mission for Global-Scale Monitoring of the Environment. IEEE Transactions on Geoscience and Remote Sensing 45, 3307-3316. URL: http: / / ieeexplore.ieee.org/document/4358862/, doi:10.1109/TGRS. 2007.901027 .

Rutter, A., Morton, A., 1977. A predictive model of rainfall interception in forests : III : Sensitivity of the model to stand parameters and meteorological variables. Journal of Applied Ecology 14, 567-588.

Rutter, A.J., 1967. An analysis of evaporation from a stand of Scots pine. Forest Hydrology 403, 417.

Rutter, A.J., Kershaw, K.A., Robins, P.C., Morton, A.J., 1971. A predictive model of rainfall interception in forests, 1 . Derivation of the model from observations in a plantation of Corsican pine. Agricultural Meteorology 9, 367-384. doi:10 . 1016/0002-1571(71) 90034-3.

Rutter, A.J., Morton, A.J., Robins, P.C., 1975. A predictive model of rainfall interception in forests : II : generalization of the model and comparison with observations in some coniferous and hardwood stands. Journal of Applied Ecology 12, 367-380.

Sato, A.M., de Souza Avelar, A., Coelho Netto, A.L., 2011. Spatial variability and temporal stability of throughfall in a eucalyptus plantation in the hilly lowlands of southeastern Brazil. Hydrological Processes 25, 1910-1923. doi:10.1002/ hyp. 7947.

Savenije, H.H., 2005. Interception, in: Water Encyclopedia. John Wiley \& Sons, Inc., Hoboken, NJ, USA, pp. 235-238. doi:10 .1002/ 047147844 X. sw 460. 
Schellekens, J., Scatena, F.N., Bruijnzeel, L.A., Wickel, A.J., 1999. Modelling rainfall interception by a lowland tropical rain forest in northeastern Puerto Rico. Journal of Hydrology 225, 168-184. doi:10 .1016/S0022-1694 (99) 00157-2.

Schotanus, P., Nieuwstadt, F.T.M., De Bruin, H.A.R., 1983. Temperature measurement with a sonic anemometer and its application to heat and moisture fluxes. Boundary-Layer Meteorology 26, 81-93. doi:10 . 1007 /bf 00164332.

Sellers, P.J., Lockwood, J.G., 1981. A computer simulation of the effects of differing crop types on the water balance of small catchments over long time periods. Quarterly Journal of the Royal Meteorological Society 107, 395-414. doi:10 . 1002 /qj. 49710745210.

Shinohara, Y., Onozawa, Y., Chiwa, M., Kume, T., Komatsu, H., Otsuki, K., 2009. Spatial variations in throughfall in a Moso bamboo forest: sampling design for the estimates of stand-scale throughfall. Hydrological Processes 24. doi:10.1002/ hyp. 7473 .

Shuttleworth, W.J., Calder, I.R., 1979. Has the Priestley-Taylor Equation Any Relevance to Forest Evaporation? Journal of Applied Meteorology 18, 639-646.

Soubie, R., Heinesch, B., Granier, A., Aubinet, M., Vincke, C., 2016. Evapotranspiration assessment of a mixed temperate forest by four methods: Eddy covariance, soil water budget, analytical and model. Agricultural and Forest Meteorology 228-229, 191-204. doi:10.1016/j.agrformet. 2016.07 .001$.

Staelens, J., De Schrijver, A., Verheyen, K., Verhoest, N.E.C., 2006. Spatial variability and temporal stability of throughfall water under a dominant beech (Fagus sylvatica L.) tree in relationship to canopy cover. Journal of Hydrology 330, 651-662. doi:10.1016/j.jhydrol.2006.04.032.

Sterk, G., Stein, A., 1997. Mapping Wind-Blown Mass Transport by Modeling Variability in Space and Time. Soil Science Society of America Journal 61, 232. doi:10.2136/sssaj1997.03615995006100010032x.

Stewart, J.B., 1977. Evaporation from the wet canopy of a pine forest. Water Resources Research 13,915-921. doi:10.1029/WR013i006p00915.

Stockinger, M.P., Lücke, A., Mcdonnell, J.J., Diekkrüger, B., Vereecken, H., Bogena, H.R., . Interception effects on stable isotope driven streamwater transit time estimates. Geophysical Research Letters URL: https://agupubs . onlinelibrary.wiley.com/doi/pdf/10.1002/2015GL064622, doi:10.1002/2015GL064622.

Stoffelen, A., Pailleux, J., Källén, E., Vaughan, J.M., Isaksen, L., Flamant, P., Wergen, W., Andersson, E., Schyberg, H., Culoma, A., Meynart, R., Endemann, M., Ingmann, P., Stoffelen, A., Pailleux, J., Källén, E., Vaughan, J.M., Isaksen, L., Flamant, P., Wergen, W., Andersson, E., Schyberg, H., Culoma, A., Meynart, R., Endemann, M., Ingmann, P., 2005. The atmospheric dynamics mission for global wind field measurement. Bulletin of the American Meteorological Society 86, 73-88. URL: http://journals.ametsoc.org/doi/10. 1175/BAMS-86-1-73, doi:10.1175/BAMS-86-1-73.

Stull, R.B., 2011. Wet-bulb temperature from relative humidity and air temperature. Journal of Applied Meteorology and Climatology 50, 2267-2269. doi:10 .1175/ JAMC-D-11-0143.1. 
Stull, R.B., 2012. An introduction to boundary layer meteorology. volume 13. Springer Science \& Business Media, Dordrecht.

Su, Z., Timmermans, W.J., Van Der Tol, C., Dost, R., Bianchi, R., Gómez, J.A., House, A., Hajnsek, I., Menenti, M., Magliulo, V., Esposito, M., Haarbrink, R., Bosveld, F., Rothe, R., Baltink, H.K., Vekerdy, Z., Sobrino, J.A., Timmermans, J., Van Laake, P., Salama, S., Van Der Kwast, H., Claassen, E., Stolk, A., Jia, L., Moors, E., Hartogensis, O., Gillespie, A., 2009. EAGLE 2006 - Multi-purpose, multi-angle and multi-sensor in-situ and airborne campaigns over grassland and forest. Hydrology and Earth System Sciences 13, 833-845. doi:10.5194/ hess-13-833-2009.

Sun, X., Onda, Y., Chiara, S., Kato, H., Gomi, T., 2015. The effect of strip thinning on spatial and temporal variability of throughfall in a Japanese cypress plantation. Hydrological Processes 29, 5058-5070. doi:10 .1002/hyp.10425.

Sun, X., Onda, Y., Kato, H., 2014. Incident rainfall partitioning and canopy interception modeling for an abandoned Japanese cypress stand. Journal of Forest Research 19,317-328. doi:10.1007/s10310-013-0421-2.

Teklehaimanot, Z., Jarvis, P.G., Ledger, D.C., 1991. Rainfall interception and boundary layer conductance in relation to tree spacing. Journal of Hydrology 123, 261-278. doi:10.1016/0022-1694(91)90094-X.

Thom, A.S., 1975. Momentum, mass and heat exchange of plant communities. volume 1. Academic Press.

Thom, A.S., Stewart, J.B., Oliver, H.R., Gash, J., 1975. Comparison of aerodynamic and energy budget estimatives of fluxes over a pine forest. Quarterly Journal of the Royal Meteorological society 101, 93-105.

Tiktak, A., Bouten, W., 1988. Monitoring of hydrologycal processes under Douglas fir, in: Mathy, P. (Ed.), Air Pollution and Ecosystems: Proceedings of an International Symposium, Springer Netherlands, Dodrecht. pp. 891-895.

Tiktak, A., Bouten, W., 1994. Soil water dynamics and long-term water balances of a Douglas fir stand in the Netherlands. Journal of Hydrology 156, 265-283. doi:10.1016/0022-1694(94)90081-7.

Timmermans, J., Su, Z., van der Tol, C., Verhoef, A., Verhoef, W., 2013. Quantifying the uncertainty in estimates of surface-atmosphere fluxes through joint evaluation of the SEBS and SCOPE models. Hydrol. Earth Syst. Sci. 17, 1561-1573. doi:10.5194/hess-17-1561-2013.

Tobón M, C.., Bouten, W., Sevink, J., 2000. Gross rainfall and its partitioning into throughfall, stemflow and evaporation of intercepted water in four forest ecosystems in western Amazonia. Journal of Hydrology 237, 40-57. doi:10 . 1016/S0022-1694(00)00301-2.

van der Tol, C., 2012. Validation of remote sensing of bare soil ground heat flux. Remote Sensing of Environment 121, 275-286. doi:10.1016/j.rse.2012. 02.009 .

van der Tol, C., Gash, J.H., Grant, S.J., McNeil, D.D., Robinson, M., 2003. Average wet canopy evaporation for a Sitka spruce forest derived using the eddy correlationenergy balance technique. Journal of Hydrology 276, 12-19. doi:10.1016/ S0022-1694(03)00024-6. 
van der Tol, C., Verhoef, W., Timmermans, J., Verhoef, A., Su, Z., 2009. An integrated model of soil-canopy spectral radiances, photosynthesis, fluorescene, temperature and energy balance. Biogeosciences 6, 3109-3129.

Trenberth, K.E., 2014. Challenges for Observing and Modeling the Global Water Cycle, in: Remote Sensing of the Terrestrial Water Cycle. American Geophysical Union (AGU), pp. 511-519. URL: http://doi.wiley.com/10.1002/ 9781118872086.ch32, doi:10.1002/9781118872086.ch32.

Turner, J., Lambert, M.J., 1987. Forest water usage and interactions with nutrition of Pinus radiata. Acta Oecologica Oecologia Plantarum 8, 37-43.

Valente, F., David, J.S., Gash, J.H.C., 1997. Modelling interception loss for two sparse eucalypt and pine forests in central Portugal using reformulated Rutter and Gash analytical models. Journal of Hydrology 190, 141-162. doi:10 . $1016 /$ S0022-1694(96)03066-1.

Vegas Galdos, F., Álvarez, C., García, A., Revilla, J.A., 2012. Estimated distributed rainfall interception using a simple conceptual model and Moderate Resolution Imaging Spectroradiometer (MODIS). Journal of Hydrology 468-469, 213-228. doi:10.1016/j.jhydrol.2012.08.043.

Verhoef, A., Van Den Hurk, B.J., Jacobs, A.F., Heusinkveld, B.G., 1996. Thermal soil properties for vineyard (EFEDA-I) and savanna (HAPEX-sahel) sites. Agricultural and Forest Meteorology 78, 1-18. doi:10 .1016/0168-1923 (95) $02254-6$.

Vose, J.M., Peterson, D.L., Patel-Weynand, T., 2012. Effects of Climatic Variability and Change on Forest Ecosystems: A Comprehensive Science Synthesis for the US Forest Sector. Forest Service General Technical Report PNW-GTR-87, 1-265.

Voss, S., Zimmermann, B., Zimmermann, A., 2016. Detecting spatial structures in throughfall data: The effect of extent, sample size, sampling design, and variogram estimation method. Journal of Hydrology 540, 527-537. doi:10 . $1016 / j$.jhydrol.2016.06.042.

Vrugt, J.A., Dekker, S.C., Bouten, W., 2003. Identification of rainfall interception model parameters from measurements of throughfall and forest canopy storage. Water Resources Research 39,1-10. doi:10.1029/2003WR0 02013.

Wallace, J., McJannet, D., 2006. On interception modelling of a lowland coastal rainforest in northern Queensland, Australia. Journal of Hydrology 329, 477-488. doi:10.1016/j.jhydrol.2006.03.003.

Wallace, J., McJannet, D., 2008. Modelling interception in coastal and montane rainforests in northern Queensland, Australia. Journal of Hydrology 348, 480-495. doi:10.1016/j.jhydrol.2007.10.019.

Wallace, J.S., Verhoef, A., 2000. Modelling interactions in mixed-plant communities: light, water and carbon dioxide, in: Marshall, B., Roberts, J.A. (Eds.), Leaf Development and Canopy Growth. Sheffield Academic Press, UK, pp. 204-250.

Watanabe, T., Mizutani, K., 1996. Model study on micrometeorological aspects of rainfall interception over an evergreen broad-leaved forest. Agricultural and Forest Meteorology 80, 195-214. doi:10 .1016/0168-1923 (95) 02301-1. 
Webb, E.K., Pearman, G.I., Leuning, R., 1980. Correction of flux measurements for density effects due to heat and water vapour transfer. Quarterly Journal of the Royal Meteorological Society 106, 85-100. doi:10 .1002/qj . 49710644707.

Webster, R., Oliver, M.A., 1992. Sample adequately to estimate variograms of soil properties. Journal of Soil Science 43, 177-192. doi:10 . 1111/j .1365-2389. 1992.tb00128.x.

Webster, R., Oliver, M.A., 2007. Geostatistics for environmental scientists. Wiley.

Weligepolage, K., Su, Z., Gieske, A.S.M., 2012. Surface roughness analysis of a conifer forest canopy with airborne and terrestrial laser scanning techniques. International Journal of Applied Earth Observation and Geoinformation 14, 192 203. doi:10.1016/j.jag.2011.08.014.

Xiao, Q., McPherson, E.G., Ustin, S.L., Grismer, M.E., 2000. A new approach to modeling tree rainfall interception. Journal of Geophysical Research: Atmospheres 105, 29173-29188. doi:10.1029/2000 JD900343.

Zeng, N., Shuttleworth, J., Gash, J., 2000. Influence of temporal variability of rainfall on interception loss. Part I. Point analysis. Journal of Hydrology 228, 228-241. doi:10.1016/S0022-1694 (00)00140-2.

Zimmermann, A., Germer, S., Neill, C., Krusche, A.V., Elsenbeer, H., 2008. Spatiotemporal patterns of throughfall and solute deposition in an open tropical rain forest. Journal of Hydrology 360, 87-102. doi:10.1016/j . jhydrol . 2008 . 07.028 .

Zimmermann, A., Wilcke, W., Elsenbeer, H., 2007. Spatial and temporal patterns of throughfall quantity and quality in a tropical montane forest in Ecuador. Journal of Hydrology 343, 80-96. doi:10.1016/j.jhydrol.2007.06.012.

Zimmermann, A., Zimmermann, B., 2014. Requirements for throughfall monitoring: The roles of temporal scale and canopy complexity. Agricultural and Forest Meteorology 189-190, 125-139. doi:10.1016/j.agrformet.2014.01. 014.

Zimmermann, A., Zimmermann, B., Elsenbeer, H., 2009. Rainfall redistribution in a tropical forest: Spatial and temporal patterns. Water Resources Research 45, 1-18. doi:10.1029/2008WR007470.

Zimmermann, B., Zimmermann, A., Lark, R.M., Elsenbeer, H., 2010. Sampling procedures for throughfall monitoring: A simulation study. Water Resources Research 46,1-15. doi:10.1029/2009WR007776. 



\section{Author's Biography}

César Cisneros Vaca was born in Quito, Ecuador, on the 16th of July 1980. In 1997 he started to study at National Polytechnic School in Ecuador (EPN). After finishing three semesters of Basic Sciences studies, he decided to move to the Army Polytechnic School (ESPE), located in Sangolquí-Ecuador, to pursue the degree on Geography and Environmental Sciences. In April 2005, he graduated with a thesis focused on the study of landscapes of the Páramo Ecosystems in the Ecuadorian Andes. From 2005, he started to work in the laboratory of Geographic Information Systems of the NGO Grupo Randi Randi. He participated in projects related to watershed management and hydrological modelling in the northern part of the Ecuadorian Andes. In 2008, he moved to Cochabamba, Bolivia, to study a Professional Master in Geo-information Science and Earth Observation applied to Water Resources in CLAS, University of San Simon. In 2009, He returned to Ecuador and worked on a project dedicated to the preliminary designs of the water treatment plants for Quito City. In 2010, he got a scholarship to join the Water Resources and Management program of the Faculty of Geo-information Science and Earth Observation (ITC), from the University of Twente, the Netherlands. His master thesis was focused on modelling groundwater recharge in the Sardon Catchment in Spain. Later on, he returned to Ecuador in 2011, and he worked for the first National Forest Inventory a project supported by FAO-Finland. He developed methodologies to quantify aboveground biomass for the different type of forest in Ecuador by combining field data and optical remote sensing images. In 2013, he awarded a four-year scholarship from the Secretariat for Science and Technology of Ecuador (SENESCYT) for pursuing his Ph.D. degree in ITC, University of Twente. His research interest covers forest hydrology, forest biomass estimation, and remote sensing applied to water resources research. 



\section{Author's Publications}

Cisneros Vaca, C., Ghimire, C., van der Tol, C., 2018. Spatial Patterns and Temporal Stability of Throughfall in a Mature Douglas-fir Forest. Water 10, 317. https://doi.org/10.3390/w10030317.

Cisneros Vaca, C., van der Tol, C., Ghimire, C.P., 2018. The influence of long-term changes in canopy structure on rainfall interception loss: a case study in Speulderbos, the Netherlands. Hydrology and Earth System Science. 22, 3701-3719. https://doi.org/10.5194/hess-22-3701-2018.

Schilperoort, B., Coenders-Gerrits, M., Luxemburg, W., Jiménez Rodríguez, C., Cisneros Vaca, C., Savenije, H., 2018. Technical note: Using distributed temperature sensing for Bowen ratio evaporation measurements. Hydrol. Earth Syst. Sci 22, 819-830. https://doi.org/10.5194/hess-22-819-2018.

Cisneros Vaca, C., van Der Tol, C., 2018. Sensitivity of Sentinel-1 to rain stored in temperate forests. In IGARSS 2018 : IEEE International Geoscience and Remote Sensing Symposium : Observing, Understanding and Forecasting the Dynamics of Our Planet. IEEE Press. Conference proceedings.

Cisneros Vaca, C., van Der Tol, C., 2018. Modelling rainfall interception loss with SCOPE. Agricultural and Forest Meteorology. Under review. 